\title{
A new measurement of the E1 amplitude in ${ }^{12} \mathrm{C}(\alpha, \gamma){ }^{16} \mathrm{O}$
}

\author{
Dissertation \\ zur Erlangung des Grades eines \\ Doktors der Naturwissenschaften \\ in der \\ Fakultät für Physik und Astronomie \\ der Ruhr-Universität Bochum
}

vorgelegt von

Lucio Gialanella aus Rom

Bochum 2000 



\section{Contents}

$\begin{array}{ll}\text { Foreword } & 1\end{array}$

1 The ${ }^{12} \mathrm{C}(\alpha, \gamma){ }^{16} \mathrm{O}$ reaction in stars and in laboratories 3

1.1 The ${ }^{12} \mathrm{C}(\alpha, \gamma){ }^{16} \mathrm{O}$ reaction in stars . . . . . . . . . . . 3

1.1.1 Basic concepts of stellar evolution and nucleosynthesis . . . 3

1.1.2 The helium burning and the ${ }^{12} \mathrm{C}(\alpha, \gamma){ }^{16} \mathrm{O}$ reaction . . . . . . 6

1.2 The ${ }^{12} \mathrm{C}(\alpha, \gamma){ }^{16} \mathrm{O}$ reaction in laboratories . . . . . . . . . 7

1.2.1 Basic concepts of the general theory of nuclear reactions . . 8

1.2.2 Resonance reactions: R-matrix formalism . . . . . . . . . 12

1.2.3 Direct capture reactions . . . . . . . . . . . . 15

1.2.4 The ${ }^{12} \mathrm{C}(\alpha, \gamma){ }^{16} \mathrm{O}$ reaction mechanism . . . . . . . . 16

1.2.5 Experimental State-of-the-Art . . . . . . . . . . . 19

2 Experimental setup $\quad 23$

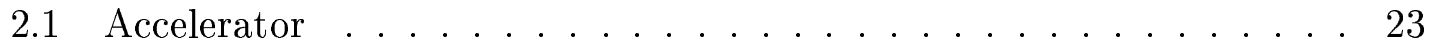

2.2 Gas target . . . . . . . . . . . . . . . . 24

2.3 The $\gamma$ ray detection setup . . . . . . . . . . . . 26

2.4 Particle detectors . . . . . . . . . . . . . . . . 29

2.5 Electronics and acquisition system . . . . . . . . . . 30

2.6 Auxiliary measurements . . . . . . . . . . . . . 35

2.6.1 Gas target pressure profile . . . . . . . . . 35

2.6.2 Energy calibration of the HPGe . . . . . . . . 38

2.6.3 Effective $\gamma$ target length . . . . . . . . . . . 39

2.6.4 E2 suppression .................... 40

2.6.5 Elastic scattering cross section . . . . . . . . . . 41 
3 Data analysis $\quad 45$

3.1 Determination of the cross section . . . . . . . . . . . 45

3.1.1 Analysis of the $\gamma$-spectra . . . . . . . . . . . 47

3.1.2 Monte Carlo simulation of the experiment . . . . . . . 50

3.1.3 Full energy peak analysis . . . . . . . . . . . . 53

3.1.4 Measurement of the absolute cross section . . . . . . . 61

3.2 Extrapolation to the relevant astrophysical energy . . . . . . . . 65

$\begin{array}{ll}\text { Epilogue } & 75\end{array}$

$\begin{array}{ll}\text { Aknowledgments } & 77\end{array}$

$\begin{array}{lr}\text { Data tables } & \mathbf{7 9}\end{array}$

$\begin{array}{lr}\text { Some photographs } & 81\end{array}$

$\begin{array}{ll}\text { Deutschsprachige Zusammenfassung } & 87\end{array}$

$\begin{array}{lr}\text { References } & 97\end{array}$ 


\section{Foreword}

If one would like to explain the interests and the methodology of Nuclear Astrophysics by means of one example, many researchers in this field would probably suggest the case of ${ }^{12} \mathrm{C}(\alpha, \gamma){ }^{16} \mathrm{O}$, because of the tight and intriguing interplay of Nuclear Physics and Astrophysics aspects that one encounters in the study of this reaction. ${ }^{12} \mathrm{C}(\alpha, \gamma){ }^{16} \mathrm{O}$ plays a key role in the processes of stellar evolution and nucleosynthesis for stars that undergo the nuclear helium burning during their lifetime. The cross section of ${ }^{12} \mathrm{C}(\alpha, \gamma){ }^{16} \mathrm{O}$ at the relevant astrophysical energy $E_{0}=300 \mathrm{keV}$ determines, together with the concurrent triple- $\alpha$ reaction, the ratio ${ }^{12} \mathrm{C} /{ }^{16} \mathrm{O}$ at the end of this burning stage. All available stellar models turn out to be extremely sensitive to the value of this parameter and their predictions about the isotopic abundances and the fate of a star at the end of its evolution change significantly if one varies the cross section of ${ }^{12} \mathrm{C}(\alpha, \gamma){ }^{16} \mathrm{O}$ by about $10 \%$. Similar variations can be induced by other parameters, for example the extension of the convective regions in the core during helium burning. As a consequence, the possibility of gaining a deeper understanding of these processes is connected to the knowledge of the cross section of ${ }^{12} \mathrm{C}(\alpha, \gamma){ }^{16} \mathrm{O}$ with a precision better than $10 \%$. At $E_{0}$ the cross section of ${ }^{12} \mathrm{C}(\alpha, \gamma){ }^{16} \mathrm{O}$ is expected to be of the order of $10^{-17} \mathrm{~b}$, that makes its direct measurement not feasible. Therefore its determination has been a challenge, over more than thirty years, for both experimentalists and theoriticians. This effort had as a result that the reaction mechanism is presently rather well understood and many nuclear parameters necessary to extrapolate the experimental data to $E_{0}$ are well constrained. Nevertheless, the required precision has not yet been achieved and new data are needed. There are cases in physics, in which any good experiment is a useful one: this happens, for example, when new phenomena are investigated. This does not apply to ${ }^{12} \mathrm{C}(\alpha, \gamma){ }^{16} \mathrm{O}$. Here one has a rather large number of experiments already performed and one has to carefully study their results in order to identify some aspects that have been neglected and/or where additional information is required. This is the case of the $E 1$ component of the ${ }^{12} \mathrm{C}(\alpha, \gamma){ }^{16} \mathrm{O}$ cross section. Actually one finds several $E 1$ data sets in the literature, but they show large systematic deviations, that is not surprising in view of the difficulty of such experiments. To clarify the situation one should try to perform selective experiments to study separately 
this aspect of the reaction. This is the purpose of the present work. Besides that, some results of the analysis of different possible extrapolations of the present and of the previous data are presented, but a complete analysis of all existing data, that would be of extreme importance, is beyond the purpose of the present thesis.

In the first chapter, I shortly recall some basic concepts necessary to outline the astrophysical and nuclear aspects of this reaction. The description of the reaction mechanism and a review of the previous measurements complete this part. The second chapter is devoted to the description and the characterization of the experimental setup. Finally, in the third chapter I report on the results of the experiment and their extrapolation to the astrophysical relevant energy. Here I used an original approach based on the application of the Monte Carlo method in order to obtain the probability distribution of the extrapolated value of the cross section. I will finally resume the results of this work and shortly discuss the perspectives of a new experimental approach for ${ }^{12} \mathrm{C}(\alpha, \gamma){ }^{16} \mathrm{O}$. 


\section{Chapter 1}

\section{The ${ }^{12} \mathrm{C}(\alpha, \gamma){ }^{16} \mathrm{O}$ reaction in stars and in laboratories}

\subsection{The ${ }^{12} \mathrm{C}(\alpha, \gamma)^{16} \mathrm{O}$ reaction in stars}

After several decades of experimental and theoretical work in the field of nuclear astrophysics, the basic processes of stellar evolution and nucleosynthesis are well understood and described in several text books $[1,2]$. Nevertheless, it is useful to shortly resume their basic concepts. The following section is devoted to the helium burning and the importance of the ${ }^{12} \mathrm{C}(\alpha, \gamma){ }^{16} \mathrm{O}$ reaction in that phase of stellar evolution.

\subsubsection{Basic concepts of stellar evolution and nucleosynthesis}

The accepted scientific picture of the stellar evolution is a sequence of core nuclear burnings, that provide the necessary energy to temporary block the gravitational contraction of the star, originating from a so called proto-star. The ignition of nuclear burning is connected to the combined effect of the raise of the core temperature and of the core density following the gravitational contraction of the star itself. Indeed, the increase of the mean kinetic energy of the ions in the core enhances the penetration factor $P$ through the Coulomb barrier; this, together with the raise of the density of the ions, increases the rate of some nuclear reactions, up to the point in which the consequent energy production is high enough to sustain the gravitational pressure. Then hydrostatic equilibrium is reached and it is usual to refer to this situation as quiescent burning.

The penetration factor $P$ through the Coulomb barrier between two bare nuclei depends on their relative kinetic energy and on their nuclear charges. For energies much smaller than the height of the Coulomb barrier, that is normally the case for 
nuclear reactions taking place during quiescent burning, a simple expression is valid [1]:

$$
P=\exp (-2 \pi \eta)
$$

where

$$
\eta=\frac{Z_{1} Z_{2} e^{2}}{\hbar v_{\infty}}
$$

$Z_{1} e$ and $Z_{2} e$ being the nuclear electric charges of the two interacting nuclides and $v_{\infty}$ their relative velocity at infinite distance. $\eta$ is called the Sommerfeld parameter and represents the ratio between the minimum approach distance of the two interacting nuclides and their Compton wavelength. The penetration factor, expressed in this form, is usually factored out in the expression of the reaction cross section, as is a term $1 / E$, that accounts for the dependence of the cross section on the de Broglie wavelength squared:

$$
\sigma(E)=\frac{1}{E} \exp (-2 \pi \eta) S(E)
$$

where $S(E)$, the so called $S$-factor, contains the dependence of the cross section on the nuclear effects. For a given reaction, the expected reaction rate in the stellar interior $\langle\sigma v\rangle$ is obtained by folding the cross section with the Maxwell-Boltzmann distribution of the relative ion velocity $v$ in the stellar plasma. Expressing the relative velocity $v$ in terms of relative energy $E$ and using equation 1.3, the rate is defined, besides some constants, by the following equation [1]:

$$
\langle\sigma v\rangle \propto \int_{0}^{\infty} S(E) \exp \left(-2 \pi \eta-\frac{E}{k T}\right) d E
$$

The energy dependence of the integrand of equation 1.4 is represented by a peak, called Gamow peak, whose width and position are determined by the exponential behaviour of the penetration factor and the Maxwell-Boltzmann distribution, if one can assume $S(E)$ to be weakly dependent on energy. Otherwise, strong nuclear resonances can shift and deform the Gamow peak. In any case, the Gamow peak determines the range of energy that efficiently contributes to the burning and one has to know $S(E)$ over the whole width of the Gamow peak to fully determine the rate of a given reaction. 
Because the height of the Coulomb barrier between two nuclei depends upon their nuclear charges, the first stage of stellar evolution is hydrogen burning, that happens if the mass of the cloud of gas generating the star exceeds 0.1 solar masses $\left(M_{\odot}\right)$. One should note that putting limits on the stellar mass as if it would alone determine the ignition of core burning is somewhat arbitrary and large fluctuations are expected. The values given here and in the following have to be considered as indicative. During the hydrogen burning the hydrogen core is slowly replaced by a helium core: if the mass of the star is larger than about $2 M_{\odot}$, helium burning starts after the end of the core hydrogen burning, that in turn eventually continues in a shell around the core (shell burning). In a similar way heavier and heavier elements are generated and can undergo a core nuclear burning, provided the star mass is high enough, while new shells are formed. But even with arbitrary large masses, this process cannot account for the production of the elements beyond iron, as one can argue having a look at the curve representing the binding energy per nucleon as a function of nuclear mass. Besides local oscillations, this curve reaches an absolute maximum in the region of iron: it then follows that fusion reactions giving products not heavier than iron will generally produce energy, otherwise they will generally require energy to occur. This means that once a star has an iron core, there is no way to prevent the gravitational collapse, that proceeds through a so-called type II supernova explosion.

This very general description of the life of stars needs detailed informations on the stellar structure and composition, besides the necessary nuclear data. The initial chemical composition of a star originating from the interstellar gas, as resulting from the big bang nucleosynthesis, consists essentially of hydrogen and helium, with just a very small amount of lithium, beryllium and boron, while younger stars originating from gas containing material ejected by previous supernova explosions, the fraction of heavier elements, the so called "metals", is higher. The effects of changes in the chemical composition of a star can be dramatic: for example, the hydrogen burning can proceed much faster in the presence of carbon, nitrogen and oxygen, that act as catalysts in the so called CNO cycle, but we will see later other possible effects of the chemical composition on stellar evolution. In a similar way, the energy transport from the core to the stellar surface is a critical aspect and it depends upon the temperature and density gradient along the stellar radius. The energy transport in a star happens mostly via convection and radiation, while conduction plays a minor role because of the very short mean path of ions and electrons compared with the stellar radius [1]. The basic criterion to the onset of convection can be derived assuming that an element of the plasma moves by an amount $d r$ along the radius in an adiabatic way, i.e. no energy exchange with the surroundings takes place. If this element of plasma turns out to have a smaller density than the surrounding, then the hydrostatic force pushes it outward, starting a convective instability. Otherwise 
hydrostatic equilibrium is set. Assuming that there is an uniform chemical composition, this means that convection takes place in those regions of a star, where the temperature gradient exceeds the adiabatic one (Schwarzschild criterion). Actually the chemical composition, namely a chemical gradient along the radius, can play a major role: if the molecular weight decreases outwardly with sufficient rapidity, super-adiabatic temperature gradients can be counterbalanced (Ledoux criterion). In this situation convection does not occur, but thermal instabilities are present, so the corresponding regime is called semi-convection ([3] and references therein). For temperature gradients smaller than the adiabatic one, the main energy transport mechanism is radiation. Still one has to consider that the convective regions are not very sharply defined due to the kinetic energy gained by the plasma in its outward or inward run in the convective cells, giving rise to the so-called over- and under-shooting, respectively: these processes can provide a relatively efficient way of mixing different shells.

The complete description of stellar evolution is of course extremely more complex and many aspects are neglected in the previous summary: however, we have now the necessary tools to understand the astrophysical importance of the ${ }^{12} \mathrm{C}(\alpha, \gamma){ }^{16} \mathrm{O}$ nuclear reaction.

\subsubsection{The helium burning and the ${ }^{12} \mathrm{C}(\alpha, \gamma){ }^{16} \mathrm{O}$ reaction}

At the end of hydrogen burning, the stellar core consists essentially of ${ }^{4} \mathrm{He}$, because the synthesis of elements heavier than ${ }^{4} \mathrm{He}$ is strongly inhibited by the absence of stable nuclei for $A=5$ and $A=8$. The helium core slowly contracts and its temperature and density increase consequently. The increasing core temperature causes the expansion of the outer hydrogen shell, that in turn determines a cooling of the outer surface, that therefore emits radiation of longer wavelength. If the star mass is large enough the helium burning is ignited by the gravitational contraction when the temperature of the core reaches about $10^{8} \mathrm{~K}$. Because of the shift in color to the red and the large dimension, these stars are called Red Giants. The triple $\alpha$ reaction is the first one taking place and it allows to jump over the mass stability gaps. The triple $\alpha$ reaction is a two step reaction: first $2 \alpha$ particles combine to form ${ }^{8} \mathrm{Be}$, whose lifetime $\left(1 \times 10^{-16} \mathrm{~s}\right)$ is long enough to occasionally allow the capture of a third $\alpha$ particle to form ${ }^{12} \mathrm{C}$. The probability of this process is enhanced by the fact that the capture of the third particle is a resonant reaction to the $\mathrm{E}_{x}=7654 \mathrm{keV}, \mathrm{J}^{\pi}=0^{+}$ state in ${ }^{12} \mathrm{C}$. The ${ }^{12} \mathrm{C}$ produced contributes itself to the helium burning through the ${ }^{12} \mathrm{C}(\alpha, \gamma){ }^{16} \mathrm{O}$ reaction, while the synthesis of heavier elements is essentially blocked by the extremely low cross section of ${ }^{16} \mathrm{O}(\alpha, \gamma){ }^{20} \mathrm{Ne}$. The amount of ${ }^{16} \mathrm{O}$ relative to ${ }^{12} \mathrm{C}$ in the ashes of the helium burning is determined by the competition between ${ }^{12} \mathrm{C}(\alpha, \gamma){ }^{16} \mathrm{O}$ and the triple $\alpha$ reaction, whose cross section is experimentally 
constrained with a precision of about $10 \%[1]$. The ratio ${ }^{16} \mathrm{O} /{ }^{12} \mathrm{C}$ has a strong influence on the isotopic abundances and the mass of the stellar core in the following burning stages (see $[4,3]$ ). The extreme sensitivity of the results of stellar model calculations upon the rate of ${ }^{12} \mathrm{C}(\alpha, \gamma){ }^{16} \mathrm{O}$ has suggested the possibility of gaining information about this reaction by means of astrophysical considerations, somehow bypassing the difficulties encountered in determining it experimentally. This idea has been exploited [5] following the evolution of a set of massive stars ranging from 12 to $40 \mathrm{M}_{\odot}$ and leaving the cross section of the reaction as a free parameter in order to reproduce the observed stellar abundances of the intermediate mass isotopes $(16 \leq A \leq 32)$ : this procedure leads to an estimated rate of $1.7 \pm 0.5$ times the value given by a previous compilation [6], that corresponds to a $S$-factor of $170 \pm 50 \mathrm{keV}$ $\mathrm{b}$ at $E_{0}=300 \mathrm{keV}$. Recent calculations [7] have shown that a more complete treatment of convection mechanisms puts this result in doubts: in particular the effect of over-shooting can compensate a variation of the rate of ${ }^{12} \mathrm{C}(\alpha, \gamma){ }^{16} \mathrm{O}$. To understand how this can happen, one has to consider that, after the start of the helium burning, the extreme high energy production causes the temperature gradient in the core to become super-adiabatic and, therefore, in this stage one has a convective core. The triple $\alpha$ reaction will tend to increase the concentration of ${ }^{12} \mathrm{C}$, that is destroyed by ${ }^{12} \mathrm{C}(\alpha, \gamma){ }^{16} \mathrm{O}$. A variation of the rate of the latter reaction, say, a reduction, should then bring a reduction of the final amount of ${ }^{16} \mathrm{O}$ : but if one assumes an increase of the over-shooting, this will not happen. Indeed, over-shooting provides a way of chemical mixing and, in this case, it will bring new ${ }^{4} \mathrm{He}$ from the outer shell to the ${ }^{12} \mathrm{C}$ rich core environment, that will enhance the final amount of ${ }^{12} \mathrm{C}$ in spite of the reduced production cross section. More generally, similar arguments show that a variation of the ${ }^{12} \mathrm{C}(\alpha, \gamma){ }^{16} \mathrm{O}$ cross section can be counterbalanced or enhanced by a reasonable variation of over-shooting of the convective core. Consequently, it seems questionable to use astrophysical arguments to constrain the ${ }^{12} \mathrm{C}(\alpha, \gamma){ }^{16} \mathrm{O}$ cross section: on the contrary, a detailed and precise knowledge of this reaction cross section can shed light on the convection mechanisms in stars, that is not a well known aspect in stellar models.

\subsection{The ${ }^{12} \mathrm{C}(\alpha, \gamma){ }^{16} \mathrm{O}$ reaction in laboratories}

In this section I review the main properties of the ${ }^{12} \mathrm{C}(\alpha, \gamma){ }^{16} \mathrm{O}$ reaction. The theory of nuclear reactions, with special regard to angular correlations in $\gamma$ spectroscopy and R-matrix theory, plays an important role in the understanding of the state of the art of ${ }^{12} \mathrm{C}(\alpha, \gamma){ }^{16} \mathrm{O}$, in both its theoretical and experimental aspects. These issues are discussed in detail in several books (for example $[8,9,10]$ ); here I will give just the main lines and the results directly relevant to the subject of this thesis. In the first section I will describe some general characteristics of nuclear reactions and 
some details about the $\gamma$ angular distributions for the case of radiative capture. In section 1.2.2 I will consider resonance nuclear reactions and the R-matrix formalism to describe them, while the non-resonant reaction mechanism of direct capture is outlined in section 1.2.3. Finally I will summarize the experimental state of the art of ${ }^{12} \mathrm{C}(\alpha, \gamma){ }^{16} \mathrm{O}$.

\subsubsection{Basic concepts of the general theory of nuclear reac- tions}

Let us consider a nuclear reaction of the type:

$$
a+X \rightarrow Y+b
$$

that represents the process that occurs when an incoming particle $a$ is absorbed by a target nucleus $X$ emitting a particle $b$ (here and in the following the term "particle" is extended to both massive particles and photons) and leaving the residual nucleus $Y$. A compact notation for equation 1.5 is $X(a, b) Y$. The pair of particles on the left side of equation 1.5 in a definite quantum state is called the entrance channel of the reaction, while the pair of emitted particle and residual nucleus is called a reaction channel; generally, there are several competing reaction channels for a given entrance channel. A full description of the reaction would require a description of the motion of all interacting particles, including their components, that is generally neither possible nor wanted. It is rather desirable to express the observable quantities, essentially the probability of getting a given reaction, as a function of the properties of the interacting nuclei. Therefore nuclear reactions are described in terms of total cross section $\sigma(E)$ and differential cross section, that is defined as $d \sigma(E, \theta, \phi) / d \Omega$. Here and through the whole text, $E$ indicates the center-of-mass energy, while $\theta$ and $\phi$ define the trajectories of the reaction products (in standard notation).

Let $\mathbf{s}_{\mathbf{0}}, \mathbf{s}_{\mathbf{1}}, \mathbf{s}_{\mathbf{2}}$, and $\mathbf{s}_{\mathbf{3}}$ be respectively the spins of $X, a, Y$, and $b$, while $\mathbf{l}_{\mathbf{1}}$ and $\mathbf{l}_{\mathbf{2}}$ are the orbital angular momenta in the initial and final states. In the so-called channel spin scheme of nuclear reactions, the following vector equations hold:

$$
\begin{gathered}
a=s_{0}+s_{1} \\
b=a+l_{1} \\
s_{2}+s_{3}=c \\
c+l_{2}=b
\end{gathered}
$$

where $\mathbf{a}, \mathbf{b}$ and $\mathbf{c}$ are respectively the angular momentum of the input channel, 
the intermediate state (say a compound nucleus) and the output channel. If the entrance channel has a definite parity $\pi_{i}$, then it is conserved through the reaction:

$$
\pi_{i}=\pi_{c}=\pi_{f}
$$

where $\pi_{c}$ and $\pi_{f}$ are the parities of the intermediate and final states, respectively. The parity in the input channel is the product of the parity of the wave function of the internal coordinates and spin of the pair of interacting particles times the parity associated with the relative motion. The latter can be described by a plane wave [8], whose spatial part can be written as:

$$
\begin{gathered}
\text { incident wave } \propto \exp (i k z)=\Sigma_{l=0}^{\infty} A_{l}(r) Y_{l, 0} \\
A_{l}(r)=\int Y_{l, 0}(\theta) \exp (i k r \cos (\theta)) d \Omega
\end{gathered}
$$

Here the quantization axis is the beam axis: $Y_{l, 0}(\theta)$ 's are the spherical harmonics with $m=0$, whereas the $Y_{l, m}(\theta)$ 's are defined as simultaneous eigenfunctions of the square of the total angular momentum $\mathrm{L}^{2}$ and its projection on the $z$-axis $\mathrm{L}_{\mathrm{z}}$ with eigenvalues $l(l+1)$ and $m$, respectively. Equation 1.8 represents a plane wave, whose parity and angular momentum are not definite, as composed of partial waves, each having a defined angular momentum $l$ and parity $(-1)^{l}$. According to the decomposition of the incident plane wave of equation 1.8 , we can write the total reaction cross section $\sigma_{r}(E)$ as follows:

$$
\sigma_{r}(E)=\sum_{l=0}^{\infty} \sigma_{r, l}(E)
$$

where $\sigma_{r, l}(E)$ is the cross section for the reactions initiated by projectiles with an angular momentum $l$ at the energy $E$. One should note, however, that just a few terms of this series effectively contribute to the total cross section, due to the centrifugal barrier, that prevents the components with higher $l$ to reach the nuclear surface. As regards the differential cross section $d \sigma(E, \theta, \phi) / d \Omega$, we have to consider the form of the outgoing wave:

$$
\text { outgoing wave } \propto q(E, \theta) \exp (i k r) r^{-1}
$$


where $\theta$ is the angle between the beam direction, the $z$ axis, and the direction in which the outgoing particles move. The function $q(E, \theta)$ is called the amplitude of the reaction. In principle it depends upon $\phi$ as well, but this dependence vanishes when unpolarized beams and targets are considered, as in the present work. The differential cross section is connected to the reaction amplitude:

$$
\frac{d \sigma(E, \theta)}{d \Omega} \propto|q(E, \theta)|^{2} \equiv W(E, \theta)
$$

where $W(E, \theta)$ is the angular distribution of the reaction products. Let us consider the case of a resonance reaction taking place in a region where the levels of the compound nucleus are widely separated in comparison with their widths, so that the nuclear wave function of the compound nucleus has a defined spin c and parity. This will select even or odd $l$ 's, while, in case of zero spin projectile and target, it will select just a particular $l=c$ : in both cases, the effect of such selection is to define the parity of the wave function for the reaction, that has important consequences in the output channel. Indeed, because in the outgoing channel the parity operation corresponds to replacing $\theta$ by $\pi-\theta$ and $\varphi$ by $\varphi+\pi$, the following relation between the reaction amplitudes holds:

$$
q(E, \pi-\theta)=\Pi q(E, \theta)
$$

where $\Pi= \pm 1$, and again the dependence upon $\phi$ vanishes. Substituting equation 1.13 into equation 1.12 , one obtains:

$$
\frac{d \sigma(E, \pi-\theta)}{d \Omega}=\frac{d \sigma(E, \theta)}{d \Omega}
$$

This means that each time the wave function for the reaction has a definite parity, the differential cross section is symmetric about $\theta=90^{\circ}$. If we expand $d \sigma(E, \theta) / d \Omega$ or, equivalently, $W(E, \theta)$ in terms of Legendre polynomials:

$$
W(E, \theta)=\sum_{k} a_{k}(E) P_{k}(\cos \theta)
$$

only Legendre polynomials with even indices appear in the sum. This generally does not hold if the parity of the reaction wave function is not definite: the presence of odd- $k$ terms in equation 1.15 implies the interference between compound states of opposite parity, that is between the contributions from different $l$, that happens 
because of the definite phase relations between the components with different $l$ in the incident plane wave (see equation 1.8) deformed in the nuclear potential. To determine experimentally the coefficients $a_{k}$, as defined in equation 1.15 , it would be necessary to have pointlike detectors. For the case of real detectors, one measures:

$$
W(E, \theta)=\Sigma_{k} a_{k}^{\prime}(E) Q_{k} P_{k}(\cos \theta)
$$

where the $Q_{k}$, called attenuation coefficients, account for the finite detector size and the $a_{k}^{\prime}$ are determined comparing equation 1.16 with equation 1.15 . Let us now consider the coefficients $a_{k}$ in equation 1.15 in the case of radiative capture reactions, particularly with regards to their connection to the entrance channel angular momentum $l_{1}$, the outgoing $\gamma$-ray multipolarity $L_{2}$, and the absorption and emission operators. Using the same symbols as in equations 1.2.1, with the only change of $L_{2}$ replacing $l_{2}$, the coefficients $a_{k}$ are defined as:

$$
\begin{gathered}
a_{k}=\sum_{l_{1} l_{1}^{\prime} L_{2} L_{2}^{\prime} b b \prime}(-)^{a-c}\left(16 \pi^{2} a^{2}\right)^{-1} \bar{Z}\left(l_{1} b l_{1}^{\prime} b^{\prime} ; a k\right) \bar{Z}_{1}\left(L_{2} b L_{2}^{\prime} b^{\prime} ; c k\right) \\
\times\left\langle b \| l_{1} \mid a\right\rangle\left\langle b^{\prime} \| l_{1}^{\prime} \mid a\right\rangle^{*}\left\langle c \mid L_{2} \| b\right\rangle\left\langle c \mid L_{2}^{\prime} \| b^{\prime}\right\rangle^{*},
\end{gathered}
$$

where the terms $\bar{Z}\left(l_{1} b l_{1}^{\prime} b^{\prime} ; a k\right)$ and $\bar{Z}_{1}\left(L_{2} b L_{2}^{\prime} b^{\prime} ; c k\right)$ are combinations of ClebschGordan coefficients [9], and the terms $\left\langle b \| l_{1} \mid a\right\rangle$ and $\left\langle c \mid L_{2} \| b\right\rangle$ are operator reduced matrix elements, defined through the Wigner-Eckart theorem. They represent, respectively, the absorption of an incoming particle with momentum $l_{1}$ in the entrance channel and the emission of a $\gamma$-ray of multipolarity $L_{2}$ in the exit channel. From equation 1.12 and equation 1.15, it follows that the decomposition of the total cross section of equation 1.10 can be rewritten for radiative capture reactions in term of the multipolarity of the emitted $\gamma$-ray:

$$
\sigma_{r}(E)=\sum_{L=1}^{\infty}\left(\sigma_{r, E L}(E)+\sigma_{r, M L}(E)\right)
$$

where $\sigma_{r, E L}(E)$ and $\sigma_{r, M L}(E)$, the partial cross sections relative to electric and magnetic multipole emission, respectively, are combinations of the appropriate $a_{k}$. Parity and angular momentum conservation determine the selection rules for $\gamma$ emission. If a quantum with wave function $|L M\rangle$ is emitted in the transition from the state $\left|b m_{b}\right\rangle$ with parity $\pi_{b}$ to the state $\left|c m_{c}\right\rangle$ with parity $\pi_{c}$, then the following equations hold: 


$$
\begin{gathered}
\mathbf{b}=\mathbf{c}+\mathbf{L} \\
|b-c| \leq L \leq|b+c| \\
m_{a}-m_{b}=m \\
\pi_{b}=\pi_{L} \pi_{c}
\end{gathered}
$$

where the parity of a multipole $\mathrm{L}, \mathrm{M}$ is given by:

$$
\pi_{L}= \begin{cases}(-1)^{L} & \text { for electric multipole } \\ (-1)^{L+1} & \text { for magnetic multipole }\end{cases}
$$

For a given transition different multipoles are, in principle, possible. Actually the emission of lower order multipole radiation is favored, since the probability $P$ of emitting radiation of wavelength $\lambda$ from a $2^{L}$-pole of linear dimension $\mathrm{R}$ is [8]:

$$
P \propto\left(\frac{R}{\lambda}\right)^{2 L}
$$

with $R / \lambda$ of the order of $10^{-4}$ for nuclei. Moreover, electric multipoles are strongly favored with respect to magnetic ones [8]. As a consequence, the series in equation 1.18 usually contains only a few terms and multipole mixtures for a specified transition are not encountered very often, although they cannot be considered exceptional. As the last point of this section, let us consider the fact that there are no multipoles of order $L=0$ in the radiation field, and, hence, no radiative transition can take place between two states with spin 0 . Still other processes exist that could allow such transitions. In particular, the so-called internal pair formation could occur, if the energy difference between the two states is larger than $2 m_{e} c^{2}$, where $m_{e}$ is the electron mass. In this type of internal conversion, the transition energy is directly used to create an electron-positron pair. Actually, this process has been suggested and found for the ground state transition from the first ${ }^{16} \mathrm{O}$ excited state $\left(E_{x}=6049 \mathrm{keV}, J^{\pi}=0^{+}\right)[8]$. This process might play an important role in the determination of the stellar reaction rate of ${ }^{12} \mathrm{C}(\alpha, \gamma){ }^{16} \mathrm{O}$ (see section 1.2.4).

\subsubsection{Resonance reactions: $\mathrm{R}$-matrix formalism}

Low energy nuclear reactions show strong and often closely spaced resonances. The theory of resonance reactions is of great importance in nuclear astrophysics: indeed non-resonant processes, mainly direct capture (see next section), play a major role only if no strong resonance is close to the astrophysical relevant energy region. A 
description of these processes could be obtained by solving the Schroedinger equation for the system, that is generally not possible. Alternatively the R-matrix formalism describes a nuclear reaction in terms of a discrete set of parameters. The basic idea is to identify in the configuration space of the nucleons the volume $v$, say a sphere with radius $a$, corresponding to the compound nucleus, where the nuclear forces act, and express the wave function there in terms of some resonance parameters without solving the Schroedinger equation, that would require the knowledge of the nuclear potential. Matching the wave function inside and outside $v$, where just the well-known electromagnetic interaction is eventually present and the Schroedinger equation is solvable, it is possible to write down the reaction cross section in terms of the resonance parameters, that can be treated as phenomenological quantities. To see in detail how this is performed, let us consider the scattering of a spinless particle with $l=0$, assuming that the scattering potential vanishes outside $v$ [10]. Inside $v$, one should solve the Schroedinger equation and get the wave function $\Phi$ and a series of virtual states corresponding to the resonance energies, i.e. for a potential $V$ :

$$
-\frac{\hbar^{2}}{2 m} \frac{d^{2} \Phi}{d r^{2}}+V \Phi=E \Phi
$$

Rather than trying to do that, one considers the set of functions $X_{\lambda}$, solutions of equation 1.25 with an additional boundary condition at $r=a$ that let the $X_{\lambda}$ correspond to stationary states with energies $E_{\lambda}$. In formulas:

$$
-\frac{\hbar^{2}}{2 m} \frac{d^{2} X_{\lambda}}{d r^{2}}+V X_{\lambda}=E_{\lambda} X_{\lambda}
$$

and

$$
\left(\frac{d X_{\lambda}}{d r}+b X_{\lambda}\right)_{r=a}=0
$$

where $b$ is an arbitrary parameter. The $X_{\lambda}$ form a complete set in $v$ and one can expand $\Phi$ in terms of $X_{\lambda}$ :

$$
\Phi=\Sigma_{\lambda} A_{\lambda} X_{\lambda}
$$

where the coefficients $A_{\lambda}$ are defined by: 


$$
A_{\lambda}=\int_{0}^{a} X_{\lambda} \Phi d r
$$

Using equation 1.29 and equation 1.27 one gets the $A_{\lambda}$ and then, substituting in equation 1.28 , one obtains:

$$
\Phi(r)=G(r, a)\left[\Phi^{\prime}(a)+b \Phi(a)\right]
$$

where

$$
G(r, a)=\frac{\hbar^{2}}{2 m} \sum_{\lambda} \frac{X_{\lambda}(r) X_{\lambda}(a)}{E_{\lambda}-E}
$$

and $\Phi^{\prime}(r)$ is the derivative of $\Phi(r)$ respect to $r$. On the surface of $v$ one has:

$$
\Phi(a)=R\left[\Phi^{\prime}(a)+b \Phi(a)\right]
$$

with the R-function defined as:

$$
R=G(a, a)=\sum_{\lambda} \frac{\gamma_{\lambda}^{2}}{E_{\lambda}-E}
$$

where $\gamma_{\lambda}^{2}$, called the reduced width of the state $\lambda$, is:

$$
\gamma_{\lambda}^{2}=\frac{\hbar^{2}}{2 m}\left[X_{\lambda}(a)\right]^{2}
$$

One has now to match the logarithmic derivative of $\Phi$

$$
\Phi^{\prime}(r) / \Phi(r)
$$

inside and outside $v$, i.e. for $r=a$.

Outside $v$, let $I \propto \exp (-i k r)$ be the incoming and $O \propto \exp (i k r)$ the outgoing plane waves. Then:

$$
\Phi=I-U O
$$


$U$, called the collision function, is related to the scattering cross section:

$$
\sigma=\frac{\pi}{k^{2}}\left|1-U^{2}\right|
$$

Therefore, outside $v$ we have:

$$
\Phi^{\prime}(r) / \Phi(r)=\frac{I^{\prime}-U O^{\prime}}{I-U O}
$$

while on the surface of $v$, from equation 1.32:

$$
\left(\Phi^{\prime}(r) / \Phi(r)\right)_{r=a}=\frac{1-b R}{R}
$$

Comparing equation 1.37 and equation 1.38, one gets $U$, and therefore $\sigma$, as a function of the $\gamma_{\lambda}^{2}$ and $E_{\lambda}$. The extension of this formalism to any reaction is straightforward, but rather complicated. Essentially one has to consider all possible different channels: this means that $U, O, I$, and $b$ become matrices, while the relations among them still hold and one defines reduced widths $\gamma_{\alpha \lambda}$ and energy levels $E_{\alpha \lambda}$ for each channel. In case $V(r)$ does not vanish for $r>a$, the wave functions in the external region are generally given by the regular and irregular Coulomb functions.

The R-matrix formalism is very useful to describe the cross section in an energy interval were only a few resonances dominate, whose parameters, that determine also the sign of the interference between them, can be determined via a fit to the experimental data. Otherwise, it would consist just in writing the unknown nuclear wave function, and therefore the cross section, in terms of an infinite set of equally unknown parameters. But even when the cross section is mostly determined by a few resonances, the effect of all the other levels is not neglected: for this purpose, a background term is introduced, in form of the tail of a far lying resonance.

In section 3.2 the R-matrix formalism will be applied to the case of ${ }^{12} \mathrm{C}(\alpha, \gamma){ }^{16} \mathrm{O}$ and the relevant formulas will be given in order to extrapolate $\sigma_{E 1}(E)$ to $E_{0}=300$ $\mathrm{keV}$, the Gamow energy for the helium burning in red giants.

\subsubsection{Direct capture reactions}

There is another reaction mechanism, besides resonance capture, playing a very important role in low energy nuclear reactions, that is direct capture. This process consists, as the name suggests, in the direct capture of the projectile, that passes 
from an initial continuum state to a final nuclear state without formation of a compound nucleus. The direct capture is essentially an extra-nuclear process and, due to the short range of the nuclear interaction, it is induced by the electromagnetic interaction. As a consequence, direct capture cross sections do not present resonances. Because the electromagnetic interaction is rather well known, direct capture cross sections can be calculated in a rather simple and accurate way, provided the spectroscopic factors for the final states are known ([11] and references therein). To do that, one writes the Hamiltonian of the system as:

$$
H=H_{0}+H_{\text {int }}
$$

where $H_{0}$ describes the projectile-target system and $H_{\text {int }}$ represents the interaction between the particles and the electromagnetic field. Assuming that $H_{\text {int }}$ can be treated with the perturbation theory the following equation holds according to Fermi's golden rule:

$$
\frac{d \sigma}{d \Omega} \propto \frac{E_{\gamma}}{\left(2 s_{0}+1\right)\left(2 s_{1}+1\right)} \sum_{m_{i} m_{f} P}\left|\left\langle f, m_{f}\left|H_{i n t}\right| i, m_{i}\right\rangle\right|^{2}
$$

where $s_{0}$ and $s_{1}$ are the spins of projectile and target and $P(P= \pm 1)$ is the circular polarization of the $\gamma$-radiation, while $\left|i, m_{i}\right\rangle$ and $\left|f, m_{f}\right\rangle$ are, respectively, the initial and final wave functions of the system, respectively. For a given final state, the reaction will select those partial waves that can initiate the reaction and the multipolarity of the corresponding $\gamma$-radiation, that determines $H_{\text {int }}$. If both direct and resonant capture are possible, then one should expect, for a given multipolarity, the presence of interference terms in the total cross section.

\subsubsection{The ${ }^{12} \mathrm{C}(\alpha, \gamma){ }^{16} \mathrm{O}$ reaction mechanism}

Figure 1.1 shows the level scheme of ${ }^{16} \mathrm{O}$ together with some information about the ${ }^{12} \mathrm{C}(\alpha, \gamma){ }^{16} \mathrm{O}$ reaction: the stellar energy window, i.e. the Gamow peak, is around $E_{0}=0.3 \mathrm{MeV}$, while the experimental data go down to about $E=1.0 \mathrm{MeV}$. The Q-value of the reaction, defined as $\mathrm{Q}=\mathrm{M}_{16} \mathrm{O}-\left(\mathrm{M}_{12} \mathrm{C}+\mathrm{M}_{4} \mathrm{He}\right)$, is $7.162 \mathrm{MeV}$. Firstly, one should note that only the ${ }^{16} \mathrm{O}$ states with natural parity, i.e. $\pi=(-1)^{\mathrm{J}}$ where $J$ is the angular momentum of the level, can be directly populated via ${ }^{12} \mathrm{C}(\alpha, \gamma){ }^{16} \mathrm{O}$. This is a consequence of the fact that the ground states of both ${ }^{4} \mathrm{He}$ and ${ }^{16} \mathrm{O}$ have spin 0 and positive parity: indeed, from equation 1.2.1 and equation 1.7, it follows that just those states of ${ }^{16} \mathrm{O}$ with spin and parity $J^{\pi}=l^{-1^{l}}$ with $l=0,1,2, \ldots$, where $l$ is the orbital angular momentum in the entrance channel, can be populated in 
their magnetic substate with $m=0$, if the beam axis is the quantization axis. If one looks at radiative capture, the states with $J^{\pi}=0^{+}$have to be disregarded (see section 1.2.1). The question has been raised [12], whether the capture into the ${ }^{16} \mathrm{O}$ might also proceed through internal pair formation. We leave the answer to future experiments and come back to radiative capture channels. With $s$-wave $(l=0)$ partial wave excluded in virtue of the previous arguments, the next components to be considered are $p$-wave $(l=1)$ and $d$-wave $(l=2)$. These partial waves can populate, respectively, $J^{\pi}=1^{-}$and $J^{\pi}=2^{+}$states or go directly to the ground state via the direct capture process.

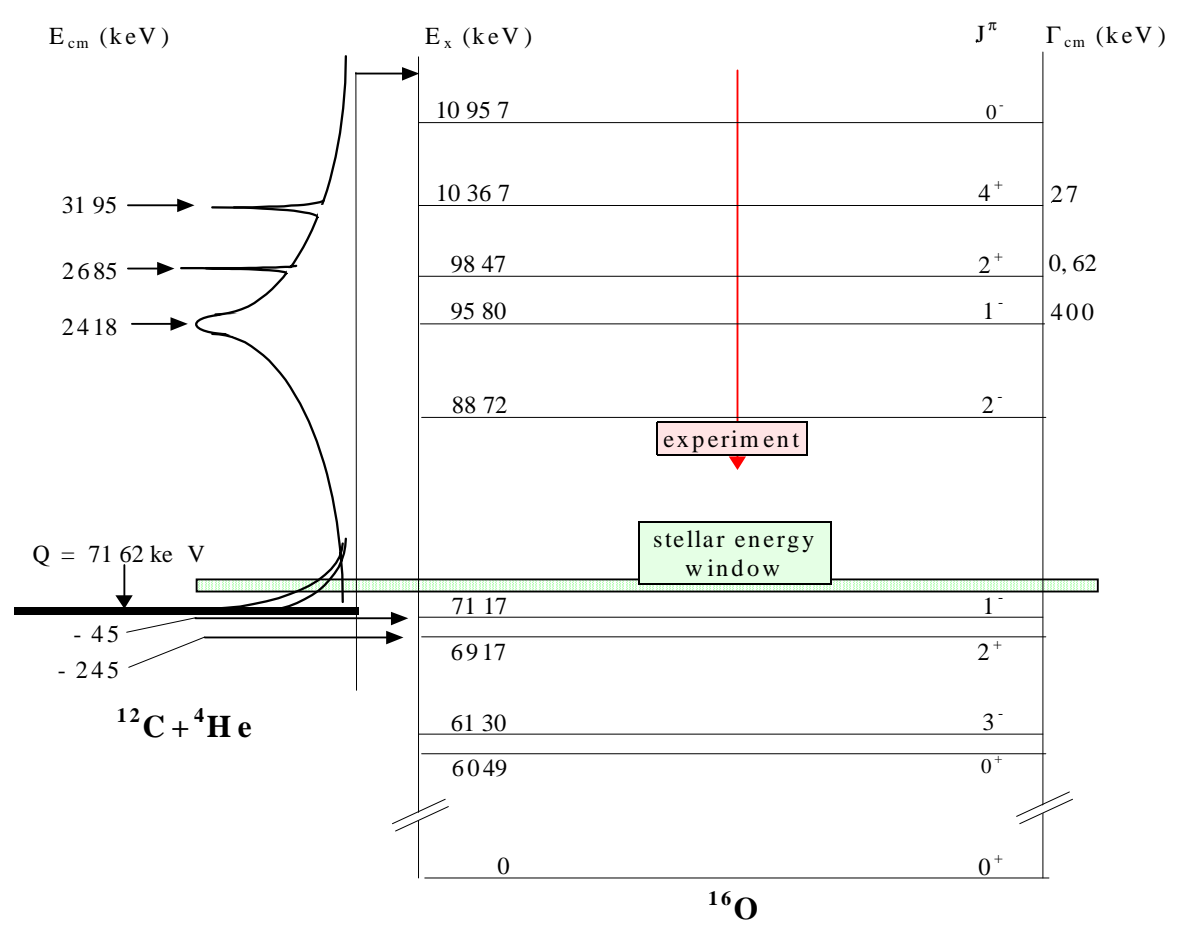

Figure 1.1: Level scheme of ${ }^{16} \mathrm{O}$. The curve on the left side represents the ${ }^{12} \mathrm{C}(\alpha, \gamma){ }^{16} \mathrm{O} S(E)$ factor

Reactions initiated by $p$-wave would proceed through $E 1$ emission and in this case $H_{\text {int }}$ for direct capture (see section 1.2.3) is [11]:

$$
H_{i n t}(E 1) \propto\left(\frac{Z_{1}}{M_{1}}-\frac{Z_{2}}{M_{2}}\right)
$$

where $Z_{1}, M_{1}, Z_{2}$, and $M_{2}$ are the charge and mass of the projectile and target nuclei, respectively. For ${ }^{12} \mathrm{C}(\alpha, \gamma){ }^{16} \mathrm{O}$, one finds: 


$$
\left(\frac{Z_{1}}{M_{1}}-\frac{Z_{2}}{M_{2}}\right)=\left(\frac{Z_{{ }^{4} H e}}{M_{4} H e}-\frac{Z_{{ }^{12} C}}{M_{12} C}\right) \approx 0,
$$

and, consequently, direct capture is negligible for the $p$-wave, that rather populates $1^{-}$states. At $E_{0}$ just two $1^{-}$levels $\left(E_{x}=9580 \mathrm{keV}\right.$ and $\left.E_{x}=7117 \mathrm{keV}\right)$ are assumed to dominate the cross section through their, in the order, low and high energy tails and the corresponding interference term.

With regard to $d$-wave, just the resonant capture via the $E_{x}=6917 \mathrm{keV}$ level has to be considered, together with direct capture.

The reactions initiated in $p$-wave proceed through $E 1$ emission, while in the case of $d$-wave it is $E 2$ emission. Capture via $\gamma-\gamma$ cascades, for which an $E 2 / M 1$ multipole admixture was found [13], are believed to give a maximum contribution of at most $10 \%$ to $S\left(E_{0}\right)$ [13]. Higher angular momentum components do not play an important role, due to the increase of the centrifugal barrier and the lack of states with natural parity and spin greater than 2 in ${ }^{16} \mathrm{O}$ at the relevant energy region. According to equation 1.18, we can write:

$$
\sigma(E)=\sigma_{E 1}(E)+\sigma_{E 2}(E)
$$

The cross section at $E_{0}$ is expected to be of the order of $10^{-17} \mathrm{~b}$ : a direct measurement is not possible with present techniques, and presumably this will be the case for a long time. Therefore, it is necessary to extrapolate the experimental data. Since $\sigma_{E 1}(E)$ and $\sigma_{E 2}(E)$ have different energy dependencies, one must have an independent and precise information on each multipole cross section to put the extrapolation to $E_{0}$ on a firm ground. The necessary information can be gained considering the angular distribution $W\left(E, \theta_{\gamma}\right)$ of the $\gamma$-rays. For this purpose, it is usual to express $W\left(E, \theta_{\gamma}\right)$ in terms of $\sigma_{E 1}(E)$ and $\sigma_{E 2}(E)$. This is done writing in equation 1.15 the coefficients $a_{k}$ in terms of the different multipole cross sections, whereas the relation between them is obtained comparing equation 1.12 and equation 1.18. The resulting expression is:

$$
\begin{aligned}
W\left(E, \theta_{\gamma}\right) & =3 \sigma_{E 1}(E)\left(1-Q_{2} P_{2}\left(\cos \theta_{\gamma}\right)\right) \\
& +5 \sigma_{E 2}(E)\left(1+\frac{5}{7} Q_{2} P_{2}\left(\cos \theta_{\gamma}\right)-\frac{12}{7} Q_{4} P_{4}\left(\cos \theta_{\gamma}\right)\right) \\
& +6 \sqrt{3} \sqrt{\sigma_{E 1}(E) \sigma_{E 2}(E)} \cos \varphi_{12}\left(Q_{1} P_{1}\left(\cos \theta_{\gamma}\right)-Q_{3} P_{3}\left(\cos \theta_{\gamma}\right)\right) \\
& \equiv W_{E 1}\left(E, \theta_{\gamma}\right)+W_{E 2}\left(E, \theta_{\gamma}\right)+W_{E 1, E 2}\left(E, \theta_{\gamma}\right)
\end{aligned}
$$

where $\varphi_{12}$ is the phase difference between $p$ - and $d$-waves. From equation 1.44 results that angular distribution measurements can give information on the different components of the cross section, provided the relevant attenuation coefficients are known 
with sufficient precision. The detection geometry should determine attenuation coefficients possibly close to one, that is the condition of a point-like detector, in order to have a sensitive setup. Moreover several detection angles should be available to perform a good fit of $W\left(E, \theta_{\gamma}\right)$ to the experimental data, that should extend over a wide energy region. All these conditions would require a rather complicated and expensive setup. As we will see in the next section, usually a compromise is found and angular distributions are measured just at a few angles and selected energies.

A closer inspection of equation 1.44 suggests another possibility of gaining informations about $\sigma_{E 1}(E)$ and $\sigma_{E 2}(E)$. Indeed, replacing the explicit expressions of the $P_{k}(\cos \theta)$ and assuming unitary attenuation coefficients, one gets:

$$
\begin{aligned}
& W_{E 1}\left(E, \theta_{\gamma}\right) \propto f_{E 1}(E) \sin ^{2} \theta_{\gamma} \\
& W_{E 2}\left(E, \theta_{\gamma}\right) \propto f_{E 2}(E) \sin ^{2} \theta_{\gamma} \cos ^{2} \theta_{\gamma} \\
& W_{E 1, E 2}\left(E, \theta_{\gamma}\right) \propto f_{E 1, E 2}(E) \cos \theta_{\gamma}\left(\cos ^{2} \theta_{\gamma}+1\right)
\end{aligned}
$$

Equations 1.45 show that, if a pointlike detector is placed at $\theta_{\gamma}=90^{\circ}$, it would observe just the yield of the $E 1$ multipole. Such a setup is not feasible: in practice, one uses a far detection geometry in order to reach the condition to keep the $E 2$ contamination in the observed spectra well below the statistical error affecting the measurements. Anyway, the price is a low detection efficiency limiting the exploitable energy range. On the other hand, if the detection setup covers the full solid angle, the total cross section will be measured, whereas, as expected, the term $W_{E 1, E 2}\left(E, \theta_{\gamma}\right)$ vanishes with the integration over $4 \pi$. By means of those two measurements and equation 1.43 also $\sigma_{E 2}$ is determined.

\subsubsection{Experimental State-of-the-Art}

Besides measurements of the ${ }^{12} \mathrm{C}(\alpha, \gamma){ }^{16} \mathrm{O}$ reaction, other experiments can provide useful information to extrapolate the cross section to $E_{0}$, as long as their cross sections depend on the same nuclear parameters as ${ }^{12} \mathrm{C}(\alpha, \gamma){ }^{16} \mathrm{O}$. It is usual, in a somewhat artificial way, to refer to these measurements as to indirect measurements, in comparison with the direct measurements of ${ }^{12} \mathrm{C}(\alpha, \gamma){ }^{16} \mathrm{O}$. In this section we shortly resume the previous measurements according to this classification.

\section{Direct measurements}

Most direct measurements were performed detecting the emitted $\gamma$-ray alone $[14$, $15,13,16,12]$ : the only exception is [17], where $\gamma$-recoil coincidences were observed. References [14, 13, 17, 16, 12] report a E1 measurement, while [15] studied the angle 


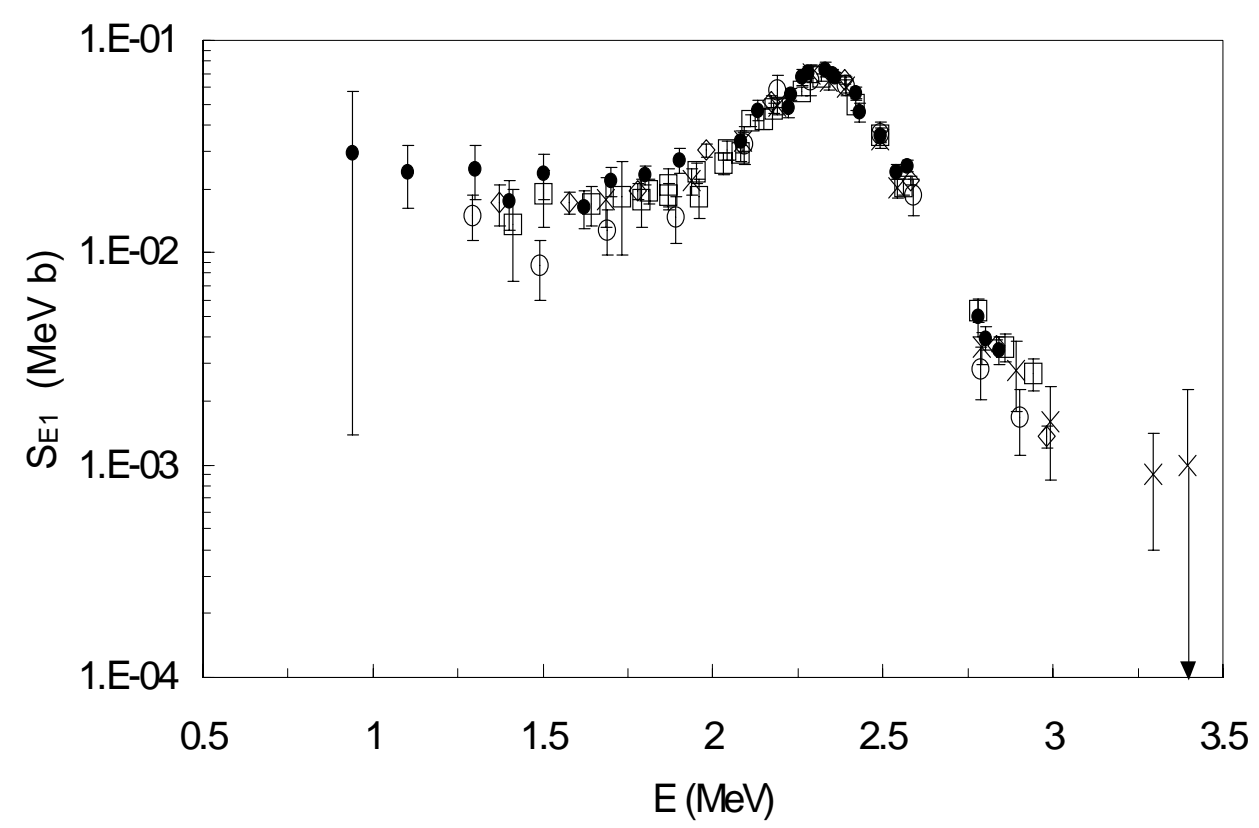

Figure 1.2: Results of previous $E 1$ measurements in form of astrophysical $S(E)$ factor $(\triangle[13], \circ[17], \times[12], \bullet[14], \diamond[16])$

integrated cross section. References $[14,15,13]$ performed a measurement of the total cross section nearly on top of the $E=2.42 \mathrm{MeV} J^{\pi}=1^{-}$resonance, where $\sigma_{E 2}$ is expected to be negligible relatively to $\sigma_{E 1}\left(\sigma_{T O T} \approx \sigma_{E 1}\right)$ : the results of these measurements are resumed in table 1.1.

\begin{tabular}{|cccc|}
\hline Ref. & $\begin{array}{c}E_{\text {norm }} \\
(\mathrm{MeV})\end{array}$ & $\begin{array}{c}\sigma_{\text {norm }} \\
(\mathrm{nb})\end{array}$ & $\begin{array}{c}\delta \sigma_{\text {norm }} \\
(\mathrm{nb})\end{array}$ \\
\hline$[14]$ & 2.420 & 37.1 & 1.6 \\
{$[15]$} & 2.397 & 57 & 8 \\
{$[15]$} & 2.397 & 53 & 4 \\
{$[13]$} & 2.36 & 46 & 6 \\
\hline
\end{tabular}

Table 1.1: Absolute cross section measurements for ${ }^{12} \mathrm{C}(\alpha, \gamma){ }^{16} \mathrm{O}$

All reported E1 measurements finally relied on measurements at $\theta_{\gamma}=90^{\circ}$, eventually corrected considering the $\sigma_{E 1} / \sigma_{E 2}$ ratio obtained by means of angular distribution measurements $[14,13,16]$. Reference [13] measured the angular distributions at several energies, while references $[14,16]$ measured just at few energies. Anyway, just in one case [12] the detector was in far geometry: unfortunately, the detection setup consisted of a single $2^{\prime \prime} \times 2^{\prime \prime}$ BGO crystal and the detection efficiency was rather low, such that the measurements were limited to the energy range $E=1.6$ 
to $3.2 \mathrm{MeV}$. Figure 1.2 shows the $S_{E 1}$ data of references $[14,13,17,16,12]$. It is clear that systematic differences are present, both in the absolute value and the energy dependence of the cross section. The situation slightly improves, as regard the absolute value, if a common normalization standard is used for all data sets. Between the sources of the systematic errors possibly affecting some, or perhaps all, of the previous measurements are an incorrect background subtraction, especially as regards the high energy region where the beam induced background dominates, or an inproper subtraction of the $E 2$ contribution to the observed spectra.

\section{Indirect measurements}

As seen in section 1.2.2, the extrapolation of the ${ }^{12} \mathrm{C}(\alpha, \gamma){ }^{16} \mathrm{O}$ cross section to $E_{0}=$ $300 \mathrm{keV}$ using the R-matrix theory of nuclear reactions can be done in terms of reduced widths (see equation 1.34) of the relevant states for different channels. With regard to the reduced $\alpha$-widths, information has to be achieved from different sources than ${ }^{12} \mathrm{C}(\alpha, \gamma){ }^{16} \mathrm{O}$. To this purpose, the ${ }^{12} \mathrm{C}(\alpha, \alpha){ }^{12} \mathrm{C}$ elastic scattering and the $\beta$-delayed $\alpha$ spectrum of ${ }^{16} N$ have been exploited. In the first case, the elastic scattering cross sectioifn $\sigma_{e l}(E, \theta)$ is written as [18]:

$$
\sigma_{e l}(E, \theta) \propto \frac{1}{\sqrt{E}} \sum_{l=0}^{\infty}(2 l+1) \sin ^{2} \delta_{l}
$$

where the phase shifts $\delta_{l}$ are connected to the reduced $\alpha$-widths and can be fitted using the R-matrix formalism (see section 3.2). Presently there are two measurements published [19, 20], whereas [19] was ignored in any compilation and first mentioned in [12]. A third measurement was recently presented [21], but not yet published. Similarly, the low energy tail of the $\beta$-delayed $\alpha$ spectrum of ${ }^{16} \mathrm{~N}$ is quite sensitive to the reduced $\alpha$-width of the $E_{x}=7.117 \mathrm{MeV}$ subthreshold state [22]. As a consequence it puts a strong constraint on $S_{E 1}(300)$ once these data are included in a R-matrix fit (see section 3.2). In principle the needed reduced $\alpha$-widths could be determined by means of $\alpha$ transfer reactions. Unfortunately the results of this kind of measurements are strongly dependent on the nuclear potential parameters and on the calculation of the contribution of compound nucleus reactions. Recently a new approach has been reported [23] that tries to solve the above mentioned problems exploiting the cluster configurations of ${ }^{6} \mathrm{Li}\left({ }^{4} \mathrm{He}+{ }^{2} \mathrm{H}\right)$ and ${ }^{7} \mathrm{Li}\left({ }^{4} \mathrm{He}+{ }^{3} \mathrm{H}\right)$. The influence of the nuclear potential parameters on the data analysis is strongly reduced considering $\alpha$ transfer reactions at sub-Coulomb energies, where the well known Coulomb potential plays a major role. The two reactions ${ }^{12} \mathrm{C}\left({ }^{6} \mathrm{Li},{ }^{2} \mathrm{H}\right){ }^{16} \mathrm{O}$ and ${ }^{12} \mathrm{C}\left({ }^{7} \mathrm{Li},{ }^{3} \mathrm{H}\right){ }^{16} \mathrm{O}$ are studied and the results are used to determine the extrapolation of $\sigma_{E 1}$ and $\sigma_{E 2}$ to $E_{0}$. Finally, a new indirect method to determine reaction 
cross sections was proposed, the Trojan Horse Method. The method is based on the quasi-free mechanism occurring in reactions with three body exit channels where one of the interacting particles, say the target, has a high clustering probability. The three body cross section can then be factorized into three terms: a kinematical factor, a term describing the cluster momentum distribution in the target nucleus, and a term representing the two body virtual reaction between the projectile and one of the clusters of the target. Imposing proper kinematical conditions in the exit channel, it is possible to determine the two body reaction energy: in virtue of the momentum distribution of the clusters in the target, virtual reactions at very low energy can be selected and the corresponding cross sections will be enhanced by the fact of having penetrated the Coulomb barrier at higher energy; that is the idea behind the name given to this method. In [24], the reaction ${ }^{6} \mathrm{Li}\left({ }^{12} \mathrm{C}, \alpha{ }^{12} \mathrm{C}\right){ }^{2} \mathrm{H}$ has been considered and ${ }^{12} \mathrm{C}-\alpha$ coincidences have been measured. The results should be comparable, and actually they show a good agreement, to the elastic ${ }^{12} \mathrm{C}+\alpha$ scattering. 


\section{Chapter 2}

\section{Experimental setup}

The measurement of the E1 component of the ${ }^{12} \mathrm{C}(\alpha, \gamma){ }^{16} \mathrm{O}$ cross section requires a high yield and detection efficiency in combination with a good signal to background ratio, in view of the small value of the cross section, that ranges from 0.1 to 50 $\mathrm{nb}$ in the energy region from 1 to $3 \mathrm{MeV}$. This has to be achieved keeping a far detection geometry around $\theta_{\gamma}=90^{\circ}$, that allows a good suppression of the E2 component. All these aspects require a careful planning of the experimental setup: the present chapter describes it. I will outline the problems encountered and the adopted solutions, that sometimes were a compromise between the ideal case and the available resources. Finally I report the results of some measurements that were performed to characterize the experimental setup.

\section{$2.1 \quad$ Accelerator}

In the present experiment the ${ }^{12} \mathrm{C}(\alpha, \gamma){ }^{16} \mathrm{O}$ reaction was studied in inverse kinematics. The 4MV Dynamitron tandem accelerator at the Ruhr-Universitaet Bochum provided the necessary ${ }^{12} \mathrm{C}$ beam over the energy range $E_{l a b}=4.5$ to $14.0 \mathrm{MeV}$ with a particle current from 30 to $50 \mu \mathrm{A}$ at the target. Other ion beams $\left({ }^{11} \mathrm{~B}\right.$ and $\left.{ }^{16} \mathrm{O}\right)$ were also provided for calibration purposes (see next sections). The energy spread for ${ }^{12} \mathrm{C}$ ions was found to be [25] $\Delta E_{l a b}=2.8(1+q) \mathrm{keV}$ at $E_{l a b}=10.5 \mathrm{MeV}$, where $q$ is the selected charge state. The energy calibration of the analyzing magnet has been carried out previously over a wide magnetic field range [25] and resulted in a precision of heavy-ion beam energies of $4 \cdot 10^{-4}$. In the following I will indicate with $E_{l a b}$ the beam energy as determined by means of the analyzing magnet, i.e. not taking into account the energy loss in the target. 


\subsection{Gas target}

If one studies this reaction in direct kinematics, i.e. using a ${ }^{4} \mathrm{He}$ beam and a carbon target with natural isotopic composition $\left({ }^{12} \mathrm{C},{ }^{13} \mathrm{C}\right)$, the ${ }^{13} \mathrm{C}(\alpha, \mathrm{n}){ }^{16} \mathrm{O}$ contaminant reaction is a very intense source of beam induced background [1]. This problem can be solved using ${ }^{13} \mathrm{C}$-depleted targets, where the natural amount of ${ }^{13} \mathrm{C}(1.11 \%)$ can be reduced by 2 or 3 orders of magnitude $[14,16]$, in conjunction with other techniques, e.g. time of flight measurements [14] to discriminate the prompt capture $\gamma$-rays from the delayed neutron induced $\gamma$-rays. Alternatively one can interchange the roles of projectile and target $[15,13,17,12]$, that was the solution chosen here. This requires the utilization of a gas target. Such a system has to be realized without windows to confine the gas in the target chamber, otherwise the maximum beam intensities would be limited to very low values to avoid the quick damage of the windows themselves. Moreover, the interaction of the beam with the window materials would be an intense source of background. Therefore it is necessary to confine the gas using a series of pumping stages separated by apertures. Their actual dimensions are a compromise between the need of limiting the gas flow in order to match it with the performances of the pumping system and the requirement of having a good beam transmission through them. Such a system is much more complicated than a solid target, but it offers some advantages, aside those just mentioned. A gas target can stand very high beam intensities without deteriorating, whereas, for example, reference [16] reports a carbon target consumption of about $40 \%$ every ten days of beam time. Another interesting feature of a gas target is the possibility of changing easily its thickness and composition to perform test measurements or calibration runs. The main disadvantages of a gas target are its complicated and relatively expensive setup, the necessity of an efficient gas recycling system or the use of a large amount of gas. Besides that, a gas target requires a good characterization of the pressure profile and of the effective target lengths and solid angles for the different detectors. Figure 2.1 shows a scheme of the windowless gas target built for the experiment.

The beam passed first through five apertures (A6 to A2), entered the target chamber (a cylindrical gas cell of $10 \mathrm{~cm}$ length with apertures $\mathrm{A} 1$ and $\mathrm{B} 1$ of $\Phi=6 \mathrm{~mm}$ diameter each), passed through another set of apertures (B2 to B5), and was finally stopped in a Faraday cup. The Faraday cup was located at about $5 \mathrm{~m}$ distance from the gas cell, within a $1.5 \mathrm{~m}$ thick concrete wall and surrounded by a $0.5 \mathrm{~m}$ thick paraffin shield. Different pumps were used in order to match the gas pressure at each pumping stage: roots blowers (WS\# or WSU\#, where \# indicates the pumping speed in $\mathrm{m}^{3} / \mathrm{h}$ ) were used in the pumping stages close to the gas cell, where the pressure ranged between 1 and $1 \cdot 10^{-2}$ Torr, while turbomolecular pumps ( $\mathrm{TV} \#$ or $\mathrm{V} \#$, where \# indicates the pumping speed in $\mathrm{l} / \mathrm{s}$ ) reduced the pressure 


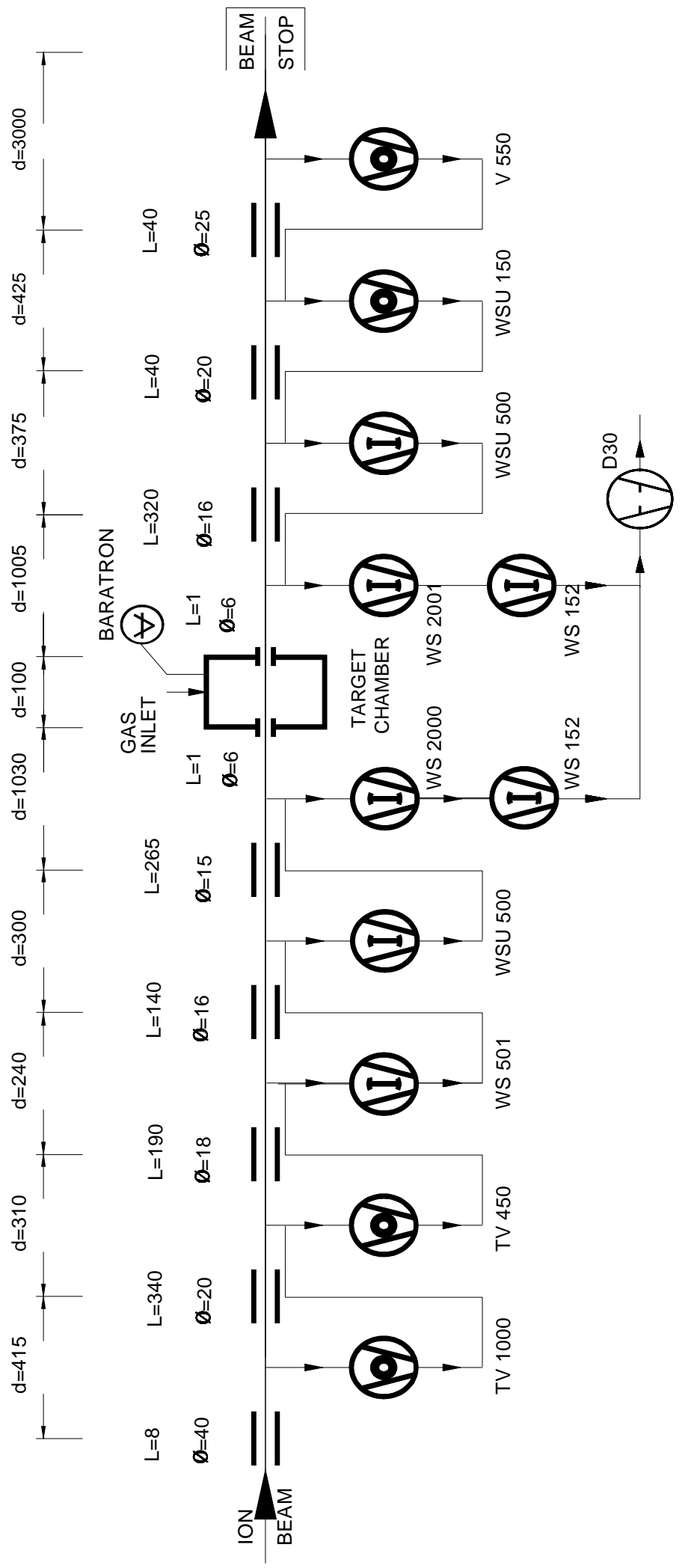

Figure 2.1: Scheme of the windowless differentially pumped gas target. The lengths $(\mathrm{L})$ and diameters $(\Phi)$ of the apertures and the distances (d) between the apertures are given in units of $\mathrm{mm}$. 
from $1 \cdot 10^{-3}$ to $1 \cdot 10^{-7}$ Torr in the following stages. Each pump was backed by the previous one and the two roots blowers adjacent to the gas cell were finally backed by a rotary pump (D30, pumping speed $=30 \mathrm{~m}^{3} / \mathrm{h}$ ). The gas cell had ports used for gas inlet, pressure measurement, and installation of a silicon detector. A second silicon detector was installed on the first pumping stage down-stream. The gas pressure in the target chamber was set by means of a needle valve and it was monitored with an absolute accuracy of $2 \%$ and a reproducibility below $1 \%$ using a Baratron capacitance manometer. Such devices provide a pressure measurement not dependent on the kind of gas. They were used also to monitor the pressure on the first pumping stages, while for the following stages ionization gauges were adopted. It was also attempted to use the gas target with gas re-circulation, replacing the D30 rotary pump with a piston pump, that was able to compress the He gas back to the gas target chamber through a two stage zeolith filter placed in a liquid nitrogen bath. Unfortunately, the gas purification achieved was not satisfactory. The situation was acceptable at lower energy, but prohibitively bad at higher energy. It was finally decided not to re-circulate the gas to have an uniform quality of the spectra over the investigated energy region. The observed gas consumption for a pressure of 20 Torr in the target chamber was $0.73 \mathrm{l} / \mathrm{s}$ at standard conditions $(\mathrm{T}=273 \mathrm{~K}, \mathrm{P}=760$ Torr).

\subsection{The $\gamma$ ray detection setup}

In the specific case of the measurement of the E1 component of the ground state transition, the increase of the detection efficiency has preferably to be achieved keeping a far geometry arrangement of the detectors at $90^{\circ}$ to the beam axis to have a good suppression of the E2 component (see section 1.2.1 and section 2.6.4). Therefore the six high purity germanium detectors (HPGe in the following) available for this experiment were arranged in a ring-shaped geometry around the gas target. The detectors were GEm p-type produced by EG\&G Ortec. Figure 2.2 shows the original drawing of one of the detectors used. Similar drawings were available for all the other detectors and they provided the necessary information to perform a realistic simulation of the experiment (see section 3.1.2). Table 2.1 summarizes the detector specifications and their respective distances to the beam axis. Figure 2.3 shows the detection setup. The detectors were located in a ring shaped geometry around the gas target chamber perpendicular to the beam axis. The mean distance between the beam axis and the detector front end was about $17 \mathrm{~cm}$. The target length seen by the detectors was limited to $53 \mathrm{~mm}$ by two lead hollow cylinders $(12.5$ $\mathrm{cm}$ thick) surrounding the beam pipe. In order to reduce the room background, the detectors were surrounded by a $5 \mathrm{~cm}$ thick lead wall. 


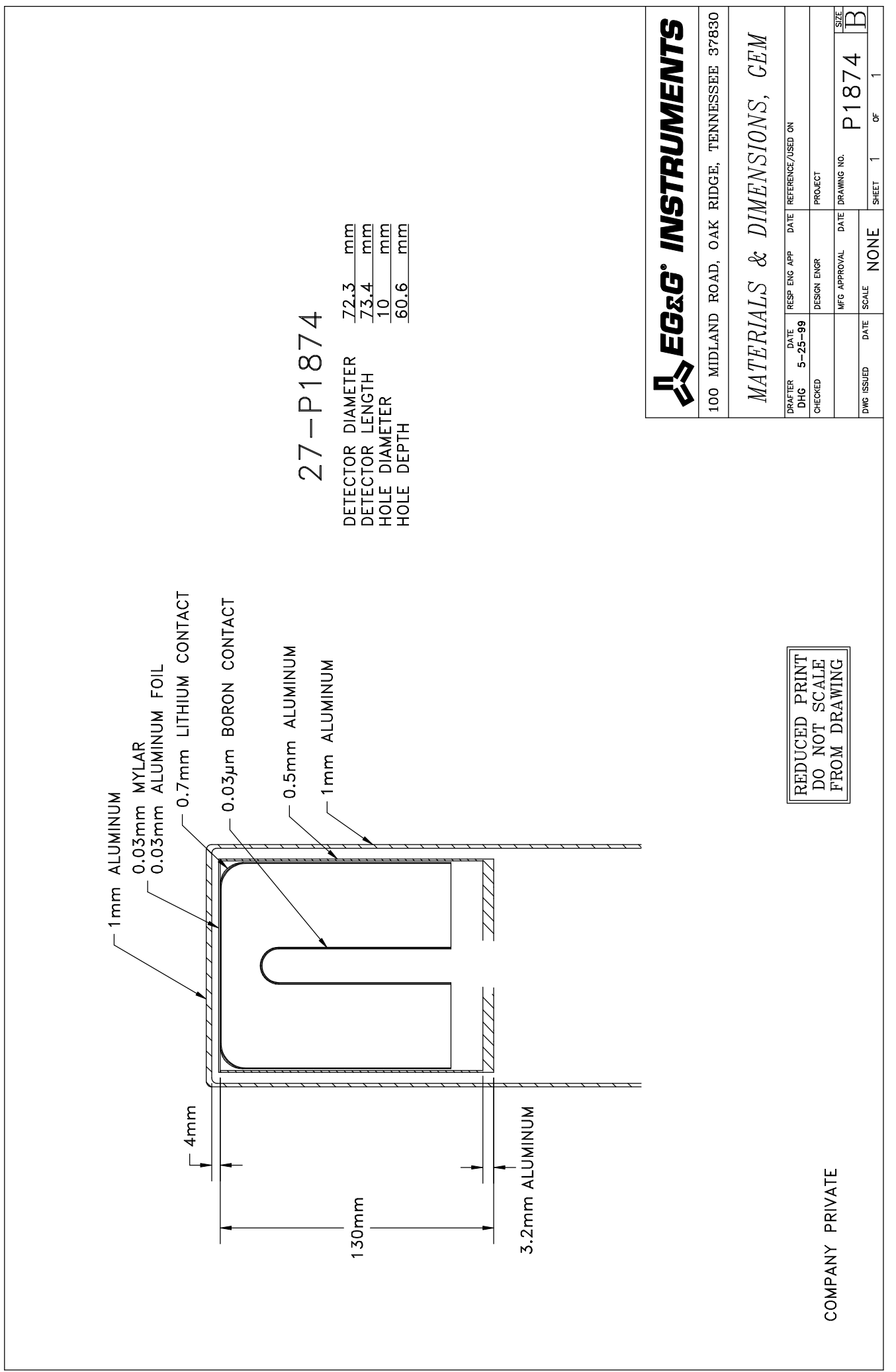

Figure 2.2: Drawing of one of the HPGe detectors used for the present experiment (EG\&G ORTEC) [26] 


\begin{tabular}{|cccccc|}
\hline $\begin{array}{c}\text { Serial } \\
\text { number }\end{array}$ & $\begin{array}{c}\text { Detector } \\
\text { diameter } \\
(\mathrm{mm})\end{array}$ & $\begin{array}{c}\text { Detector } \\
\text { length } \\
(\mathrm{mm})\end{array}$ & $\begin{array}{c}\text { Hole } \\
\text { diameter } \\
(\mathrm{mm})\end{array}$ & $\begin{array}{c}\text { Hole } \\
\text { depth } \\
(\mathrm{mm})\end{array}$ & $\begin{array}{c}\text { Distance } \\
\text { from beam } \\
\text { axis(mm) }\end{array}$ \\
\hline 27-P1874 & 72.3 & 73.4 & 10 & 60.6 & 159 \\
28-P20090 & 69.7 & 94.5 & 9.9 & 79.1 & 174 \\
28-P20091 & 69.7 & 90 & 9.7 & 76 & 168 \\
28-P20174 & 75.0 & 75.5 & 10.4 & 63.0 & 201 \\
31-P20662A & 69.5 & 82.7 & 9.7 & 69.4 & 167 \\
27-P30017 & 69.1 & 92.6 & 9.7 & 78.2 & 170 \\
\hline
\end{tabular}

Table 2.1: Dimensions (see figure 2.2) of the HPGe detectors used for the present experiment. The last column reports the respective distances to the beam axis.

\begin{tabular}{|ccc|}
\hline $\begin{array}{c}\text { Serial } \\
\text { number }\end{array}$ & $\begin{array}{c}\text { Resolution } \\
\text { at } 1.33 \mathrm{MeV}, \\
{ }^{60} \mathrm{Co},(\mathrm{keV})\end{array}$ & $\begin{array}{c}\text { Relative Efficiency } \\
\text { at } 1.33 \mathrm{MeV}, \\
60 \mathrm{Co},(\%)\end{array}$ \\
\hline $27-\mathrm{P} 1874$ & 2.35 & 66.4 \\
$28-\mathrm{P} 20090$ & 2.08 & 69.6 \\
$28-\mathrm{P} 20091$ & 1.97 & 65.7 \\
$28-\mathrm{P} 20174$ & 1.88 & 75.3 \\
$31-\mathrm{P} 20662 \mathrm{~A}$ & not available & not available \\
$27-\mathrm{P} 30017$ & 2.24 & 78.3 \\
\hline
\end{tabular}

Table 2.2: Data sheet specifications of the HPGe detectors

The cosmic ray background was reduced by a factor of 10 by means of an active shielding consisting of eleven large area NE102A plastic scintillator paddles covering the upper hemisphere of the detection apparatus (see section 2.5 for details). The neutrons produced by the beam in the beam stop Faraday cup and on the apertures of the gas target were, especially at higher beam energy, an intense source of background. In order to reduce it, a $0.5 \mathrm{~mm}$ thick Cadmium foil was inserted between the lead and the plastic scintillators in order to reduce the beam induced background. Cadmium has a very high capture cross section for thermal neutrons: the $\gamma$-rays produced by the neutron capture reactions could be efficiently suppressed by the lead wall. A ${ }^{3} \mathrm{He}$ detector monitored the neutron flux close to the detectors: this information was very useful at the higher beam energies, where the ion-beam focussing through the gas target was performed by minimizing the neutron flux. 


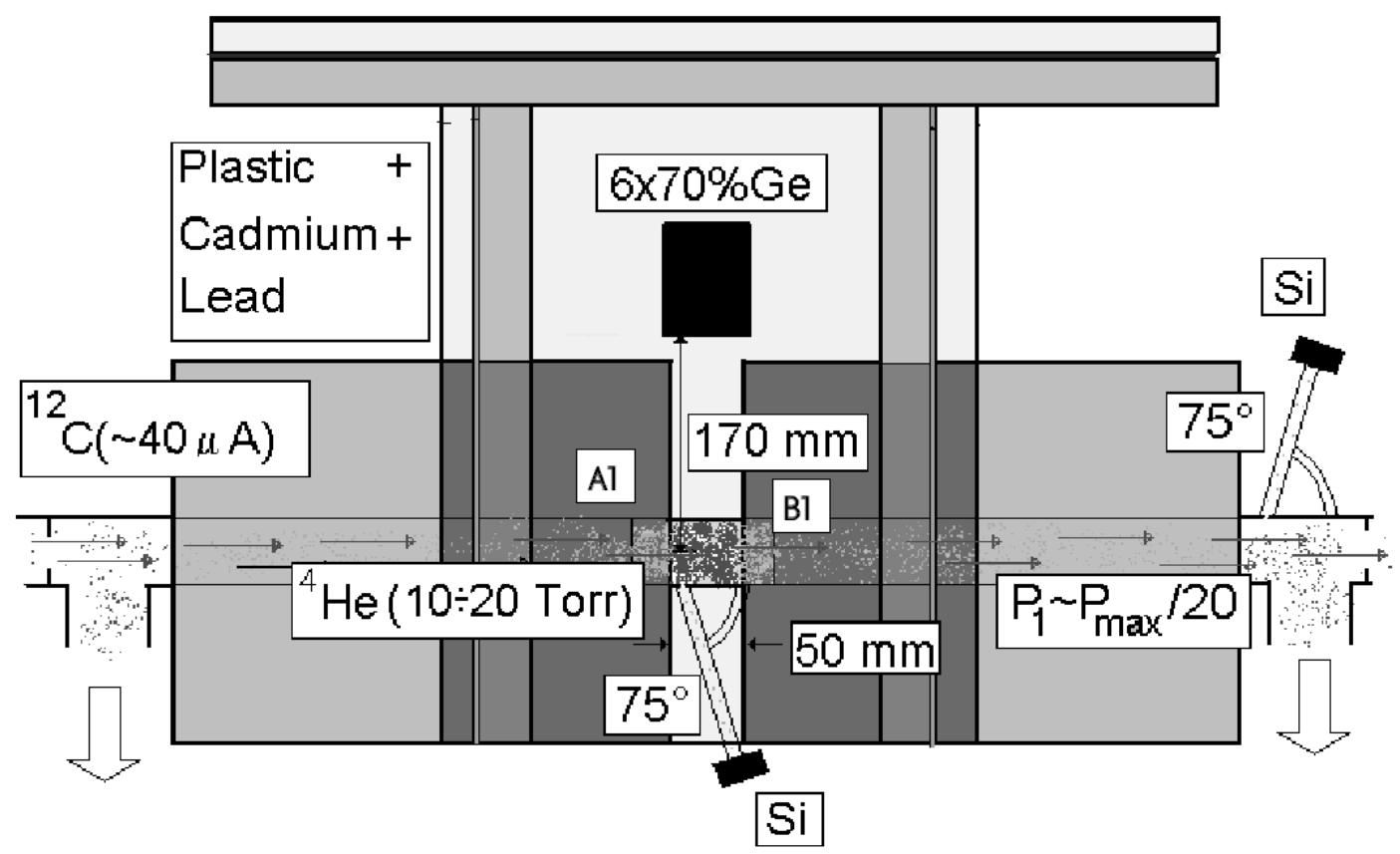

Figure 2.3: The $\gamma$ detection setup. Only one of the 6 Ge detectors in the ring-shaped geometry around the beam axis is shown here. Refer to the text for details

\section{$2.4 \quad$ Particle detectors}

In order to monitor the product of the number of projectiles impinging on the target times the density of target atoms, a $100 \mu \mathrm{m}$ thick Si surface barrier detector was installed in the target chamber at $\theta_{e l}=75^{\circ}$. The detector was collimated with an aperture (facing the detector) of radius $r=0.2 \mathrm{~mm}$ at a distance $d=164 \mathrm{~mm}$ from the beam axis and with a slit of width $s=0.4 \mathrm{~mm}$ placed at a distance $f=136$ $\mathrm{mm}$ from the aperture. The geometry defined the effective target length seen by the detector and its solid angle as [1]:

$$
l_{e f f S i 1} \Omega_{l a b}=\pi r^{2} s\left(f d \sin \theta_{l a b}\right)^{-1}=2.3 \cdot 10^{-6} \mathrm{~mm} \cdot \mathrm{sr}
$$

The geometry defined the detection angle to a precision $\Delta \theta_{l a b}=\arctan ((r+s / 2) / f)=$ $0.3^{\circ}$. In order to lower the detection energy threshold and improve the energy resolution of the detector with gas in the target chamber, the volume of its installation pipe between the slit and the detector was pumped by the downstream pumping system. Due to the small slit width, this pumping had no significant effect on the pressure profile within the gas cell (see section 2.6.1). Nevertheless the detection threshold was too high in the case of the ${ }^{1} \mathrm{H}\left({ }^{19} \mathrm{~F}, \alpha \gamma\right){ }^{16} \mathrm{O}$ reaction, that was used 
for normalization purposes (see section 3.1.4). Therefore, a second particle detector was installed on the first downstream pumping stage, where the pressure, and consequently, the detection threshold was lower. The geometry defining the effective target length was the same as for the first detector, with the only difference of the aperture facing the detector, whose radius was increased to $r=1.0 \mathrm{~mm}$ in order to have a comparable counting rate in both detectors. The effective length and solid angle for the second detector was $l_{\text {effSi2 }} \Omega_{l a b}=5.8 \cdot 10^{-5} \mathrm{~mm} \cdot \mathrm{sr}$.

\subsection{Electronics and acquisition system}

The general concept of the electronic system was to form all the signals of interest without imposing any conditions on them, leaving the necessary conditioning to an event-by-event analysis of the data, that had therefore to be collected in list-mode by the acquisition system. The trigger signal for the acquisition was generated when any of the HPGe or the Si detectors fired. Besides the signals produced by the detectors described in the previous sections, two additional signals were produced starting from them: a time signal giving the time relation between the signals from the HPGe detectors and the plastic scintillator and a time signal giving the time interval between two consecutive triggers for the acquisition. The first one was used to set the anti-coincidence condition necessary for the suppression of the cosmic background, the second one was used to suppress pile-up. Therefore, the total number of parameters to be acquired would have been 10 (6 HPGe detectors, $2 \mathrm{Si}$ detectors, 2 time signals). All these signals had to be put in suitable form for the following storage and analysis. The acquisition system (Nuclear Data 9900) was able to handle at most 8 parameters, whereas actually just six Analog-to-DigitalConverters (ADC Nuclear Data ND582 and Canberra 8701), needed to put the collected signals in digital form, were available. A closer analysis of the problem showed that actually there was no reason to store those events in which two HPGe delivered a signal in coincidence. As a matter of fact, this can happen in the following five circumstances:

1. a random coincidence between a signal coming from a nuclear reaction and a background signal

2. a random coincidence between two background signals

3. a true coincidence between two signals coming from a nuclear reaction (cascade transition)

4. a true coincidence between two $\gamma$-rays, where the second signal is the product of Compton scattering of the first one in another detector 
5. random coincidence between two signals coming from nuclear reactions.

Actually only the cases 4 and 5 produce a decrease of the full energy peak detection efficiency for the ground state transition (case 1 would do that in any case): a Monte Carlo simulation of the experiment (see section 3.1.2) shows that the probabilities that they happen are, relatively to the case of detection of a single photon, negligible $(<10 \%)$. In the other cases we reject events in which we are not interested in. Therefore it was not necessary to have one ADC for every HPGe, but it was enough to sum them up and have a parameter identifying the crystal(s) that produced the observed signal. This was done using an electronic unit designed and realized at the electronic workshop of INFN-Naples, that will be called in the following pattern unit (shortly PAT). This unit has an ECL 8 way input and an analog output: to every input $\mathrm{i}(\mathrm{i}=0, \ldots, 7)$ is associated a signal $\mathrm{V}=\mathrm{V}_{0} \cdot 2^{i}$. For example if one amplifies the signal to have $8 \mathrm{~V}$ when the 8 th input alone is present, to the 7th input will correspond an output of $4 \mathrm{~V}$, to the 6 th one of $2 \mathrm{~V}$ and so on down to the first input, that will have $0.06025 \mathrm{~V}$. If two or more inputs are simultaneously present, the output is the analog sum of them, whereas it is obviously not possible to obtain the output corresponding to a single input as sum of many. This fundamental characteristic held, although the pattern unit used during the experiment actually showed a slightly nonlinear behaviour. So it was possible to implement the single spectrum for each crystal putting the appropriate conditions on the pattern signal, as shown in figure 2.4. A block diagram of the electronic system is illustrated in figure 2.5. The signals produced by each HPGe detector and the second $\mathrm{Si}$ detector (first downstream pumping stage) were splitted: one part was formed through spectroscopy amplifiers (ORTEC 471) and sent to the acquisition system after passing a spectroscopy delay line (ORTEC 427A, delay time $\Delta t_{d e l}=1$ to $5 \mu \mathrm{s}$ depending on the detector) in order to wait for the gate signal for the ADC's being produced by the acquisition. The other part was sent to fast amplifiers, Timing Filter Amplifiers (TFA) for the HPGe (ORTEC mod. 454 and 474 , integration time $\Delta t_{i n t}=100 \mathrm{~ns}$, differentiation time $\left.\Delta t_{\text {diff }}=20 \mathrm{~ns}\right)$ and Fast Timing Amplifier (ORTEC 533, GSI DET LAB 810L) for the Si detectors, to obtain a good timing signal. As regard the first Si detector (target chamber), a similar procedure was followed, with the only difference that its signal was splitted after the spectroscopic amplifier. This was due to the fact that an integration time of $500 \mathrm{~ns}$, longer than the highest integration time provided by the fast amplifiers used, was required in order to filter out the electronic noise that was observed in the signal from the first detector. The timing signals of all detectors were sent to Constant Fraction Discriminators (LeCroy CF8000 and ORTEC 934) and their output to a Linear Fan-in-fan-out (LeCroy LF4), i.e. an OR module, whose output produced the general trigger for the acquisition system through a gate and delay generator (ORTEC GG8000). The signals from the plastic NE102A scintillators 


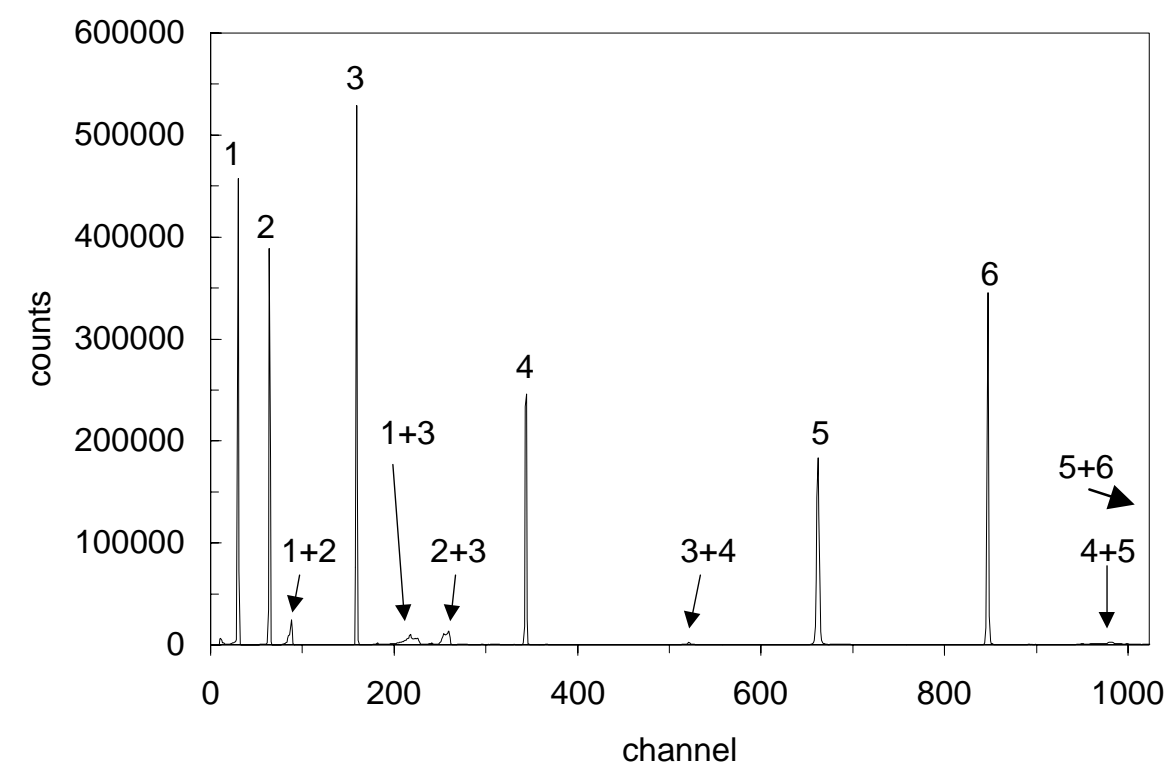

Figure 2.4: The pattern unit spectrum: each peak corresponds to events seen in only one HPGe detector, labelled from 1 to 6 . Events where two detectors fired are also visible, although the probability of higher multiplicity turns out to be negligible.

passed through a fast electronic processing to produce a timing signal. The time relation between the signals from the HPGe detectors and the NE102A paddles was determined by means of a Time-to-Analog converter (ORTEC, range $\Delta t_{d i f f}=2$ $\mu \mathrm{s})$, that was started by the signal from the HPGe and eventually stopped by the signal from the paddles. The time spectrum is shown in figure 2.6. A simple system provided pile-up rejection: a TAC (range $5 \mu \mathrm{s}$ ) was started by the trigger delayed by about $20 \mathrm{~ns}$ and stopped by the trigger itself. Therefore an isolated trigger could not generate any signal, while two triggers spaced by less than $5 \mu$ s produced one. The choice of the TAC range was done according to the shaping time of the spectroscopy amplifiers $(0.5 \mu$ s for the Si detectors, $6 \mu$ s for the HPGe detectors). Actually, the counting rate was normally low enough to leave the pile-up spectrum empty, but it turned out to be very useful during the analysis of the data as an indicator of the correct working of the setup: for example, in some cases an anomalously high rate of events with a pile-up parameter different from zero indicated that some HPGe had a shut down and, consequently, the corresponding measurements were disregarded. The six signals obtained through the described electronic processing were fed into six ADC's controlled by the Canberra multiparameter data acquisition system (DAQ in the following). Every time a trigger came, all ADC's were read and a veto signal delivered and kept on until all of them had finished their conversion. This feature guarantees an equal dead time for all detectors independently from their respective 


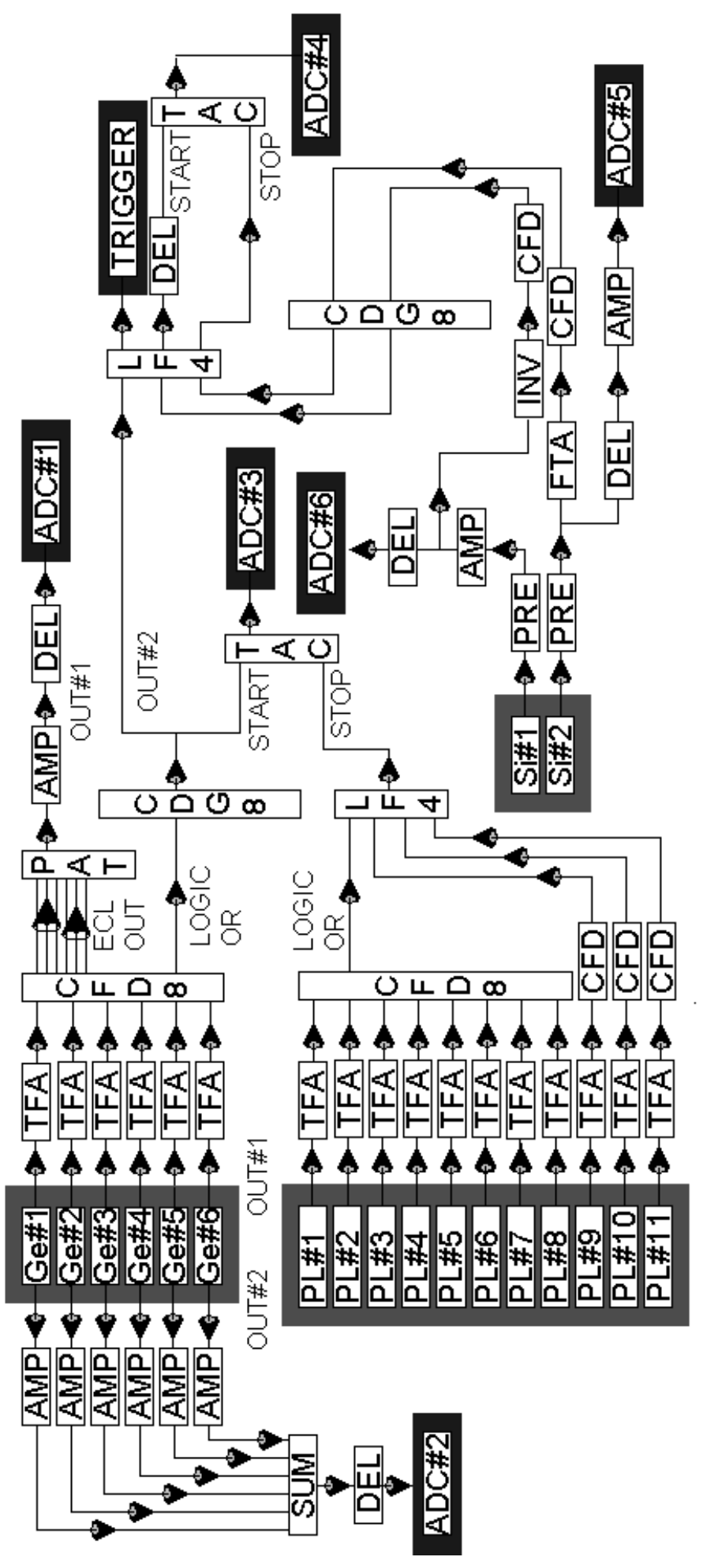

Figure 2.5: Block diagram of the electronic setup for signal processing. Refer to the text for details 


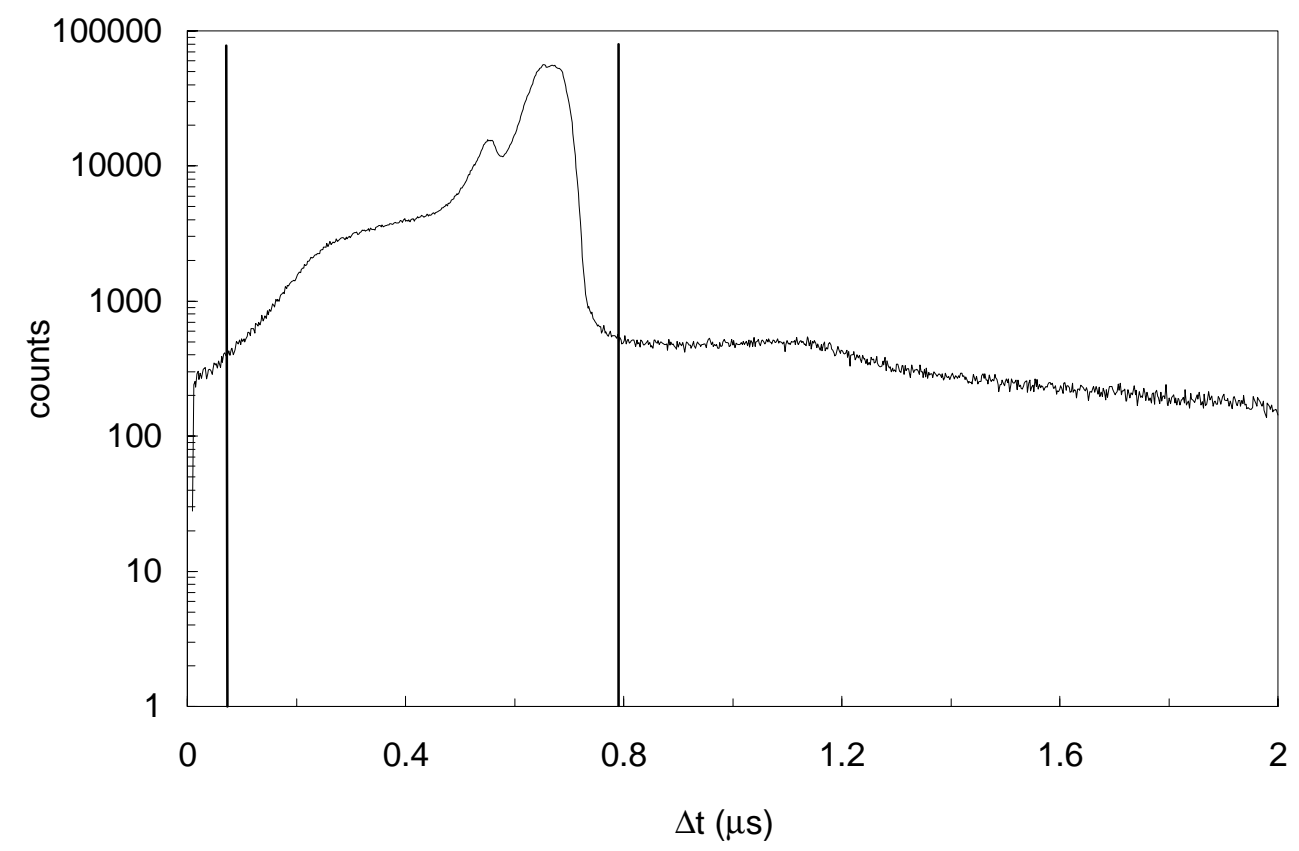

Figure 2.6: Time spectrum between HPGe and the active shield paddles: the peak structure contains coincident events originated by cosmic rays

counting rates, that is absolutely needed if one wants to normalize the yield of one detector to the yield of another, in our case the $\gamma$ yield to the yield of elastically scattered particles.

The conversion of a signal took place if a gate signal (10 $\mu$ s width) from the DAQ arrived $360 \mathrm{~ns}$ before the signal passed a preset threshold and if no veto signal was present. The output of the six ADC's was packed in an event, i.e. a vector with six components $\left(E_{H P G e}\right.$, pattern, $\left.\mathrm{TAC}_{\text {cosmic }}, \mathrm{Si1}, \mathrm{Si} 2, \mathrm{TAC}_{\text {pileup }}\right)$, and stacked in a 4 kByte buffer. When the buffer was full, it was sent to a VMS DEC Vax workstation and stored on tape: during this operation a second buffer was used. If the second buffer was full before the first one was empty, a veto signal to the ADC's temporary blocked the acquisition of further data accumulation.

The data collected had then to be analyzed event by event imposing some suitable conditions in order to increment the spectra. Firstly, all events were rejected in which the $\mathrm{TAC}_{\text {cosmic }}$ parameter fell in the coincidence peak (see figure 2.6) or the $\mathrm{TAC}_{p i l e-u p}$ was different from zero. Then the pattern parameter was conditioned with the gates determined analyzing its spectrum (see figure 2.4), in order to select those events in which only one Ge fired and to identify it: correspondingly the energy parameter $\mathrm{E}_{H P G e}$ was calibrated and the sum spectrum of all 6 HPGe was incremented with a calibration of $30 \mathrm{keV} /$ channel with no offset. A spectrum for each Si detector was built without any condition. 


\subsection{Auxiliary measurements}

\subsubsection{Gas target pressure profile}

In the extended gas cell (see figure 2.1), the gas pressure between the apertures A1 and B1 is expected to be nearly constant and unaffected by the gas flow through these apertures. The major pressure drop should occur across these apertures, followed by a further pressure drop along the tubes connecting the chamber to the first pumping stages, where a pressure reduction of 25 was observed. To measure the pressure profile the $\gamma$-flux from the ground state transition in the resonant capture reaction ${ }^{4} \mathrm{He}\left({ }^{16} \mathrm{O}, \gamma\right){ }^{20} \mathrm{Ne}$ to the $E_{x}=5.788 \mathrm{MeV}\left(J^{\pi}=1^{-}, \Gamma=0.028 \mathrm{keV}\right)$ excited state of ${ }^{20} \mathrm{Ne}$ was used as a probe. Therefore a ${ }^{16} \mathrm{O}$ ion beam at $E_{l a b}=5.29 \mathrm{MeV}$ was used. As shown in Figure 2.7, a 70\% HPGe detector was collimated, on the beam facing side, by a $10 \mathrm{~cm}$ thick lead shield with a vertical slit of $20 \mathrm{~mm}$ width and positioned at a distance of $15 \mathrm{~cm}$ to the beam axis ( $z$-axis) on a trolley that could be moved parallel to the beam pipe. This geometry defined an effective target length of $40 \mathrm{~mm}$ corresponding to a target thickness of $\Delta_{l a b}=212 \mathrm{keV}$ at 20 Torr and at the necessary ${ }^{16} \mathrm{O}$ beam energy of $5.29 \mathrm{MeV}$, that is much larger than the width of the resonance $\left(\Gamma_{l a b}=0.140 \mathrm{keV}\right)$. As a consequence, the thick target $\gamma$ yield of the resonance represented nearly a point-like source.

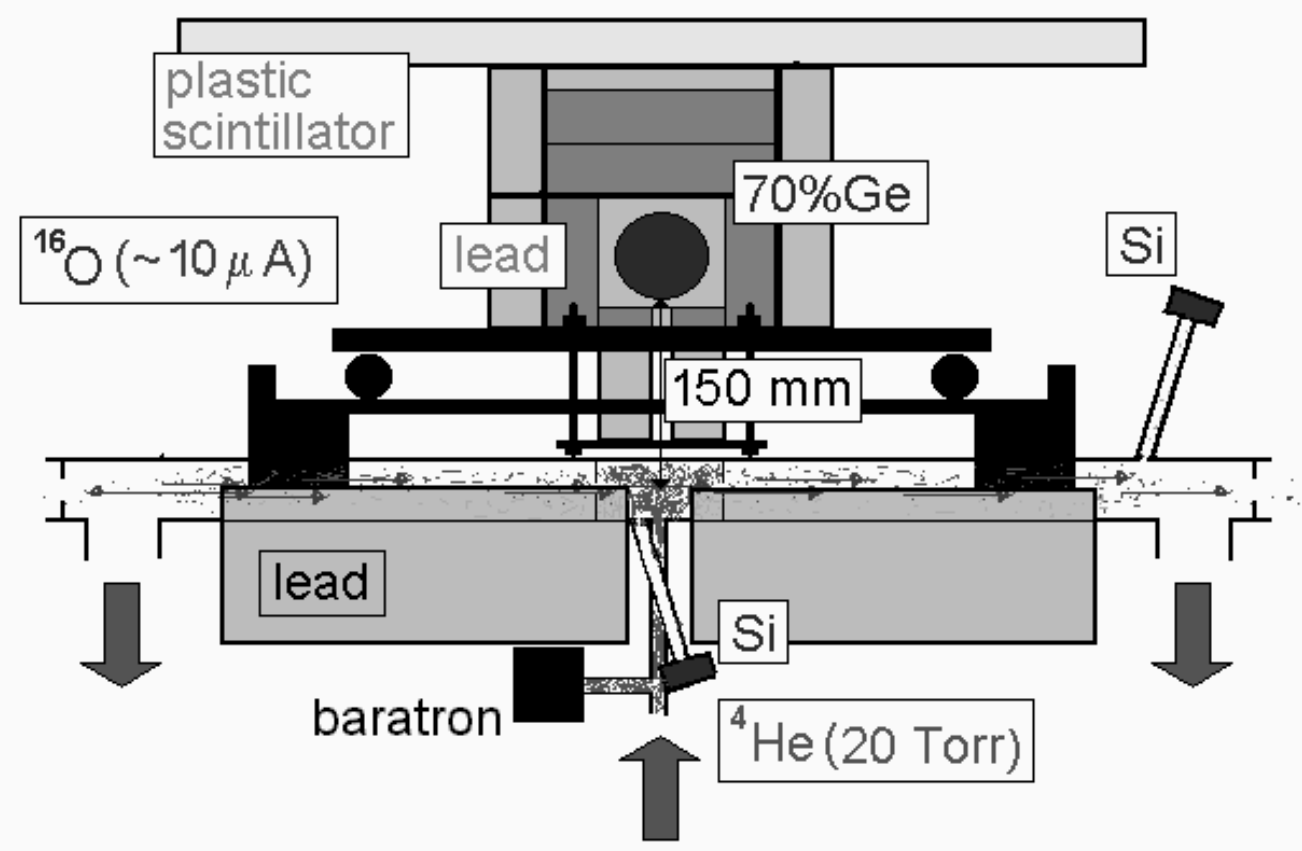

Figure 2.7: Setup for the measurement of the ${ }^{4}$ He pressure profile. See text for details 


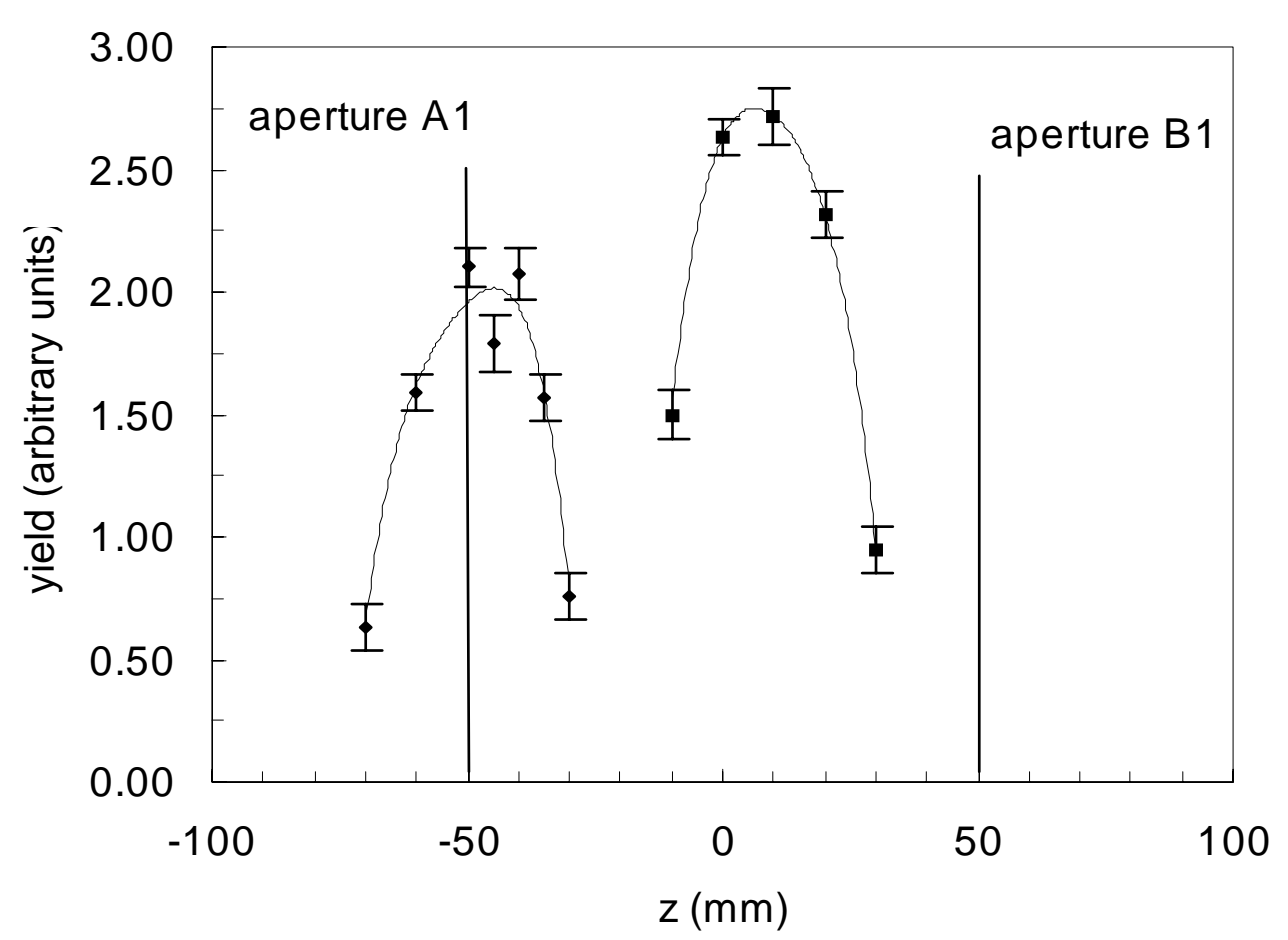

Figure 2.8: Yield curves of ${ }^{4} \mathrm{He}\left({ }^{16} \mathrm{O}, \gamma\right){ }^{20} \mathrm{Ne}$ for a given detector position at $E_{16} \mathrm{O}=$ 5.8 and $6.1 \mathrm{MeV}$. The positions of the apertures A1 and B1 are also indicated.

A collimated silicon detector (see section 2.4) viewing the central part of the gas target under $\theta_{e l}=75^{\circ}$ was used to normalize the observed $\gamma$-flux to the elastic scattering yield and, by means of that, to the incident current and target density at the center of the gas cell. At each $z$-position of the HPGe detector, a $\gamma$ yield curve of the resonance was obtained, as shown in figure 2.8. Since the maximum of the yield curve corresponds to the resonance position at the center of the slit and since the yield is proportional to the gas density (pressure) at this $z$-position, the maximum yield values as a function of the $z$-position correspond to the pressure profile. The observed yields, normalized to the pressure $P_{0}=20$ Torr at the center of the gas cell, were fitted with the following function:

$$
Y(z)=\frac{h}{1+\exp \left(\left|z-z_{0}\right|-l_{\text {eff }} / 2\right) / s}+k
$$

Table 2.6.1 reports the result of the fit. 


$$
\begin{array}{|ll|}
\hline h=\left(2.45 \cdot 10^{-5}\right) \text { arb. un. } & z_{0}=(-9.67 \pm 0.10) \cdot 10^{-2} \mathrm{~mm} \\
l_{\text {eff }}=101 \pm 2 \mathrm{~mm} & s=1.07 \pm 0.25 \mathrm{~mm} \\
k=4.1 \cdot 10^{-6} \text { arb. un. } & \nu=6 \\
\chi^{2}=7.03 & \chi_{\text {red }}^{2}=1.17 \\
\hline
\end{array}
$$

Table 2.3: Fitted parameters (see equation 2.2) for the gas target pressure profile

The resulting He pressure profile (Figure 2.9) shows a constant pressure plateau at the central region of the target chamber and a sharp pressure drop near the collimators A1 and B1, with an effective length of the central part of the target $l_{\text {eff }}=101 \pm 2 \mathrm{~mm}$, that is nearly identical with the length of the gas cell $(100 \mathrm{~mm})$. One should note, however, that, due to the relatively large lead slits used it was not possible to investigate finely with this method the wings of the pressure distribution. Consequently, the behaviour of the fit function in the regions close to the apertures could be sensitively different from the actual one and therefore the quoted errors must be taken with caution. On the other hand, the final detection setup is quite insensitive to the wings of the pressure profile, because they are well shielded by the target defining lead cylinders. Normalizing the yield curve to the pressure measured in the central part of the target and integrate it, one obtains a target thickness of $\Delta=(6.62 \pm 0.05) \cdot 10^{18} \frac{\mathrm{at}}{\mathrm{cm}^{2}}$, assuming a temperature of $293 \mathrm{~K}$.

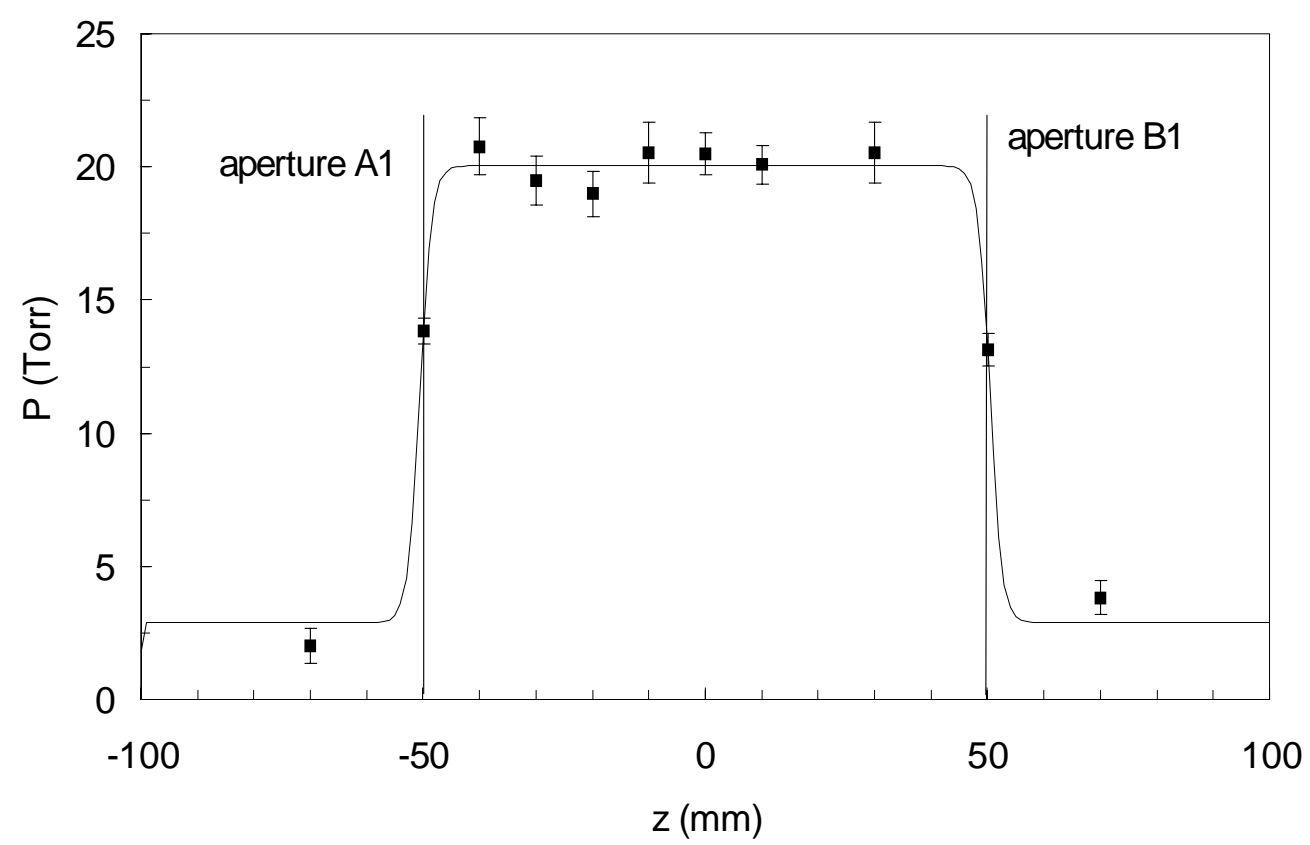

Figure 2.9: Pressure profile in the gas cell for ${ }^{4} \mathrm{He}$ gas $\left(P_{0}=20\right.$ Torr $)$ 
The corresponding energy loss turned out to be $\Delta E_{\text {exp }}=670 \mathrm{keV}$, that is in excellent agreement with the value $\Delta E_{\text {cal }}=649 \mathrm{keV}$ calculated using the code SRIM2000 [27]. A not negligible energy loss was observed in the region before the target chamber: indeed the necessary ${ }^{16} \mathrm{O}$ energy is $5290 \mathrm{keV}$, while the necessary energy to observe the resonance at the beginning of the central area of the target turned out to be 5530 $\mathrm{keV}$. The energy difference corresponds to a thickness of $2.46 \cdot 10^{18} \frac{\mathrm{at}}{\mathrm{cm}^{2}}$ : assuming a linear drop of the pressure along the pipe connecting the aperture A1 to the first pumping stage, where a pressure of 0.8 Torr was measured, this thickness corresponds to $420 \mathrm{~mm}$, that has to be compared with the geometrical length of the pipe $\mathrm{L}=465 \mathrm{~mm}$.

\subsubsection{Energy calibration of the HPGe}

The energy calibration of the HPGe detectors was performed using the ${ }^{1} \mathrm{H}\left({ }^{11} \mathrm{~B}, \gamma\right){ }^{12} \mathrm{C}$ resonance at $E_{r, c m}=148 \mathrm{keV}$ (for $P_{0}=1.0$ Torr) decaying mainly through a $\gamma$-ray cascade with $E_{\gamma}=4.44$ and $11.67 \mathrm{MeV}$. Figure 2.6.2 shows a typical calibration spectrum.

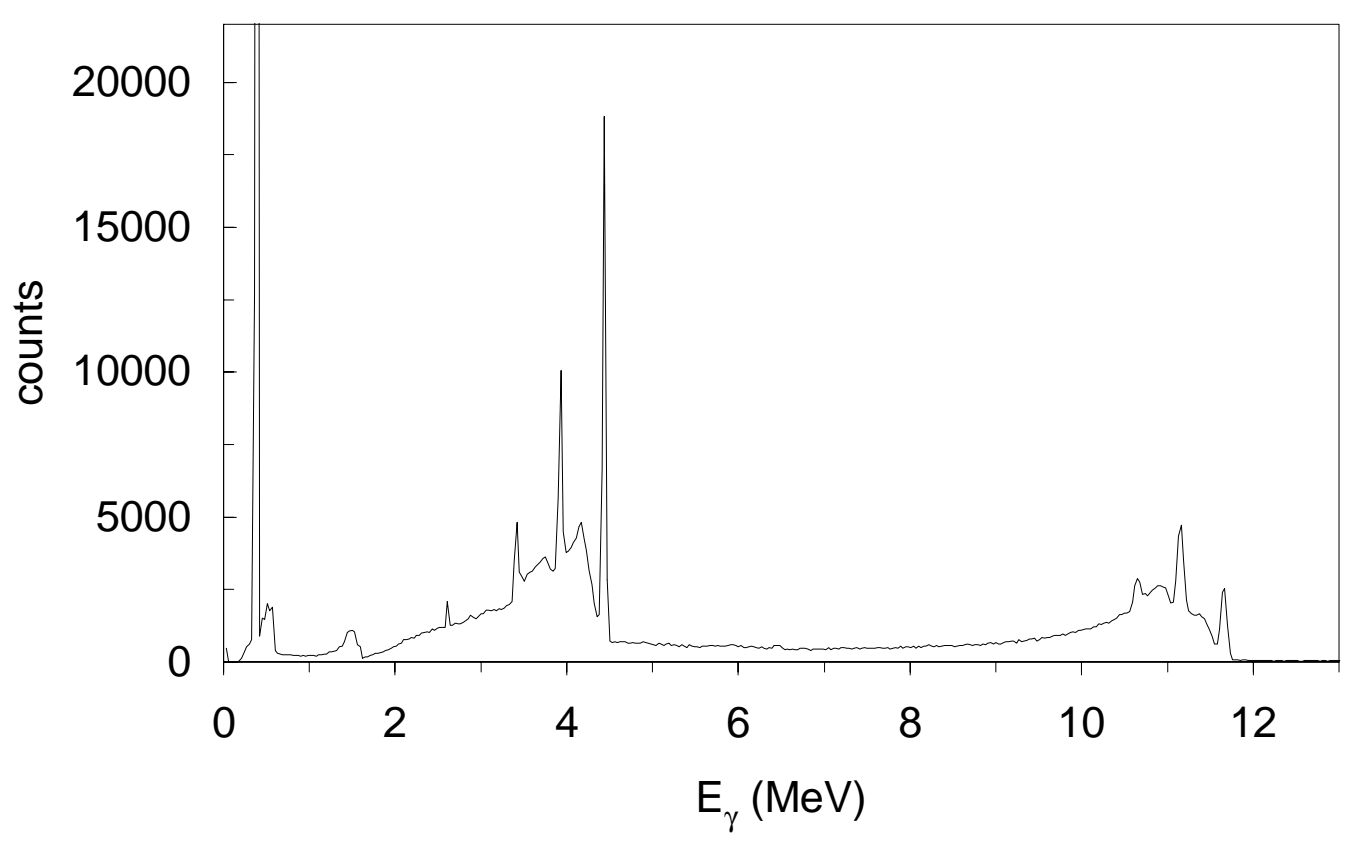

Figure 2.10: Energy calibration spectrum for the HPGe detectors

The full-energy, the single escape, and the double escape peaks were used for the calibration together with the $E_{\gamma}=2.614 \mathrm{MeV}$ background line from ${ }^{208} \mathrm{Bi}$. The calibration coefficients were measured for each detector at the beginning of every 
beam time period, for a total number of eight calibrations over four months. The whole system turned out to be exceptionally stable: indeed over this time period a significant change in the calibration coefficients was never observed.

\subsubsection{Effective $\gamma$ target length}

Again, the ${ }^{4} \mathrm{He}\left({ }^{16} \mathrm{O}, \gamma\right){ }^{20} \mathrm{Ne}$ reaction was used to determine the effective target profile for $\gamma$-detection $l_{\gamma, e f f}$, following a similar procedure to the one outlined in the previous section: in this case the full detection setup was used, i.e. all six HPGe detectors on the ring-mounting around the target. Of course, the detectors were not moved and the effective target length was determined varying the beam energy. The resonance position in the target as a function of the incident beam energy was deduced from the measurements described in the previous section. The measured yields were again normalized to the pressure $P_{0}=20$ Torr at the center of the gas cell. Table 2.4 reports the results of the fit, where the fit function and the relative parameters are the same as given in equation 2.2 .

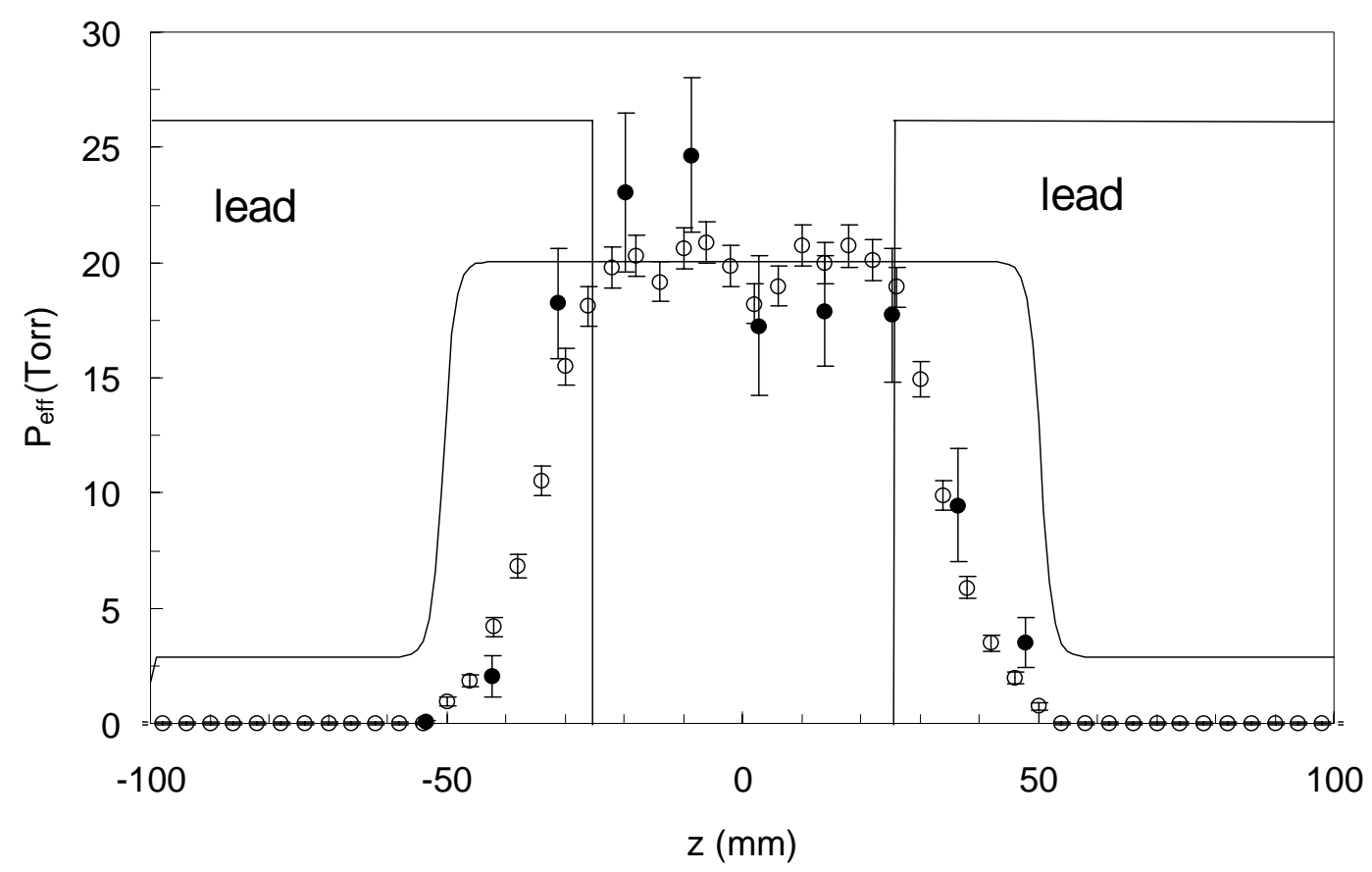

Figure 2.11: Effective target profile for $\gamma$ ray detection. The full circles are the experimental data, while the open circles are the result of a Geant simulation that used the gas pressure profile, that is drawn with a solid line. The position of the target defining lead shields is also indicated. 
The result of this measurement is shown in Figure 2.11. The observed effective target profile is compared with the result of a Monte Carlo simulation of the experiment (see section 3.1.2) and with the target pressure profile.

\begin{tabular}{|ll|}
\hline$h=(1.21 \pm 0.11) \cdot 10^{-4}$ arb. un. & $z_{0}=(0.0 \pm 1.4) \mathrm{mm}$ \\
$l_{\text {eff }}=66 \pm 4 \mathrm{~mm}$ & $s=2.9 \pm 1.4 \mathrm{~mm}$ \\
$k=(2.1 \pm 0.06) \cdot 10^{-6}$ arb. un. & $\nu=6$ \\
$\chi^{2}=6.06$ & $\chi_{\text {red }}^{2}=1.21$ \\
\hline
\end{tabular}

Table 2.4: Fitted parameters for the effective target length $l_{\gamma, e f f}$

The overall agreement between experiment and simulation is quite good and the effective target length well reproduced. It is interesting to note that also the shape of the curve, including the minimum at the middle of the target, due to the cold finger in the detectors (see figure 2.2), seems to be reproduced. For the case of ${ }^{4} \mathrm{He}\left({ }^{12} \mathrm{C}, \gamma\right){ }^{16} \mathrm{O}$, the measured effective target length corresponds to a thickness in the center-of-mass system varying from $\Delta t=60 \mathrm{keV}$ at $E_{l a b}=9.9 \mathrm{MeV}$ to $\Delta t=65$ $\mathrm{keV}$ at $E_{l a b}=5.8 \mathrm{MeV}$, with $P_{0}=20$ Torr. At higher beam energy the pressure in the gas cell was reduced to 10 Torr and correspondingly the thickness decreased to $\Delta t=30 \mathrm{keV}$ at $E_{l a b}=11.4 \mathrm{MeV}$.

\subsubsection{E2 suppression}

For the purpose of the experiment, the suppression of the $E 2$ component in the groundstate-capture is a parameter of crucial importance. The E2 contamination to the measured $\gamma_{0}$ spectra was estimated experimentally exploiting the fact that the $J^{\pi}=2^{+}$resonance at $E_{x}=9.847 \mathrm{MeV}$ has a branching to the ground state of $(61 \pm 4) \%$ [28] with an angular distribution $W_{E 2} \propto \sin ^{2} \theta_{\gamma} \cos ^{2} \theta_{\gamma}$, and branching of $(21 \pm 4) \%$ [28] to the $J^{\pi}=2^{+}$level at $E_{x}=6.917 \mathrm{MeV}$, that decays to the ground state with a nearly isotropic angular distribution. Therefore the ratio of the yields of these two transitions, taking into account the respective branching ratios, allowed to estimate an $E 2$ contribution of about $9 \%$ for the case of a source with equal intensity. Figure 2.6.4 shows the results of this measurement. Both data sets displayed in the graphic are already corrected for the respective branching ratio. 


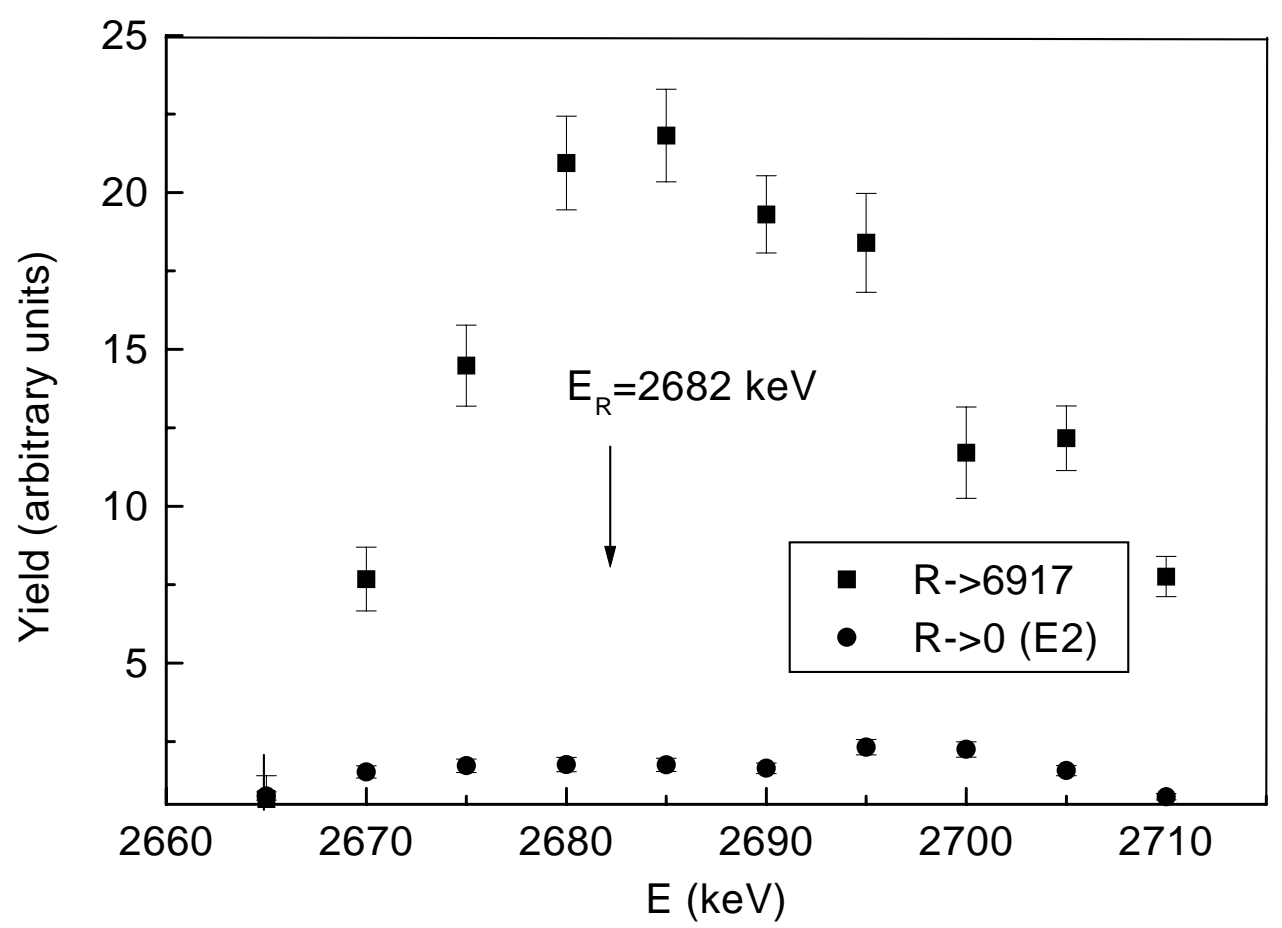

Figure 2.12: Result of the measurement of the $E 2$ suppression factor. Read the text for explanation

The result is in good agreement with the Monte Carlo simulation, that gives for this case $11 \%$ for the $E 2$ contribution. If one considers the actual case of ground state transitions, i.e. two extended sources with the same energy $E_{\gamma}$ of about 9 to $10 \mathrm{MeV}$ and angular distribution $W_{E 1}$ and $W_{E 2}$, respectively, the Monte Carlo simulation calculates an $E 2$ contamination of about $6 \%$, again in case of sources of equal intensity.

\subsubsection{Elastic scattering cross section}

Since $\gamma$-ray data are normalized to the incident beam current times the target density through the elastic scattering cross section, it was essential to determine experimentally the mean scattering angle and the deviation of the scattering cross section from the Rutherford law. If the intensity of elastically scattered projectiles $I_{s}$ and that of recoil target nuclides $\left(I_{r}\right)$ can be measured in the same detector, the intensity ratio depends sensitively on the detection angle $\theta_{l a b}$. If the scattering follows the Rutherford law, then [1]:

$$
\frac{I_{s}}{I_{r}}=\frac{\sin ^{2} \theta_{c m} \cos ^{4} \theta_{l a b}}{4 \sin _{l a b}^{2} \sin ^{4}\left(\theta_{c m} / 2\right) \cos \theta_{l a b} \cos \left(\theta_{c m}-\theta_{l a b}\right)},
$$




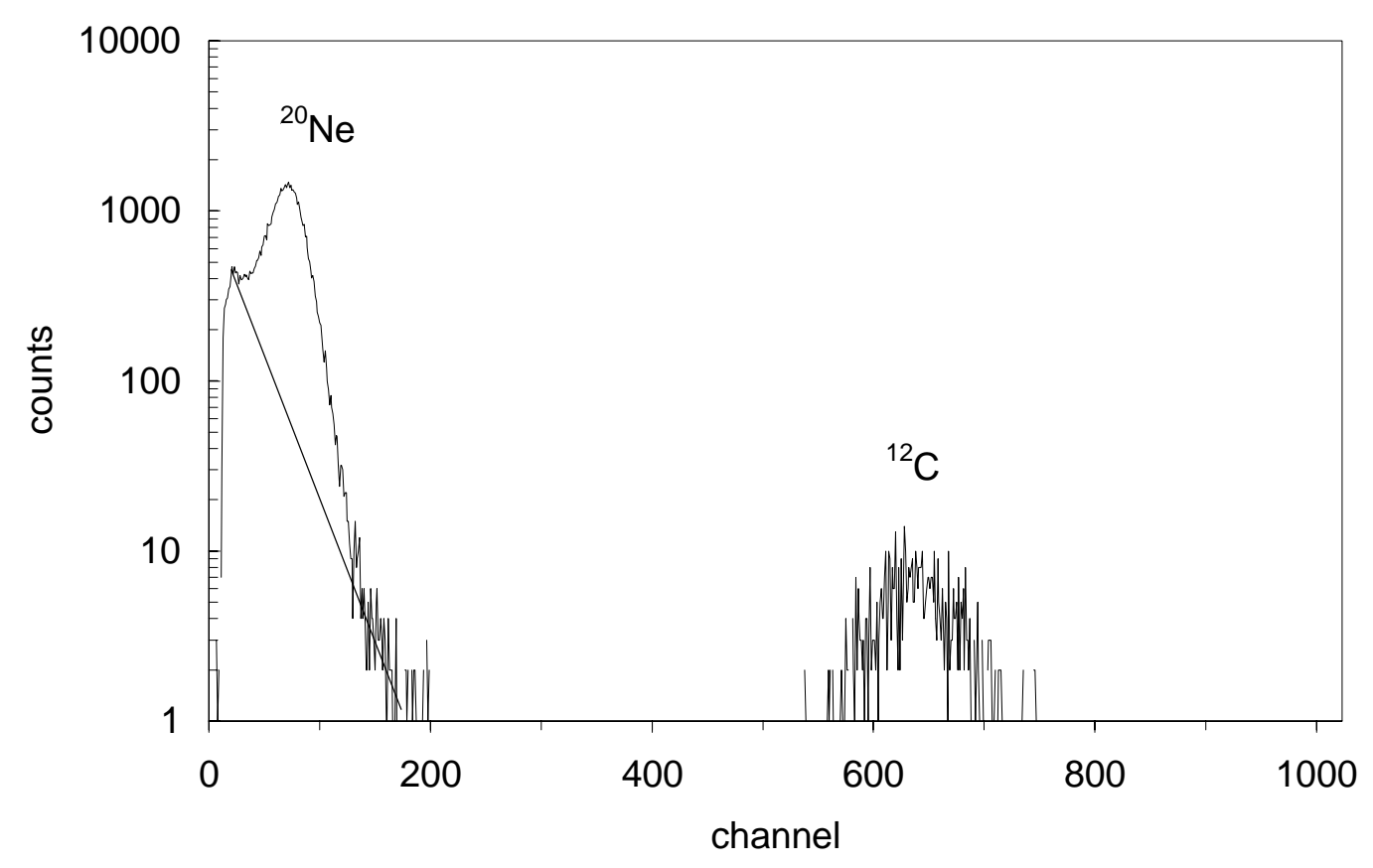

Figure 2.13: Spectrum of the elastically scattered particles for ${ }^{20} \mathrm{Ne}\left({ }^{12} \mathrm{C},{ }^{12} \mathrm{C}\right){ }^{20} \mathrm{Ne}$ at $E_{l a b}=9.0 \mathrm{MeV}$. The straight line represents the assumed background.

$\theta_{c m}$ being the center-of-mass scattering angle of the projectile.

\begin{tabular}{|c|c|c|c|}
\hline $\begin{array}{c}E_{l a b} \\
(\mathrm{MeV})\end{array}$ & $\begin{array}{c}P_{0} \\
\text { (Torr) }\end{array}$ & $\begin{array}{c}\text { Si1 } \\
Y_{{ }^{20} \mathrm{Ne}} / Y_{{ }^{12} \mathrm{C}}\end{array}$ & $\begin{array}{c}\mathrm{Si} 2 \\
Y_{{ }^{20}{ }_{\mathrm{Ne}}} / Y_{{ }^{2} \mathrm{C}}\end{array}$ \\
\hline 11.00 & 1.0 & $102.9 \pm 4.8$ & $88.4 \pm 5.6$ \\
\hline 11.00 & 1.0 & $97.5 \pm 3.9$ & $91.7 \pm 5.1$ \\
\hline 9.00 & 0.65 & $89.7 \pm 3.5$ & $93.7 \pm 6.4$ \\
\hline 7.00 & 1.0 & not analyzed $\left({ }^{*}\right)$ & $93.3 \pm 4.3$ \\
\hline 7.00 & 0.40 & $92.2 \pm 4.6$ & $91.1 \pm 7.7$ \\
\hline
\end{tabular}

Table 2.5: Results of the measurements of the elastic detection angles. The ratio of the observed elastic yields provides, through equation 2.3 , an estimate of $\theta_{e l} .\left(^{*}\right)$ Ne-peak too close to the detection threshold

In the case of ${ }^{12} \mathrm{C}$ projectiles at $E_{l a b}=9.0 \mathrm{MeV}$ incident on a ${ }^{20} \mathrm{Ne}$ gas $\left(P_{0}=\right.$ 0.65 Torr), the peaks of the projectiles and recoil nuclides were well resolved (see figure 2.13). Since the height of the Coulomb barrier for the ${ }^{12} \mathrm{C}+{ }^{20} \mathrm{Ne}$ system is about $10 \mathrm{MeV}$, equation 2.3 is valid, and this should be the case up to $E_{l a b}\left({ }^{12} \mathrm{C}\right)=11.0$ 
$\mathrm{MeV}$. The measurements were performed at different gas pressures and different energies. The results of the measurements are reported in table 2.5: their weighted average leads to $\theta_{l a b}=75^{\circ} \pm 0.3^{\circ}$ for both Si detectors.

In order to determine the deviations of the elastic scattering cross section from the Rutherford scattering law for the ${ }^{12} \mathrm{C}+{ }^{4} \mathrm{He}$ system, Ar gas (1 Torr) was admixed into He gas (2 Torr). The ${ }^{12} \mathrm{C}+{ }^{40} \mathrm{Ar}$ system should follow the Rutherford scattering law at $E_{l a b}\left({ }^{12} \mathrm{C}\right)$, using similar arguments as discussed above.

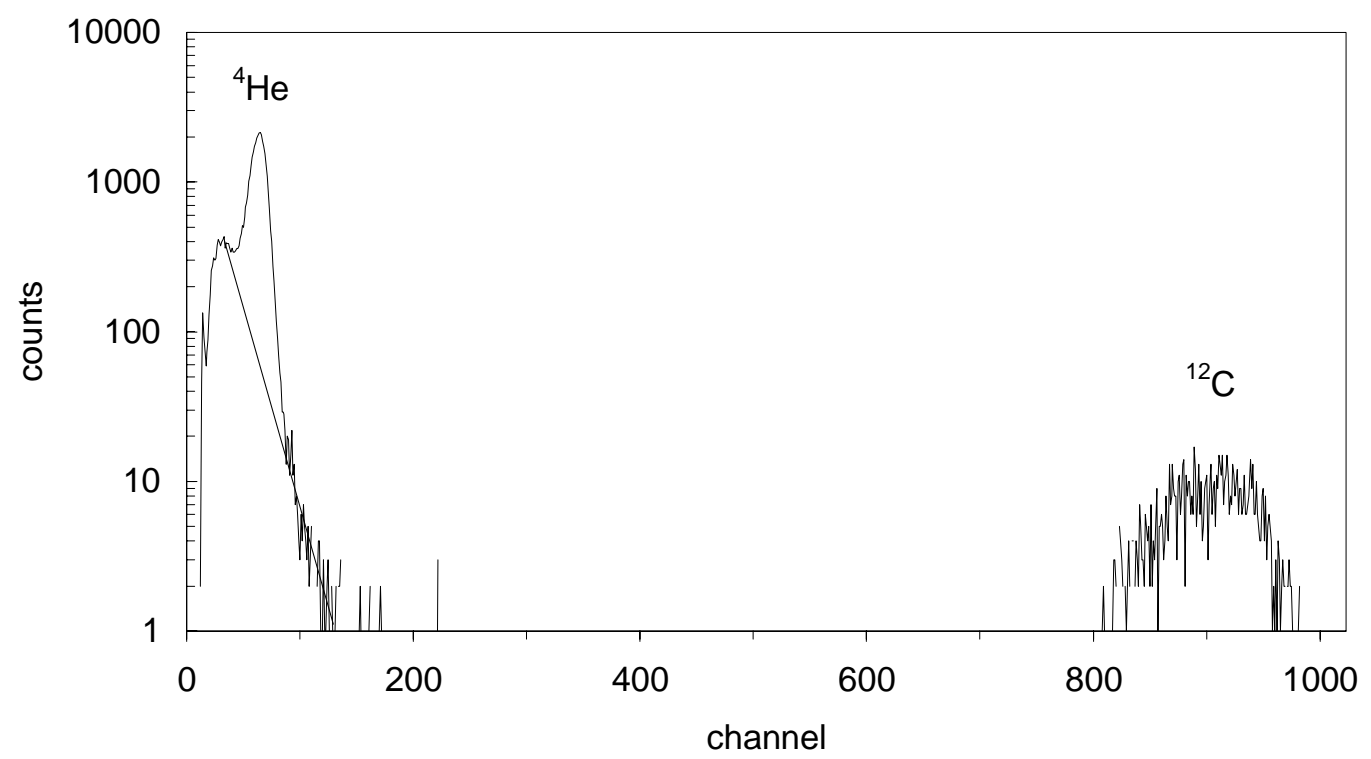

Figure 2.14: Spectrum of the elastically scattered particles for the ${ }^{12} \mathrm{C}+\left({ }^{40} \mathrm{Ar}-{ }^{4} \mathrm{He}\right)$ systems at $E_{l a b}=9.0 \mathrm{MeV}$. The straight line represents the assumed background.

The observed energy dependence of ${ }^{12} \mathrm{C}+{ }^{4} \mathrm{He}$ relative to ${ }^{12} \mathrm{C}+{ }^{40} \mathrm{Ar}$ as a funtion of the center-of-mass energy for ${ }^{12} \mathrm{C}+{ }^{4} \mathrm{He}$ at the center of the target has been normalized to one at low energy where the ${ }^{12} \mathrm{C}+{ }^{4} \mathrm{He}$ system is expected to follow the Rutherford law. Indeed, the results have been normalized to the Rutherford law at the lowest energies, where the intensity ratio approached a constant value. The data have been fitted with the following function:

$$
\frac{\sigma}{\sigma_{R}}=K_{e l}(E)=\frac{A}{1+\exp \frac{E-l}{s}}+a_{0}+\frac{A_{p} \cdot 2.354}{\sqrt{2 \pi} \cdot F W H M} \cdot \exp \left[-\frac{\left(E-E_{r}\right) \cdot 2.354}{2 \cdot F W H M}\right]^{2+a}
$$


where

$$
a= \begin{cases}a_{l e} & \text { for } E<E_{r} \\ a_{f e} & \text { for } E>E_{r} .\end{cases}
$$

Table 2.6 reports the values of the fitted parameters.

\begin{tabular}{|lll|}
\hline$a_{0}=0.731$ & $A=0.277$ & $l=2.512$ \\
$s=0.058$ & $E_{r}=2.352$ & $A_{p}=0.119$ \\
$F W H M=0.420$ & $a_{s e}=-0.082$ & $a_{l e}=-1.165$ \\
$\chi^{2}=21.3$ & $\chi_{r e d}^{2}=1.25$ & \\
\hline
\end{tabular}

Table 2.6: Fitted parameters for the deviation of the ${ }^{12} \mathrm{C}+{ }^{4} \mathrm{He}$ elastic scattering cross section from the Rutherford law (see equation 2.4 in text)

Figure 2.15 shows the results of this measurement and compares them with the results reported in [29].

The observed deviations from the Rutherford law are small and they were taken into account in the normalization of the $\gamma$-ray data.

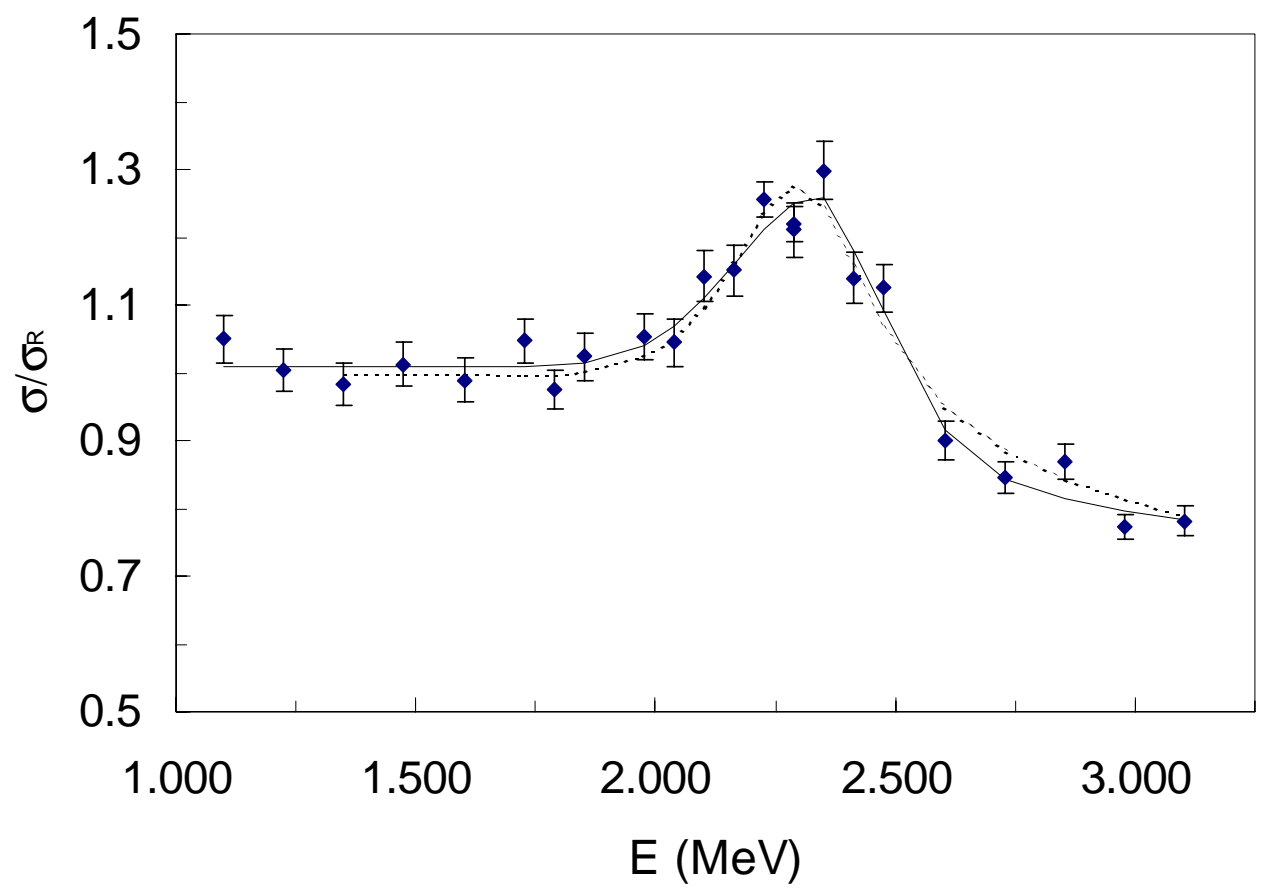

Figure 2.15: Deviation of the elastic scattering cross section from the Rutherford law for ${ }^{12} \mathrm{C}+{ }^{4} \mathrm{He}$ in the energy range relevant to this experiment. The solid line is a fit to the present data (see equation 2.4 and table 2.6). The dotted line shows the results of a previous measurement [29]. 


\section{Chapter 3}

\section{Data analysis}

This chapter is devoted to the analysis of the measured spectra. I will illustrate the procedure followed to analyze them and the extraction of the yield curve. This required the use of a Monte Carlo simulation of the experiment to determine the peak form and the efficiency curve of the $\gamma$-detection setup. The yield curve was then normalized to the $E_{x}=13.171 \mathrm{MeV}$ resonance in ${ }^{19} \mathrm{~F}(\mathrm{p}, \alpha \gamma){ }^{16} \mathrm{O}$. Then I present an extrapolation of the excitation function to the relevant astrophysical energy using the R-matrix formalism of nuclear reactions. Finally, the results of this experiment are discussed.

\subsection{Determination of the cross section}

The number of $\gamma$-rays observed during a measurement is given by the following equation:

$$
N_{\gamma}=\iint N_{p} N_{t}(z) \frac{d \sigma_{\gamma}\left(E, \theta_{\gamma}\right)}{d \Omega} \varepsilon_{\gamma}\left(E_{\gamma}, \theta_{\gamma}\right) d z d \Omega
$$

where:

- $\mathrm{z}$ is the reaction coordinate along the beam axis;

- $\theta_{\gamma}$ and $E_{\gamma}$ are, respectively, the $\gamma$ emission angle and energy;

- $\mathrm{N}_{\mathrm{p}}$ is the total number of projectiles that reached the target during the measurement;

- $\mathrm{N}_{\mathrm{t}}(\mathrm{z})$ is the target density along the target;

- $\frac{d \sigma_{\gamma}\left(E_{\gamma}, \theta_{\gamma}\right)}{d \Omega}$ is the differential cross section of the ${ }^{12} \mathrm{C}(\alpha, \gamma){ }^{16} \mathrm{O}$ reaction; 
- $\varepsilon_{\gamma}\left(E_{\gamma}, \theta_{\gamma}\right)$ is the $\gamma$ detection efficiency of the detectors;

The absence of any beam constraints between the two inner collimators of the target chamber (see figure 2.1) allows to consider the beam current as constant in the target region. $\mathrm{N}_{\mathrm{t}}(\mathrm{z})$ is proportional to the relative pressure profile $Y(z)$ (see equation 2.2) and can be written as:

$$
N_{t}(z)=N_{t 0} \frac{Y(z)}{Y(0)},
$$

where $N_{t 0}$ is the target density at the center of the target chamber. The dependence upon $z$ of the remaining terms is essentially based on the energy loss of the projectiles in the He gas:

$$
E_{l a b}(z)=E_{\text {beam }}-\int_{0}^{z} \frac{d E}{d z^{\prime}}\left(E_{l a b}\left(z^{\prime}\right)\right) d z^{\prime} .
$$

The center-of-mass energy $\mathrm{E}$ and $\mathrm{E}_{\gamma}$ change in a corresponding way. Equation 3.1 can be rewritten as follow:

$$
N_{\gamma}=N_{p} N_{t 0} \sigma_{\gamma}\left(E_{\gamma, e f f}\right) \varepsilon_{\gamma, e f f}\left(E_{\gamma, e f f}\right) l_{\gamma, e f f}
$$

where

$$
\varepsilon_{\gamma, e f f}\left(E_{\gamma, e f f}\right) l_{\gamma, e f f}=\frac{1}{\sigma\left(E_{\gamma, e f f}\right)} \iint \frac{Y(z)}{Y(0)} \varepsilon_{\gamma}\left(E_{\gamma}, \theta_{\gamma}\right) \frac{d \sigma_{\gamma}\left(E, \theta_{\gamma}\right)}{d \Omega} d z d \Omega
$$

This latter quantity is essentially the convolution along the beam (target) axis of the $\gamma$-ray angular distribution with the detection efficiency and it was determined by means of a Monte Carlo simulation of the experiment (see section 3.1.2) for different $\gamma$-ray angular distributions. In order to estimate the product $N_{p} N_{t 0}$, the elastically scattered ${ }^{4} \mathrm{He}$ ions were concurrently detected under $\theta_{\mathrm{el}}=75^{\circ}$. The number of particles detected is:

$$
N_{e l}=N_{p} N_{t 0} l_{e l, e f f} \Omega_{l a b} \sigma_{e l}\left(\theta_{e l, c m}, E_{e l, e f f}\right) \frac{\Omega_{c m}}{\Omega_{l a b}}
$$

where $\sigma_{e l}\left(\theta_{e l, c m}, E_{e l, e f f}\right)$ is the differential elastic scattering cross section at the detection angle $\theta_{e l, c m}$ and at the effective energy $E_{e l, e f f}, \frac{\Omega_{c m}}{\Omega_{l a b}}$ is the ratio of the centerof-mass solid angle to the laboratory solid angle, and $l_{e l, e f f}$ is the effective target length for the elastic scattering. $\sigma_{e l}\left(\theta_{e l, c m}, E_{e l}\right)$ can be related to the Rutherford elastic cross section $\sigma_{e l}^{R}\left(\theta_{e l, c m}, E_{e l}\right)$ :

$$
\sigma_{e l}\left(\theta_{e l, c m}, E_{e l}\right)=K_{e l}\left(E_{e l}\right) \sigma_{e l}^{R}\left(\theta_{e l}, E_{e l}\right)=1.296 K_{e l}\left(E_{e l}\right)\left(\frac{Z_{1} Z_{2}}{E_{e l}}\right)^{2} \frac{1}{\sin ^{4}\left(\theta_{e l, c m} / 2\right)^{4}}
$$


where $K_{e l}\left(E_{e l}\right)$ is given in equation 2.4. By means of all these equations, it is possible to rewrite equation 3.4 as:

$$
\sigma_{\gamma}\left(E_{\gamma, e f f}\right)=K_{n o r m} \frac{N_{\gamma}}{N_{e l}} \frac{K_{e l}\left(E_{\text {el,eff }}\right)}{\varepsilon_{\gamma}\left(E_{\gamma, e f f}\right) l_{\gamma, e f f} E_{\text {el,eff }}^{2}}
$$

where $K_{\text {norm }}$ contains all the energy independent constants appearing in the previous equations. The easiest and more accurate way to determine $\mathrm{K}_{\text {norm }}$ is to evaluate it at some energy with a known value of $\sigma_{\gamma}(E)$, that can be obtained either from the literature or, as shown in section 3.1.4, from a measurement relative to another well known reaction. We used equation 3.8 assuming $E_{\gamma, \text { eff }}=E_{\text {el,eff }}$ : this assumption was confirmed to be valid by the Monte Carlo simulation and the elastic scattering measurements. Finally, one should note that $\sigma_{\gamma}\left(E_{\gamma, e f f}\right)$ in equation 3.8 is independent from the absolute value of the pressure in the target chamber, as long as the relative pressure profile does not change significantly.

\subsubsection{Analysis of the $\gamma$-spectra}

The measurements covered the energy range $\mathrm{E}_{\text {lab }}=5.80$ to $12.40 \mathrm{MeV}$. The ${ }^{12} \mathrm{C}$ beam current of target ranged between 30 and $50 \mathrm{p} \mu \mathrm{A}$ and the gas target was normally operated at $P_{0}=20$ Torr. The spectrum background in the relevant $\gamma$ energy region varies considerably with the beam energy: at lower beam energies the room background, mainly produced by the cosmic radiation, dominates, while the beam induced background grows with increasing beam energy. This is due to some reactions that took place between the incident ions and some beam-line components, essentially the gas target collimators and partly the beam-stop Faraday cup. In order to reduce the beam induced background, at beam energies higher than $10.6 \mathrm{MeV}$ the gas target was operated with a gas pressure $P_{0}=10$ Torr instead of $P_{0}=20$ Torr. This reduced the beam angular straggling in the target, and consequently the fraction of beam hitting the down stream apertures. The different behaviour of the spectrum background can be seen in figure 3.1 that shows two spectra collected, respectively, at the lowest and at the highest measured energy. These two spectra can be compared with the spectrum observed at $\mathrm{E}_{\mathrm{lab}}=9.90 \mathrm{MeV}$ (i.e. on top of the broad $E=2.42 \mathrm{MeV}, J^{\pi}=1^{-}$resonance) that is shown in figure 3.4. In this last spectrum the capture peak shows - because of the highr cross section - very clearly its different components, originating from the different interaction mechanisms of the electromagnetic radiation with the material of the detectors. The highest energy peak corresponds to those events in which the whole $\gamma$ energy is released in one detector and it is therefore called the full energy peak (FEP), while the following lower energy peaks, referred to as, respectively, the single escape peak (SEP) and the double escape peak (DEP), correspond to events in which the detection proceeds 
via pair production and one or both, respectively, of the positron annihilation 511 $\mathrm{keV} \gamma$ quanta escape from the detector.

Finally the broad and asymmetric peak underneath these three peaks is due to those events in which the energy is mainly transferred via Compton scattering. The so-called Compton edge, corresponding to the maximum energy that a $\gamma$ quantum can transfer to an electron, is clearly visible at slightly higher energy then the SEP. Visible is also the Compton edge of the second annihilation $\gamma$-ray, following the SEP. The excellent quality of the spectrum is due to the very good energy resolution of the HPGe detectors (less than $3 \mathrm{keV}$ at $E_{\gamma}=1.1 \mathrm{MeV}$ ) and the far detection geometry, that reduces the Doppler broadening.

The cosmic background turned out to be a minor problem: it was possible, indeed, to perform an accurate measurement of it over four weeks (during Christmas holiday), while the accelerator was turned off, and consequently subtract it from the spectra, as again shown in Figure 3.1. In contrast, it was necessary to estimate the beam induced background directly from the analysis of the ${ }^{12} \mathrm{C}(\alpha, \gamma){ }^{16} \mathrm{O}$ spectra. Actually several attempts were done to measure it using gases different from ${ }^{4} \mathrm{He}$ (i.e. Ne and $\mathrm{Ar})$ at different pressures, but a satisfactory agreement with the ${ }^{12} \mathrm{C}(\alpha, \gamma){ }^{16} \mathrm{O}$ spectra was never obtained at $\gamma$ energies were no signal from the reaction is expected. This would be a reasonable condition to assume that such a measurement reproduces the background underlying the signal coming from the reaction. The spectrum presented some smooth bumps, but no lines were visible in the energy region between $E_{\gamma}=8$ and 10.5 MeV, in the limit of the short measuring time (of the order of few hours) of this background run: we will show later that for much longer running times, one gets the evidence of some very weak lines originating by $(n, \gamma)$ capture reactions in the detectors. The strong energy dependence of the background enhances the difficulty of a correct analysis of the spectra. The complete peak form extends over a much wider region, so that the estimate of the background should be constrained in relatively far regions from it, and a peak form analysis, as described in the next section, would be very difficult in view of the large number of parameters necessary to describe the complete peak form. An incorrect background subtraction could influence the energy dependence of the excitation function and its absolute value. As a consequence, the extrapolation to the relevant astrophysical energy would be strongly affected, even normalizing the data to the existing measurements. Therefore it was decided to analyze just the FEP of the collected spectra, where the signalto-background ratio is maximized. The FEP can be described in term of a few parameters and it extends over a region of the order of $100 \mathrm{keV}$, due to the excellent energy resolution of the HPGe detectors and the reduced Doppler broadening. The price to pay for this procedure is a significant reduction of the detection efficiency. On the other hand, this choice puts the analysis of the observed spectra on solid ground, reducing the risk of systematic errors possibly originating from the analysis 

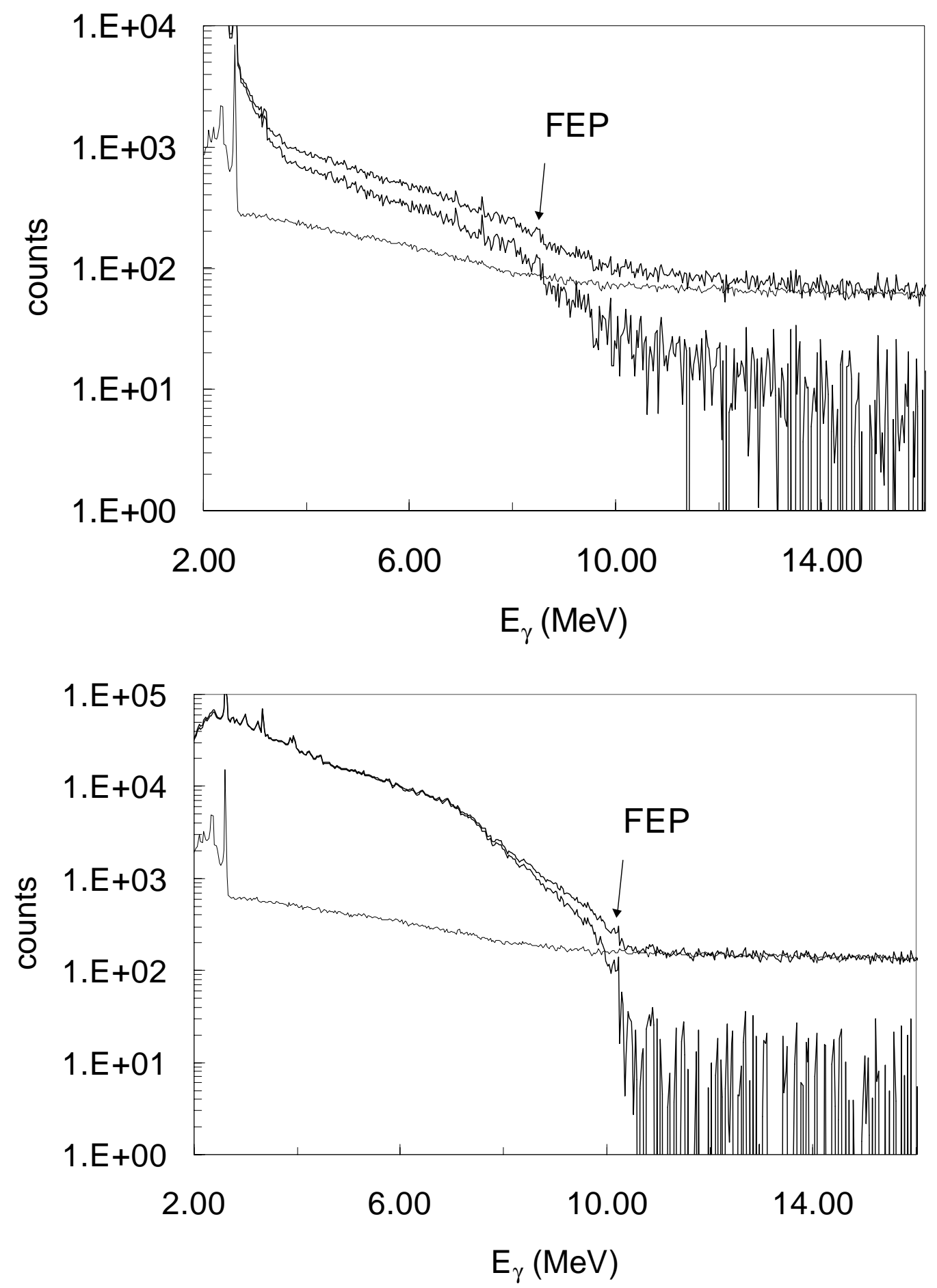

Figure 3.1: Spectra collected at $E_{l a b}=5.8$ (top, 4 week long measurement) and 12.2 $\mathrm{MeV}$ (bottom, 1 week long measurement). Also the subtracted cosmic background, normalized in the energy region $E_{\gamma}$ between 16 and $26 \mathrm{MeV}$, and the resulting spectra are shown. $(\mathrm{FEP}=$ Full-Energy-Peak $)$ 
procedure.

\subsubsection{Monte Carlo simulation of the experiment}

A full simulation of the experiment, i.e. of the observed $\gamma$ spectra, would involve a multiple integration over several probability distributions: in fact the energy loss of the ${ }^{12} \mathrm{C}$ ions in the gas target, the interaction with the ${ }^{4} \mathrm{He}$ nuclei to form ${ }^{16} \mathrm{O}$, and finally the interaction with the active material in the detectors are described by probability distributions. Due to the complexity of such integration, numerical methods have to be used. For this purpose, a grid based sampling technique would turn out to be not practicable, in view of the enormous number of grid points required. A very effective approach is to use the so called Monte Carlo method, that is a way of evaluating multiple integrals over probability distributions by means of a random sampling from the distributions themselves. This technique is very widely used to simulate the outcome of physics experiments and therefore a big effort has been done to build up libraries of routines that handle the most important aspects of such simulations. GEANT [30] is one of such libraries. Its routines allow to describe a complex apparatus and the interaction of a large number of particles: eventually the user has to implement some routines to describe some special aspects of his setup. This is the case of the extended gas target used for the present experiment. To get the distribution of the reaction coordinate along the beam axis, i.e. target axis, one has first to consider the gas pressure profile and the energy loss of the projectile ion in the gas, including straggling effects: by means of that one gets, for a given incident beam energy, the reaction energy distribution along the target. This function must then be folded with the excitation curve of the reaction to obtain the distribution of the reaction coordinate along the target. The necessary routines used for the present work were developed by D. Rogalla for a similar setup [29]: the mayor modification regarded the pressure profile, for which the function defined in equation 2.2 was adopted. As regards the rest of the setup, the geometry of the detectors was defined, for each crystal, according to the original drawings from EG\&G ORTEC (see section 2.3), while the target defining lead cylinder and the stainless steel beam line were the only passive components taken into consideration. Figure 3.2 shows the setup as defined in the Geant code.

The actual energy resolution of the detectors was taken into consideration, even though it did not play a significant role in the simulation of the observed spectra, because of broadening due to the Doppler effect and the energy loss in the target combined with the smoothing of the data to $30 \mathrm{keV} /$ channel. The simulation was first used to reproduce the observed target length measured using the ${ }^{16} \mathrm{O}(\alpha, \gamma){ }^{20} \mathrm{Ne}$ reaction (see section 2.6.3). The other two aspects of the experiment in which the simulation of the experiment was of great importance are the calculation of the 

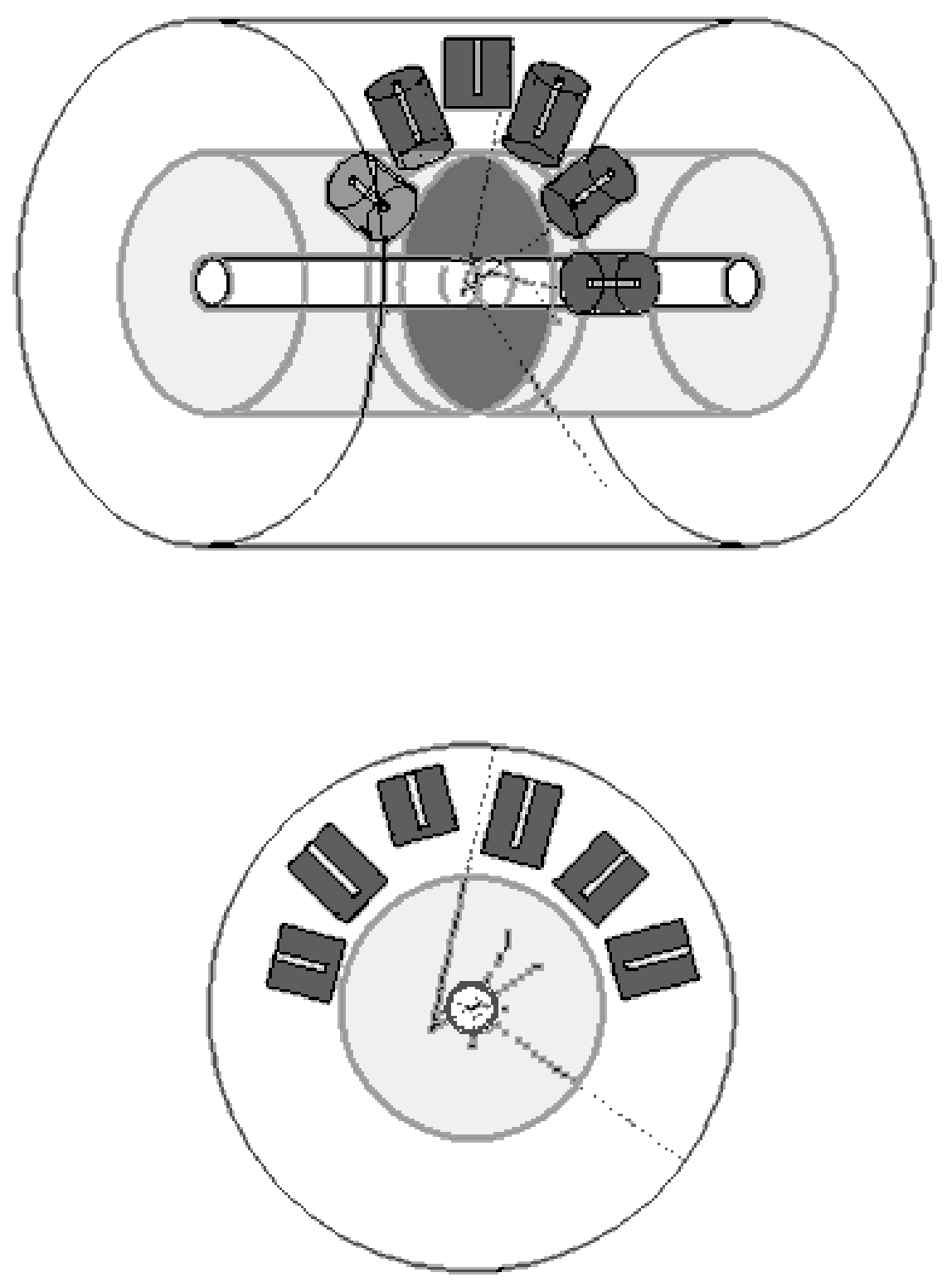

Figure 3.2: Experimental setup as defined in the Monte Carlo simulation of the experiment: top=perspective view, bottom $=$ view along the beam axis. Some events are indicated by dotted lines. 
energy dependence of the detection efficiency and the determination of the peak form of the FEP. The quantity $\varepsilon_{\gamma, e f f}\left(E_{\gamma, e f f}\right) l_{\gamma, e f f}$, defined in equation 3.5 , must be determined considering the distribution of the reaction coordinates and the $\gamma$-ray angular distribution. Therefore, all cases relevant to this experiment were separately simulated. The following list summarize the simulations performed and the cases for which they were used:

- extended source and isotropic angular distribution for ${ }^{1} \mathrm{H}\left({ }^{11} \mathrm{~B}, \gamma\right){ }^{12} \mathrm{C}$ and ${ }^{1} \mathrm{H}\left({ }^{19} \mathrm{~F}, \alpha \gamma\right){ }^{16} \mathrm{O}$

- extended source and $W_{E 1}$ angular distribution for ${ }^{4} \mathrm{He}\left({ }^{12} \mathrm{C}, \gamma\right){ }^{16} \mathrm{O}$

- extended source and $W_{E 2}$ angular distribution ${ }^{4} \mathrm{He}\left({ }^{12} \mathrm{C}, \gamma\right){ }^{16} \mathrm{O}$.

In the angular distributions for ${ }^{4} \mathrm{He}\left({ }^{12} \mathrm{C}, \gamma\right){ }^{16} \mathrm{O}$ the term $W_{E 1 E 2}$ was not taken into consideration, because around $\theta=90^{\circ}$ its effect is negligible. The geometry of the source depends on the behaviour of the excitation function of the reaction simulated in the energy range determined by the thickness of the target. In the case of resonances it is important to know the ratio of their width in the laboratory system $\Gamma_{l a b}$ with respect to the target width.

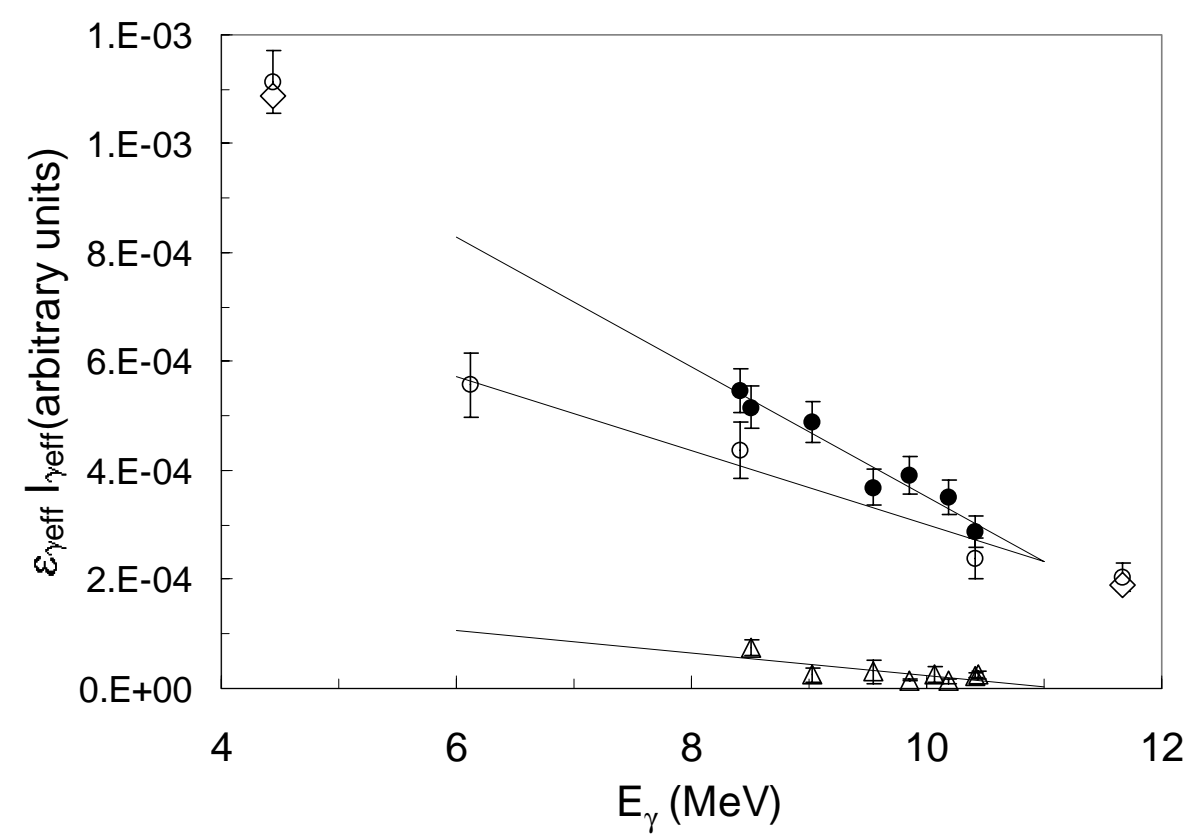

Figure 3.3: Curves calculated with the Geant simulation for $\varepsilon_{\gamma, \text { eff }}\left(E_{\gamma}\right) l_{\gamma, \text { eff }}$ (see equation 3.5) in the cases of extended sources with different angular distributions: - - $W_{E 1}$, $\circ-$ isotropic, $\triangle-W_{E 2}$. The symbols $\diamond$ represent the experimental data for the cascade transition in ${ }^{1} \mathrm{H}\left({ }^{11} \mathrm{~B}, \gamma\right){ }^{12} \mathrm{C}$ at $E_{l a b}=1.788 \mathrm{MeV}$. 
For example, the resonance in ${ }^{1} \mathrm{H}\left({ }^{11} \mathrm{~B}, \gamma\right){ }^{12} \mathrm{C}\left(E_{r, c m}=0.149 \mathrm{MeV}, \Gamma=5.8 \mathrm{keV}\right.$, $Q=15.957 \mathrm{MeV}$, i.e. $E_{l a b}=1.788 \mathrm{MeV}$ and $\left.\Gamma_{l a b}=70 \mathrm{keV}\right)$ at a pressure $P_{0}=1$ Torr and the resonance in ${ }^{1} \mathrm{H}\left({ }^{19} \mathrm{~F}, \alpha \gamma\right){ }^{16} \mathrm{O}\left(E_{r, c m}=0.323 \mathrm{MeV}, \Gamma=2.3 \mathrm{keV}, Q=8.114\right.$ $\mathrm{MeV}$, i.e. $E_{l a b}=6.46 \mathrm{MeV}$ and $\left.\Gamma_{l a b}=46 \mathrm{keV}\right)$ at a pressure $P_{0}=0.1$ Torr extend over the whole target region. Figure 3.3 shows the results of the simulations. In the case of ${ }^{1} \mathrm{H}\left({ }^{11} \mathrm{~B}, \gamma\right){ }^{12} \mathrm{C}$ it was possible to compare the simulation with experimental data. Indeed the two $\gamma$-lines at $E_{\gamma}=4.44$ and $11.66 \mathrm{MeV}$ are produced in the same $\gamma-\gamma$ cascade and their emission intensities are equal. As a consequence the ratio of the observed intensities gives the relative variation of the detection efficiency between $E_{\gamma}=4.44$ and $11.66 \mathrm{MeV}$. The good agreement between the simulated and the observed data gives confidence that the simulation can provide the necessary correction coefficient for observed $\gamma$-yields. Due to the high computing time required by the calculation, $\varepsilon_{\gamma, e f f}\left(E_{\gamma, e f f}\right) l_{\gamma, e f f}$ was calculated only at some energies and a linear fit was performed in order to get the correction coefficient in the energy range of interest. The results obtained for the peak form analysis are reported in the next section.

\subsubsection{Full energy peak analysis}

The basic idea of the peak form analysis is to constrain the shape of the fit functions, and eventually some of their parameters, for the different components of a spectrum on the basis of theoretical considerations and experimental observations, in order to identify and analyze them separately. In this case, I want to analyze a peak on a background that I cannot measure separately; on the other hand, I have the peak form at some energies, where the background is negligible, and it can be calculated at other energies by means of the Monte Carlo simulation of the experiment. Moreover, this technique can be very useful in order to reduce the number of parameter to be fitted, that turns out to be crucial if one has many parameters or few degrees of freedom for the fit. Figure 3.4 shows the peak form observed at $E_{\text {lab }}=9.90 \mathrm{MeV}$. The dotted line represents the results of the Monte Carlo simulation for the full energy peak component, the full circles are the experimental data, while the solid line is the fit to the data including also a background term, that will be described later. The Geant peak form was fitted with the following function:

$$
F_{\gamma, p e a k}=\frac{A_{\text {peak }}}{1+\exp \left[\left(\left|E_{\gamma}-E_{0}\right|-F W H M_{\text {peak }} / 2\right) / s_{\text {peak }}\right]}
$$

where $A_{\text {peak }}$ is the height at the peak center $E_{0}, F W H M_{\text {peak }}$ is the full width at half maximum of the peak, and $s_{\text {peak }}$ determine the slope of the wings of the peak. The effective energy $E_{\text {eff }}$ at which the reaction takes place is connected to the parameter 

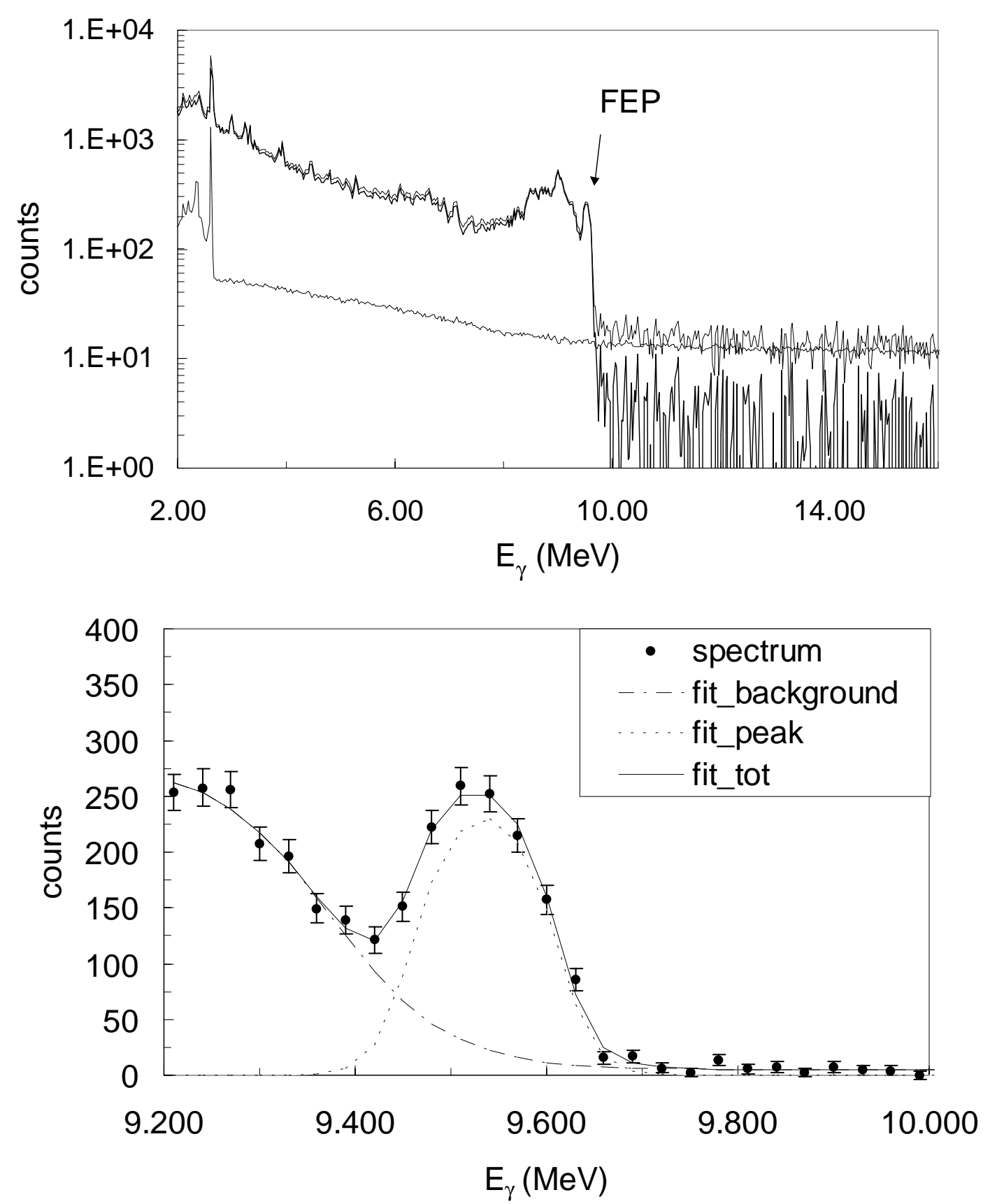

Figure 3.4: Spectrum at $E_{l a b}=9.90 \mathrm{MeV}$ (top, 13 hour measurement) and peak form analysis of the full energy peak (bottom). The peak form (dotted line) was obtained via a Monte Carlo simulation. 


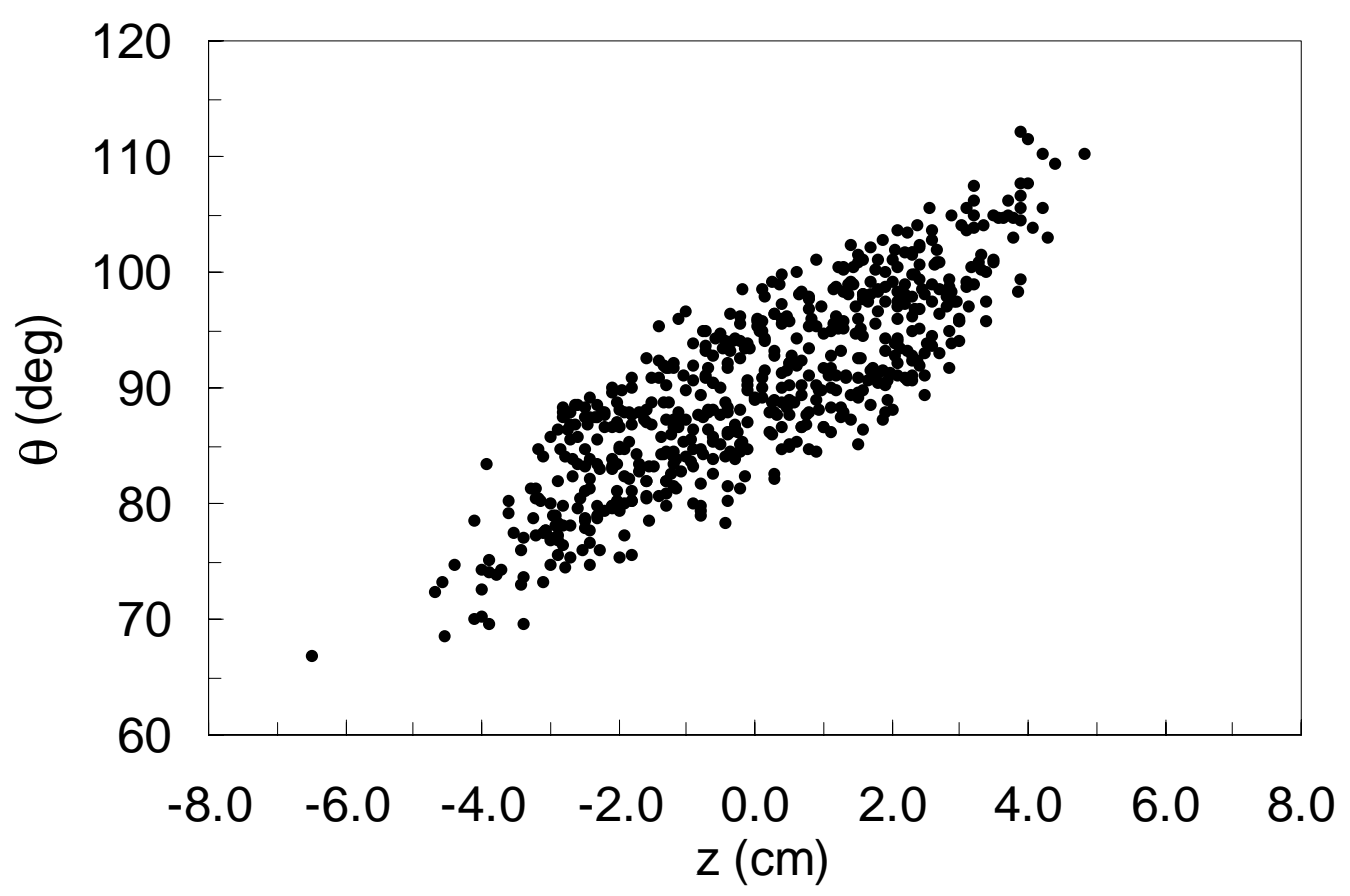

Figure 3.5: Correlation between reaction coordinate $z$ and emission angle for the detected $\gamma$-rays obtained via the Monte Carlo simulation.

$E_{0}$ through the following equation:

$$
E_{e f f}=E_{0}-Q
$$

where $Q=7.162 \mathrm{MeV}$ is the $\mathrm{Q}$-value of the reaction. This peak form was used to fit the full energy peak of the experimental spectra: all parameters, except $s_{\text {peak }}$, were varied. This was done to take into account possible fluctuations of the electronic

parameters and of the gas pressure in the target chamber. It is interesting to note that the peak form has the same dependence on the energy as the effective target profile on the reaction coordinate (see equation 2.2): this is a result of the fact that the $\gamma$ energy depends on the reaction coordinate. This is just partly due to the beam energy loss in the target: mostly it depends on the Doppler broadening and the fact that the effective detection angle is correlated to the reaction coordinate as shown in figure 3.5. As a consequence, the peak form depends also on the $\gamma$ angular distribution and must be determined for each reaction of interest. The background was fitted in an energy region of about $1 \mathrm{MeV}$ around the FEP using the following parametrization:

$$
F_{\gamma, \text { back }}=\frac{A_{b a c k}}{1+\exp \left[\left(E_{\gamma}-l_{b a c k}\right) / s_{b a c k}\right]}+k_{b a c k}
$$


where the parameters used do not have a direct physical meaning. In view of the relatively large number of parameters to be fitted, it is very important to find suitable initial values for them in order to allow the minimization routine to converge. Therefore the background parameters were first fitted alone excluding the FEP region. The fitted background was then subtracted from the spectrum and the FEP parameters were fitted to the resulting spectrum in the FEP region. Finally, the complete function $F_{\gamma}=F_{\gamma, \text { back }}+F_{\gamma, p e a k}$ was fitted to the whole spectrum.

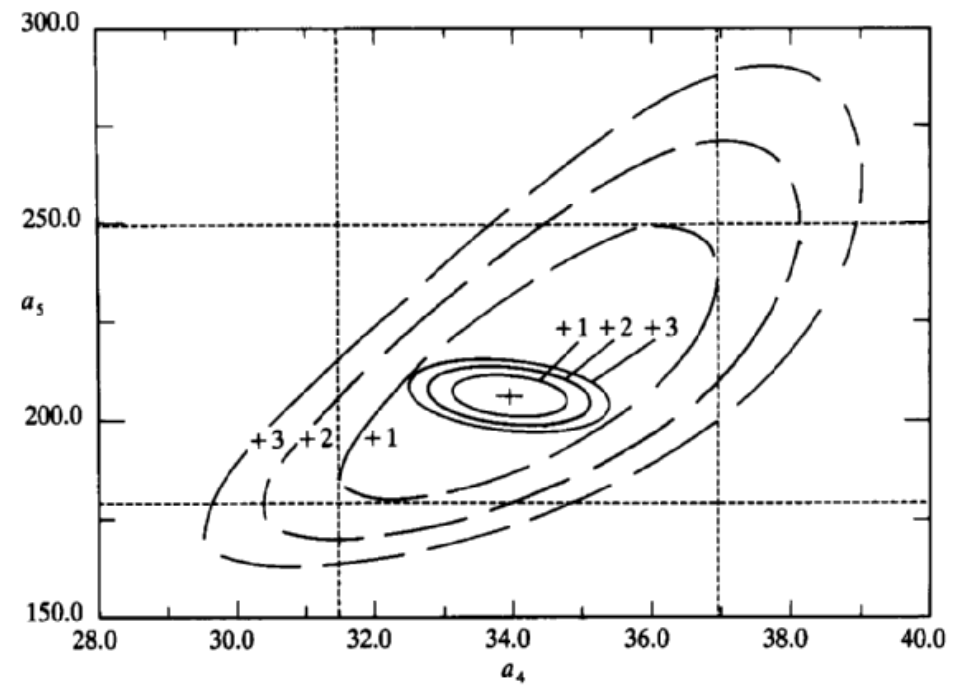

Figure 3.6: Contour plots for a $\chi^{2}$ surface with 5 parameters $\left(a_{1}\right.$ to $\left.a_{5}\right)$ in the space of two parameters $a_{4}$ and $a_{5}$. The dashed lines are obtained mimizing the $\chi^{2}$ for each pair of values $a_{4}$ and $a_{5}$ and they determine the intervals that correspond to the standard deviation of the parameters $a_{4}$ and $a_{5}$, respectively. The solid lines are obtained keeping $a_{1}$ to $a_{3}$ fixed at their best fit values: if one would use these latter plots, the errors on the parameters would be significantly underestimated (From $[31])$.

An important aspect in this kind of analysis is the correct estimate of error that affects the value of the area of the peak, and consequently the value of the cross section. Because this is a counting experiment, one might consider to assume that the area of the peak is distributed according to the Poisson distribution: this would lead to an underestimate of the error, because the error on the estimate of the fitted parameters would be neglected. In the case of fit functions that are not linear in the fitted parameters, a possible procedure is to determine the errors on the fitted parameters studying the surface described by the $\chi^{2}$ function in the $n$-dimensional parameter space, where $n$ is the number of the fitted parameters [31]. If the fit is done properly, the fitted value of the parameters corresponds to a minimum, possibly the absolute one, of the surface, where $\chi^{2}=\chi_{\text {min }}^{2}$. The depth of the minimum and 
the slope of the surface around it is correlated to the constraint put by the data to the parameters taken into consideration: in the extreme case there could be no minimum, that would correspond to a completely wrong parameterization of the fit function, and the parameters would remain totally indeterminate. If one considers the contour line on the $\chi^{2}$ surface determined by the condition $\chi^{2}=\chi_{\min }^{2}+1$, the projection of this contour line onto each axis will determine for each corresponding parameter an interval around the best fit value. This interval is an estimate of the error affecting the best-fit value of the parameter itself. To illustrate this procedure, one can consider the case in Figure 3.6 [31]. The picture shows the application of this method in the case of a fit function with five parameters, $a_{1}$ to $a_{5}$. The solid line contour plots are obtained varying two parameter, $a_{4}$ and $a_{5}$, in order to get $\chi^{2}=\chi_{\min }^{2}+1$, while the remaining three are kept fixed at the value corresponding to $\chi_{\min }^{2}$. The dashed lines, to the contrary, are obtained varying $a_{1}$ to $a_{3}$ in order to minimize $\chi^{2}$ for each couple of values $a_{4}$ and $a_{5}$. These second plots should be used.

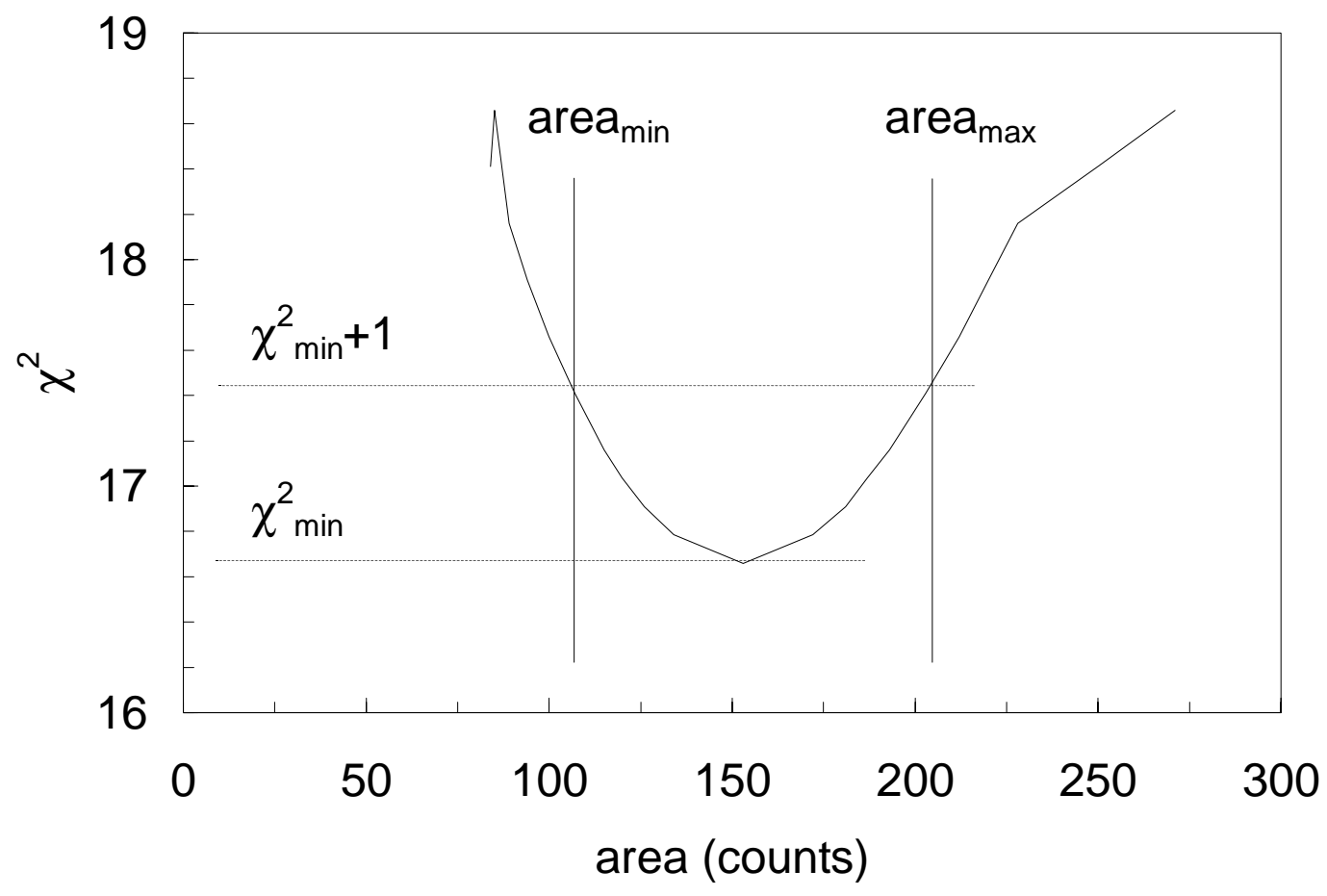

Figure 3.7: $\chi^{2}$ analysis to determine the error on the area of the FEP at $E_{l a b}=5.8$ $\mathrm{MeV}$.The vertical lines determine the interval that corresponds to one standard deviation (see text for details).

Indeed, the upper and lower limit of the projection of the $\chi^{2}=\chi_{\min }^{2}+1$ plot on one axis, say $a_{4}$, are obtained maximizing and minimizing $a_{4}$, respectively, varying all parameters with the condition $\chi^{2}=\chi_{\min }^{2}+1$. 


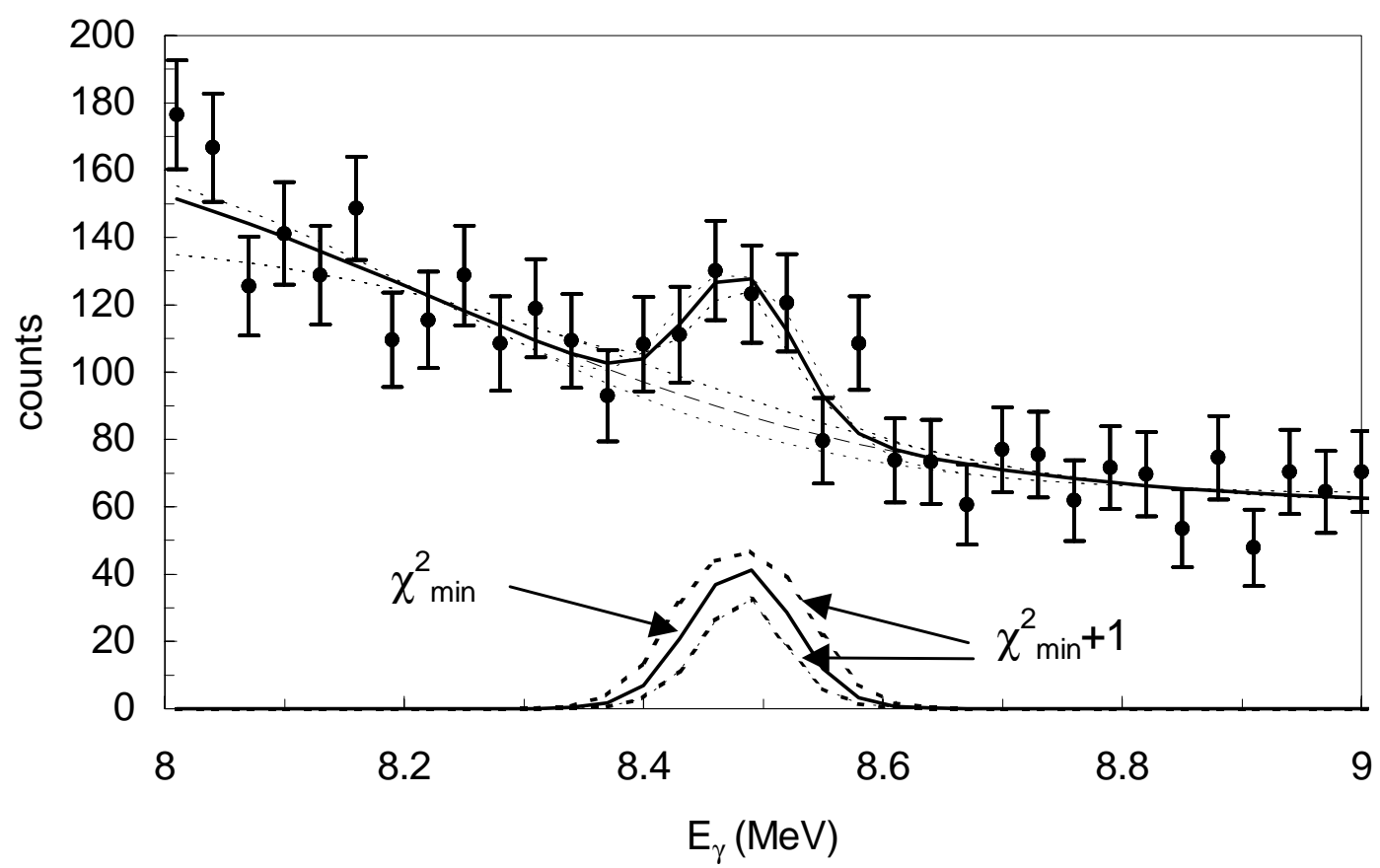

Figure 3.8: $\chi^{2}$ analysis to determine the error on the area of the FEP at $E_{l a b}=5.8$ $\mathrm{MeV}$. The solid line represents the best fit $\left(\chi^{2}=\chi_{\text {min }}^{2}\right)$ to the experimental data. The dotted lines represent the fits obtained maximizing and minimizing, respectively, the peak area with the condition $\chi^{2}=\chi_{m i n}^{2}+1$. These fits correspond to the values of the area peak indicated in figure 3.7 by the the vertical lines (see text for details).

Now, the variation of $\chi^{2}$, i.e. $\Delta \chi^{2}=\chi^{2}-\chi_{m i n}^{2}$, is also a $\chi^{2}$ distributed variable, and the procedure described corresponds to a fit with only one degree of freedom and the interval for $a_{4}$ corresponds to the interval $[0,1]$ for $\Delta \chi^{2}$. The integrated probability distribution for a $\chi^{2}$ variable for 1 degree of freedom over the range $[0,1]$ is $68.3 \%$. This is equal to the integrated probability distribution for a gaussian distribution in the range $[\mu-\sigma, \mu+\sigma]$, that is the usually quoted error on the estimate of $\mu$. Figure 3.7 shows the result I obtained for the spectrum measured at $E_{l a b}=5.8 \mathrm{MeV}$, while figure 3.8 shows the different fits obtained for $\chi^{2}=\chi_{\min }^{2}$ and $\chi^{2}=\chi_{\min }^{2}+1$. It appears clear from this kind of analysis that the major source of error is the determination of the background underneath the peak. This confirms that an analysis of the spectra over a wider energy region would not improve the precision of the estimate of the observed yield, because the increase of the precision due to the larger peak area would be largely compensated by the increase of the indetermination on the estimate of the background, that would be constrained even more weekly than in the case shown in figure 3.8. Figure 3.9 shows the result of the fit for the highest energy at which the measurement took place. 


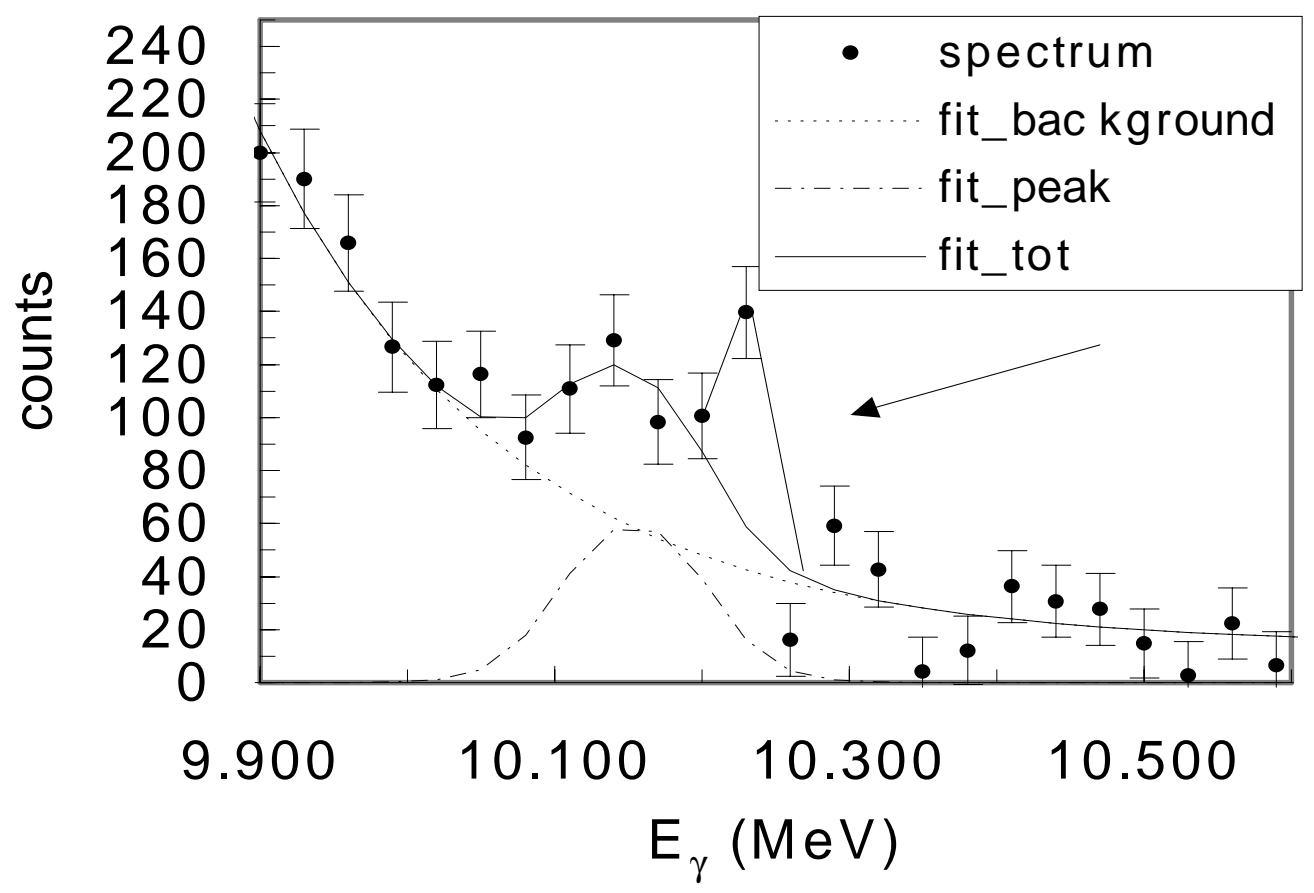

Figure 3.9: Peak form analysis for $E_{l a b}=12.20 \mathrm{MeV}$. The arrow indicates a background line $\left(E_{\gamma}=10.2 \mathrm{MeV}\right)$ appearing in all spectra at $E_{l a b}>11.0 \mathrm{MeV}$.

One can note the presence of a background line at $E_{\gamma}=10.2 \mathrm{MeV}$. This line appears in all measurements at $E_{l a b}>11 \mathrm{MeV}$, where also a steep increase of the neutron flux was observed. This line has been tentatively identified as coming from a $\gamma-\gamma$ cascade transition in ${ }^{73} \mathrm{Ge}(\mathrm{n}, \gamma){ }^{74} \mathrm{Ge}$. Anyway, thanks to the good energy resolution of the HPGe detectors, it was possible to exclude from the fit this background peak. As one can see, the quality of the fit is comparable in all cases, besides the effects of the different statistical precision.

The elastic scattering spectra were analyzed with a similar procedure. The only difference was due to the fact that the structure of these spectra is much simpler than those in the $\gamma$-spectra. Essentially one has a single peak over an exponential background, that can be very well fitted outside the peak with the following function:

$$
F_{e l, b a c k}=A \cdot \exp \left(-b E_{e l}^{t}\right)+k_{0}
$$

where $A, b, t$, and $k_{0}$ are fit parameters.

Figure 3.10 shows the results of the fit. The area of the peak was estimated in the peak region subtracting the fitted background from the spectrum. 


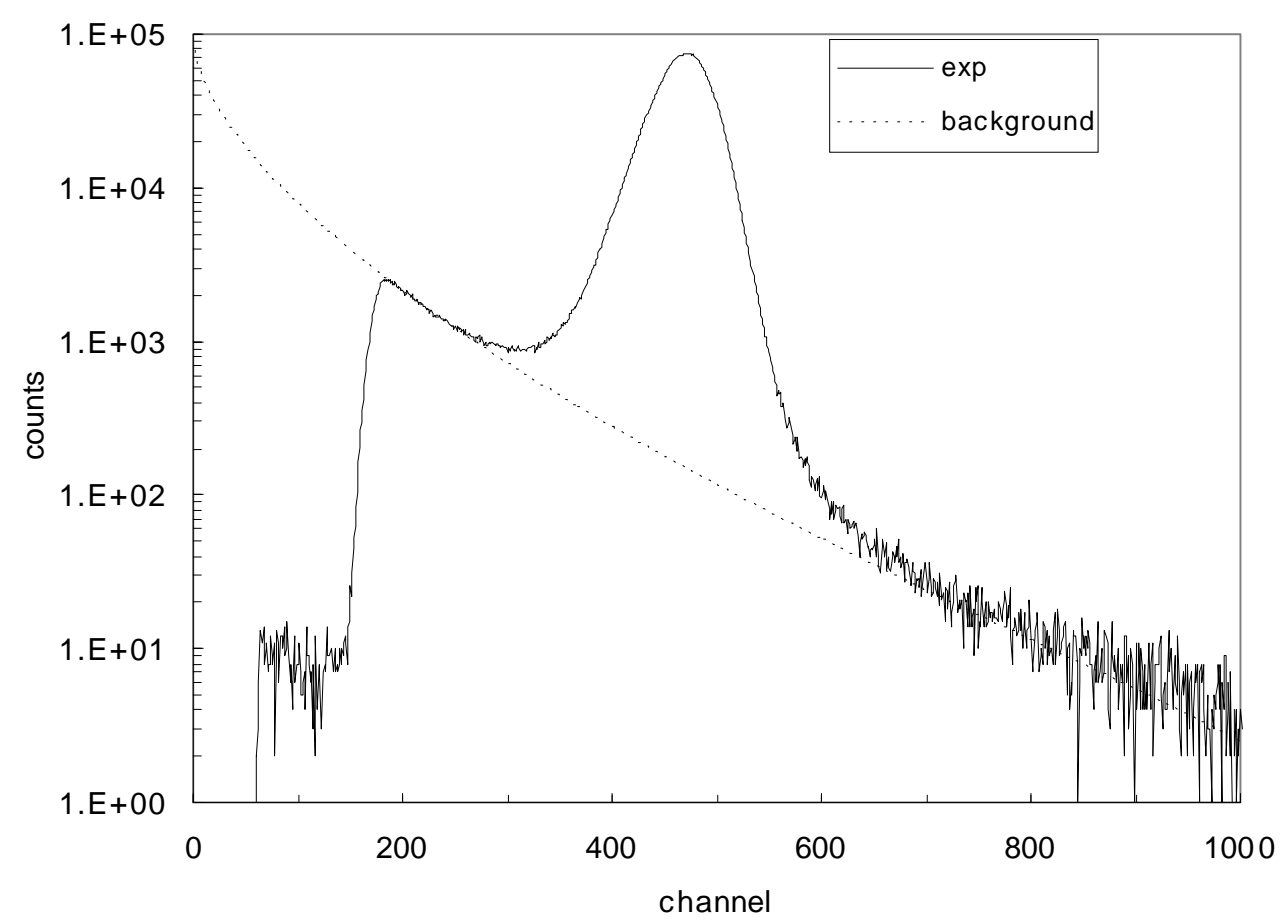

Figure 3.10: Analysis of the elastic scattering spectrum measured at $E_{l a b}=12.20$ $\mathrm{MeV}$.

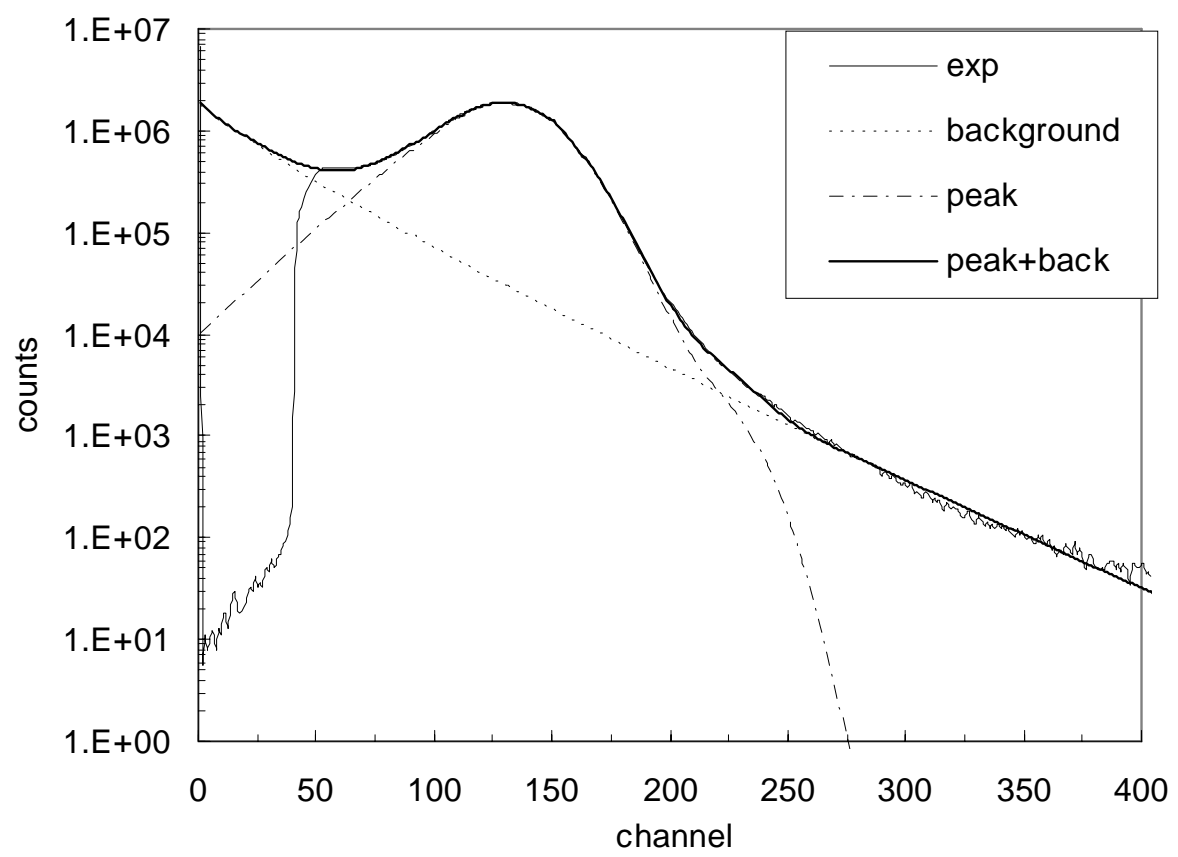

Figure 3.11: Peak form analysis for the elastic scattering spectrum measured at $E_{l a b}=5.80 \mathrm{MeV}$. The peak form was obtained at higher energies, where the peak was far enough from the threshold. 
The corresponding error was $\delta_{\text {area }}=\left(\delta_{\text {background }}^{2}+\delta_{\text {peak }}^{2}\right)^{1 / 2}$, where $\delta_{\text {background }}$ was obtained by means of a $\chi^{2}$ analysis of the background, while for $\delta_{\text {peak }}$ was calculated as the square root of the area of the peak. Only at the lowest energies $\left(E_{l a b}=5.80\right.$ and $6.40 \mathrm{MeV}$ ) this procedure was modified because here the peak position is very close to the detection threshold. For these two energies again a peak form analysis was performed. Figure 3.11 shows the results of the peak form analysis at $E_{l a b}=5.80$ $\mathrm{MeV}$.

\subsubsection{Measurement of the absolute cross section}

A well known resonance in ${ }^{1} \mathrm{H}\left({ }^{19} \mathrm{~F}, \alpha \gamma\right){ }^{16} \mathrm{O}\left(E_{r, c m}=0.323 \mathrm{MeV}, \Gamma=2.3 \mathrm{keV}\right.$, i.e. $E_{l a b}=6.46 \mathrm{MeV}$ and $\Gamma_{l a b}=46 \mathrm{keV}$ ) was used to normalize the observed relative $\gamma$ yield curve. The cross section on top of this resonance is known to be $\sigma^{F}=88 \pm 3$ $\mathrm{mb}$ [32]. This reaction populates the $E_{x}=6.130 \mathrm{MeV} J^{\pi}=3^{-}$state in ${ }^{16} \mathrm{O}$, that decays to the ground state emitting a $\gamma$-ray of $E_{\gamma}=6.13 \mathrm{MeV}$. A ${ }^{19} \mathrm{~F}$ beam was used and the gas target was operated with $H_{2}$ gas at a pressure $P_{0}=0.1$ Torr, in order to get a thin target yield.

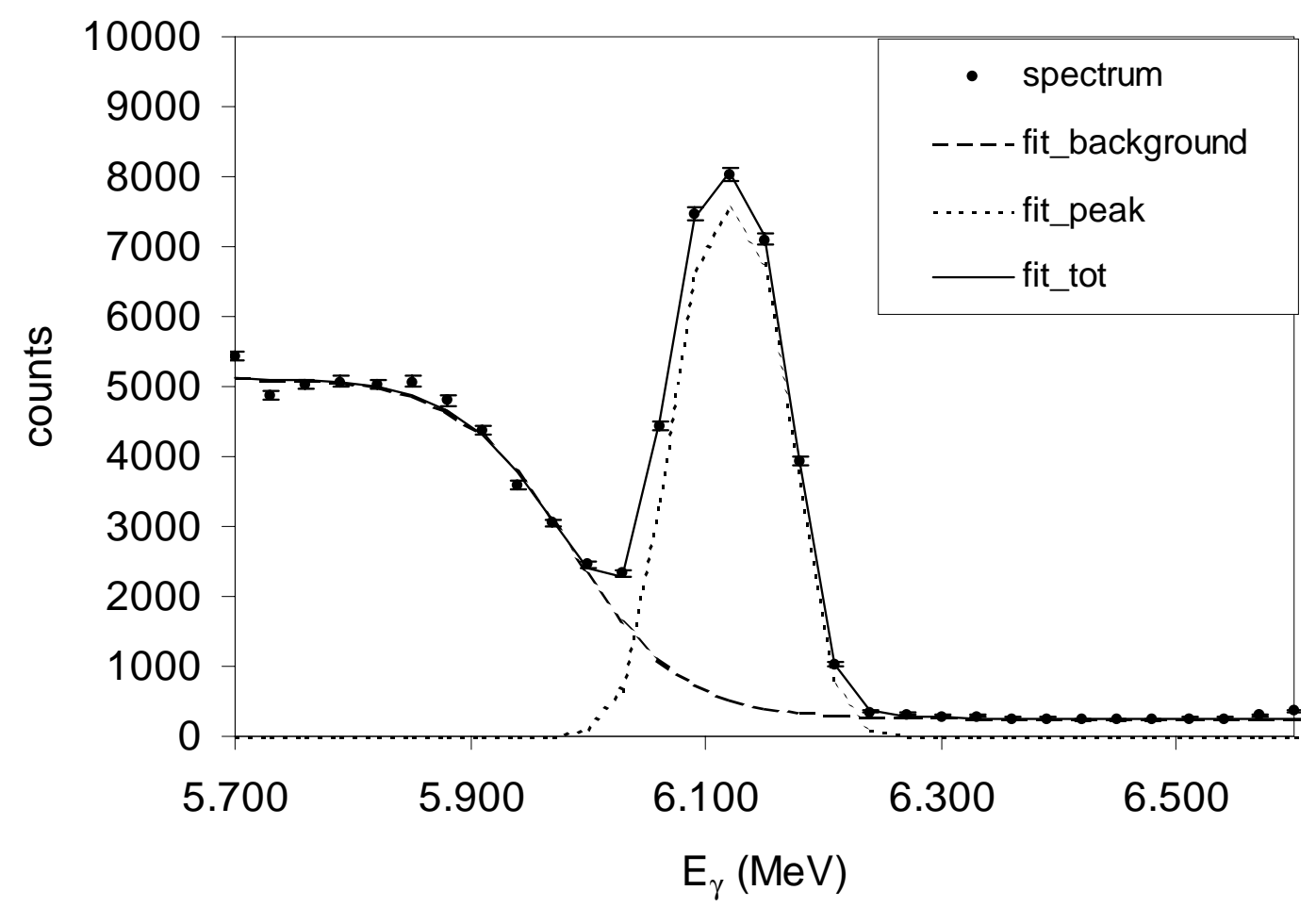

Figure 3.12: Peak form analysis for ${ }^{1} \mathrm{H}\left({ }^{19} \mathrm{~F}, \alpha \gamma\right){ }^{16} \mathrm{O}$ at $E_{l a b}=6.46 \mathrm{MeV}$.

Figure 3.12 shows the FEP of the spectrum measured at $E_{l a b}=6.46 \mathrm{MeV}$. The 
same kind of analysis as for the ${ }^{4} \mathrm{He}\left({ }^{12} \mathrm{C}, \gamma\right){ }^{16} \mathrm{O}$ was used. As regard the elastic scattering, the detector located on the first pumping stage was used because of its lower detection threshold. Figure 3.13 shows the spectrum observed concurrently with the spectrum shown in figure 3.12 . The ${ }^{19} \mathrm{~F}$ beam energy was then varied in order to find the top of the resonance, that is were the cross section is known. The resulting excitation function is shown in figure 3.14. The arrow indicates the top of the resonance at $E_{l a b}=6.453 \pm 0.001 \mathrm{MeV}$, that is in good agreement with the expected energy. In order to measure the absolute cross section of ${ }^{4} \mathrm{He}\left({ }^{12} \mathrm{C}, \gamma\right){ }^{16} \mathrm{O}$, one should note that if $I_{\gamma, F}$ and $I_{e l, F}$ are, respectively, the experimental $\gamma$ and elastic scattering yields for ${ }^{1} \mathrm{H}\left({ }^{19} \mathrm{~F}, \alpha \gamma\right){ }^{16} \mathrm{O}$ and $I_{\gamma, C}$ and $I_{e l, C}$ the corresponding quantities for ${ }^{4} \mathrm{He}\left({ }^{12} \mathrm{C}, \gamma\right){ }^{16} \mathrm{O}$, then the following equation holds:

$$
\frac{I_{\gamma}^{F} / I_{e l}^{F}}{I_{\gamma}^{C} / I_{e l}^{C}}=\frac{\left(\varepsilon_{\gamma, e f f} l_{\gamma, e f f}\right)^{F}}{\left(\varepsilon_{\gamma, e f f} l_{\gamma, e f f}\right)^{C}} \frac{(d \sigma / d \Omega)_{e l}^{C}}{(d \sigma / d \Omega)_{e l}^{F}} \frac{\sigma^{F}\left(E^{F}\right)}{\sigma^{C}\left(E^{C}\right)} \frac{\left(\frac{\Omega_{c m}}{\Omega_{l a b}}\right)_{e l}^{C}}{\left(\frac{\Omega_{c m}}{\Omega_{l a b}}\right)_{e l}^{F}},
$$

or, to our purposes,

$$
\sigma^{C}\left(E^{C}\right)=\sigma^{F}\left(E^{F}\right) \frac{I_{\gamma}^{C} / I_{e l}^{C}}{I_{\gamma}^{F} / I_{e l}^{F}} \frac{\left(\varepsilon_{\gamma, e f f} l_{\gamma, e f f}\right)^{F}}{\left(\varepsilon_{\gamma, e f f} l_{\gamma, e f f}\right)^{C}} \frac{(d \sigma / d \Omega)_{e l}^{C}}{\left(\frac{d \sigma}{d \Omega}\right)_{e l}^{F}} \frac{\left(\Omega_{c m} / \Omega_{l a b}\right)_{e l}^{C}}{\left(\Omega_{c m} / \Omega_{l a b}\right)_{e l}^{F}} .
$$

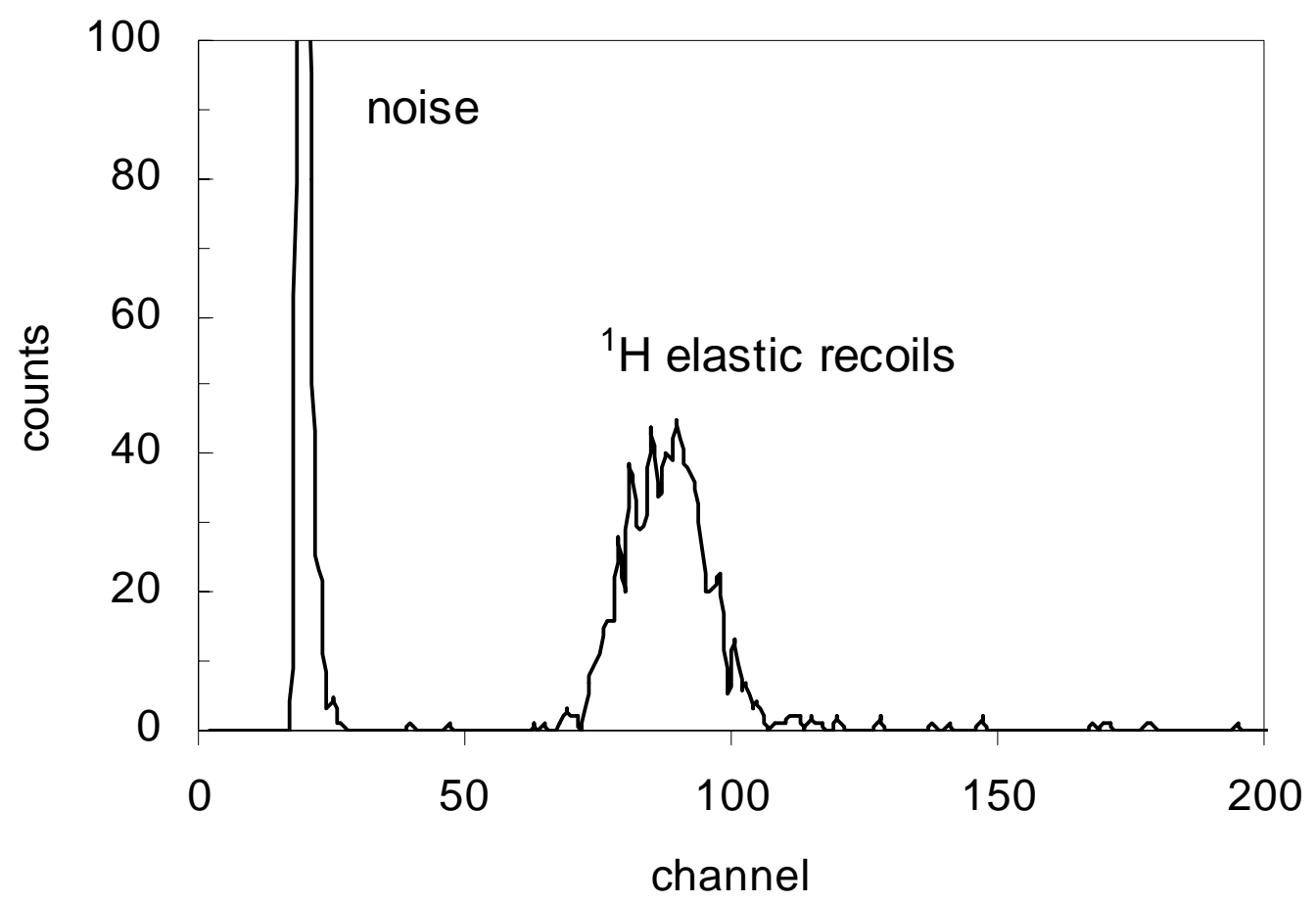

Figure 3.13: Elastic scattering spectrum for the ${ }^{19} \mathrm{~F}+{ }^{1} \mathrm{H}$ system observed in the $\mathrm{Si}$ detector located at the first pumping stage 
Here follows a list of the meaning of the different symbols used in equation 3.14:

- $\sigma^{C}$ is the cross section of ${ }^{4} \mathrm{He}\left({ }^{12} \mathrm{C}, \gamma\right){ }^{16} \mathrm{O}$ at the energy $E^{C}$;

- $\sigma^{F}$ is the cross section of ${ }^{1} \mathrm{H}\left({ }^{19} \mathrm{~F}, \alpha \gamma\right){ }^{16} \mathrm{O}$ at $E^{F}=0.323 \mathrm{MeV}$, that is $\sigma^{F}=$ $88 \pm 3 \mathrm{mb}$ from the literature [32];

- $I_{\gamma}^{C} / I_{e l}^{C}$ was measured in seven different runs during the experiment: the weighted mean of the results obtained is $(4.26 \pm 0.13) \cdot 10^{-4}$ at $E^{C}=2.365 \mathrm{MeV}$;

- $I_{\gamma}^{F} / I_{e l}^{F}$, as mentioned, was measured using the data of the second Si detector (i.e. on the first pumpimg stage downstream). Using a correction factor $\frac{\left(l_{e f f} \Omega\right)_{S i 1}}{\left(l_{e f f} \Omega\right)_{S i 2}}=0.98 \pm 0.03$, measured at higher energy, and $E^{F}=0.323 \mathrm{MeV}$ (see figure 3.14$)$, this factor turned out to be $(38.9 \pm 0.9)$;

- $\frac{\left(\varepsilon_{\gamma, e f f} l_{\gamma, e f f}\right)^{F}}{\left(\varepsilon_{\gamma, e f f} l_{\gamma, e f f}\right)^{C}}$ was calculated by means of the Geant simulation. This factor (see equation 3.5) accounts for the effect of the energy and the angular distribution on the detection efficiency and on the effective target length. One has to consider an $E_{\gamma}=6.130 \mathrm{MeV}$ isotropic extended source for ${ }^{1} \mathrm{H}\left({ }^{19} \mathrm{~F}, \alpha \gamma\right){ }^{16} \mathrm{O}$ and an $E_{\gamma}=9.527 \mathrm{MeV}, W(\theta) \propto W_{E 1}$ extended source for ${ }^{4} \mathrm{He}\left({ }^{12} \mathrm{C}, \gamma\right){ }^{16} \mathrm{O}$. In figure 3.15 the arrows indicate the points on the $\varepsilon_{\gamma, \text { eff }} l_{\gamma, \text { eff }}$-curves that have to be taken into consideration: the ratio $\frac{\left(\varepsilon_{\gamma, e f f} l_{\gamma, e f f}\right)^{F}}{\left(\varepsilon_{\gamma, e f f} l_{\gamma, e f f}\right)^{C}}$ turns out to be $1.37 \pm 0.14$;

- $\frac{(d \sigma / d \Omega)_{e l}^{C}}{(d \sigma / d \Omega)_{e l}^{F}}$ is the ratio of the elastic cross sections. In the case of ${ }^{1} \mathrm{H}\left({ }^{19} \mathrm{~F}, \alpha \gamma\right){ }^{16} \mathrm{O}$ the Rutherford law holds, while for ${ }^{4} \mathrm{He}\left({ }^{12} \mathrm{C}, \gamma\right){ }^{16} \mathrm{O}$ one has to use equation 3.7: therefore one has: $\frac{(d \sigma / d \Omega)_{e l}^{C}}{(d \sigma / d \Omega)_{e l}^{F}}=\left(\frac{E^{F} Z_{p}^{C} Z_{t}^{C}}{E^{C} Z_{p}^{F} Z_{t}^{F}}\right)^{2} K_{e l}\left(E^{C}\right) \frac{\sin ^{4}\left(\theta_{c m}^{F} / 2\right)}{\sin ^{4}\left(\theta_{c m}^{C} / 2\right)}=4.08 \cdot 10^{-2}$, where $K_{e l}(2.365)=1.23$;

- $\frac{\left(\Omega_{c m} / \Omega_{l a b}\right)_{e l}^{C}}{\left(\Omega_{c m} / \Omega_{l a b}\right)_{e l}^{F}}$ is the ratio of the center-of-mass to laboratory solid angle ratios of the two system and is equal to one. 


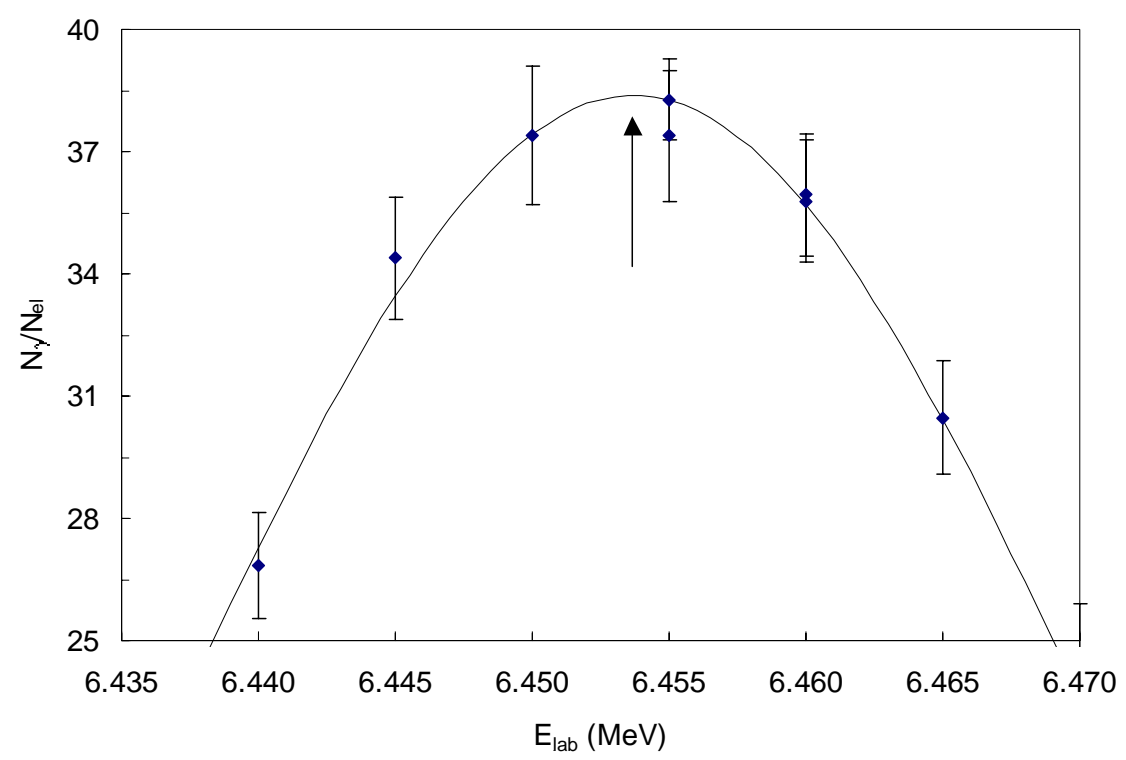

Figure 3.14: Excitation function for the ${ }^{1} \mathrm{H}\left({ }^{19} \mathrm{~F}, \alpha \gamma\right){ }^{16} \mathrm{O}$. The $\gamma$-yield is normalized to the elastic scattring yield observed in the second Si detector (first pumping stage downstream). On top of the resonance, indicated by the arrow, the cross section is known to be $88 \pm 3 \mathrm{mb}[32]$.

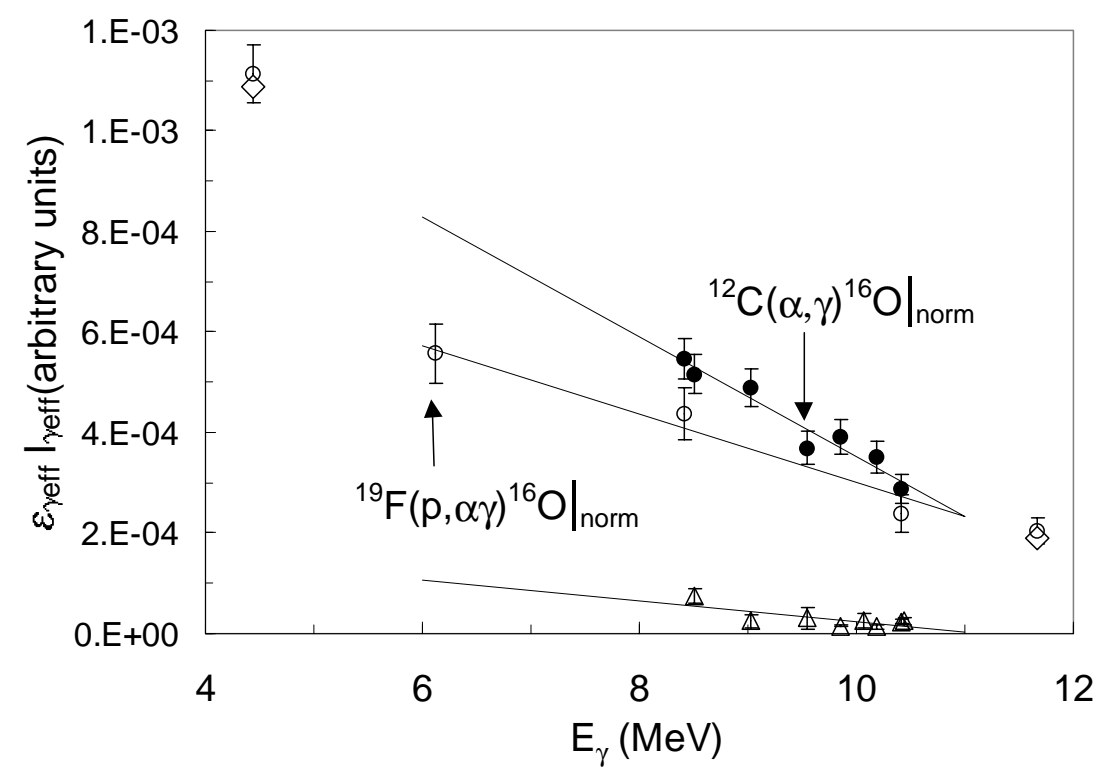

Figure 3.15: Curves calculated with the Geant simulation for $\varepsilon_{\gamma, e f f}\left(E_{\gamma}\right) l_{\gamma, e f f}$ (see equation 3.5) in the cases of extended sources with different angular distributions: - - $W_{E 1}$, o - isotropic, $\triangle-W_{E 2}$. The arrows indicate the relevant points for ${ }^{1} \mathrm{H}\left({ }^{19} \mathrm{~F}, \alpha \gamma\right){ }^{16} \mathrm{O}$ and for ${ }^{4} \mathrm{He}\left({ }^{12} \mathrm{C}, \gamma\right){ }^{16} \mathrm{O}$ (see the text for details). 
Putting all together one gets $\sigma^{C}\left(E^{C}\right)=\left(88 \cdot 10^{-3} \frac{4.26 \cdot 10^{-4}}{38.9} \cdot 1.37 \cdot 4.08 \cdot 10^{-2}\right) b=$ $54 \pm 6 \mathrm{nb}$. The resulting excitation function is shown in figure 3.16.

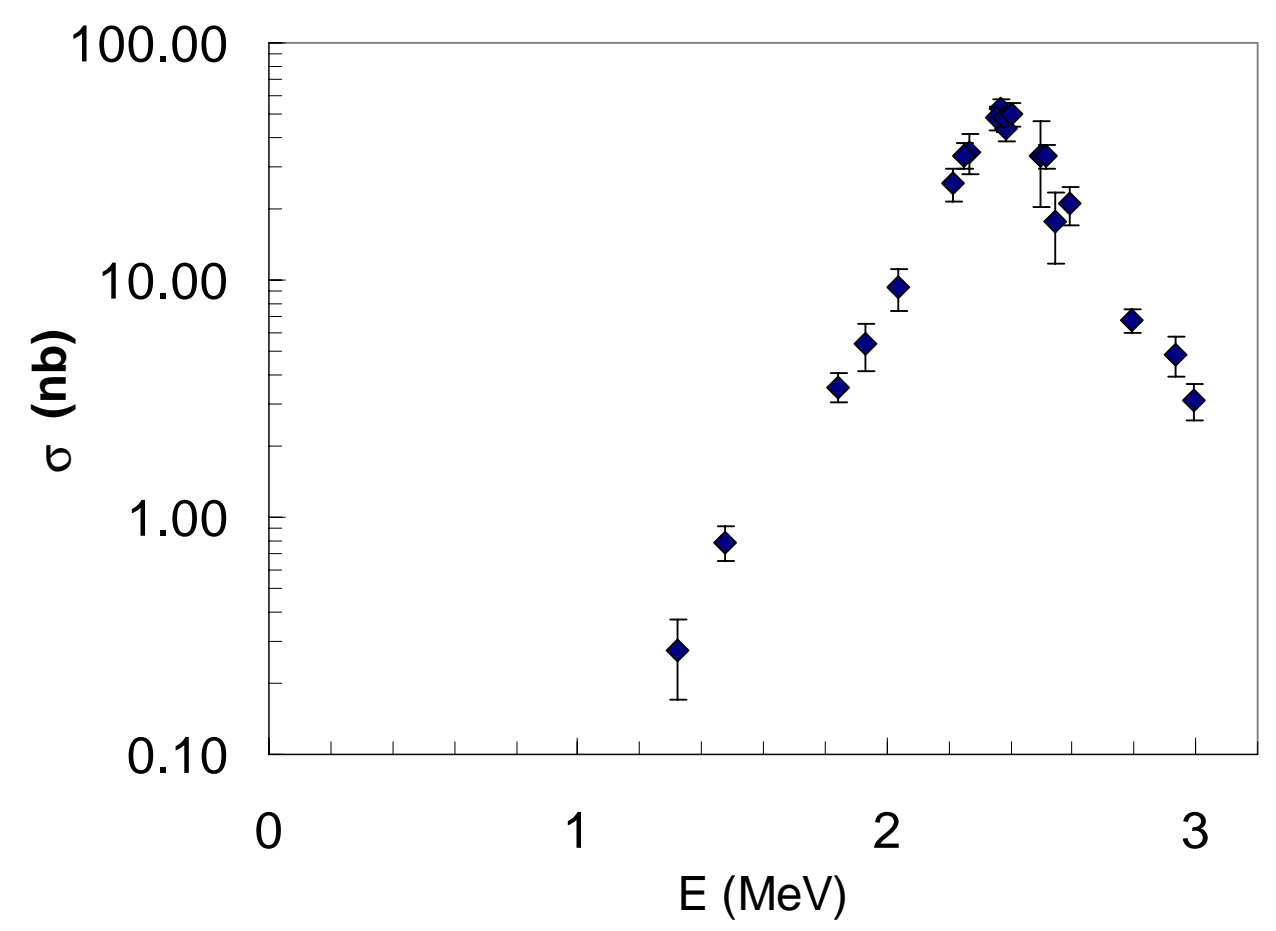

Figure 3.16: Excitation function of the ${ }^{4} \mathrm{He}\left({ }^{12} \mathrm{C}, \gamma\right){ }^{16} \mathrm{O}$ reaction measured in this work.

\subsection{Extrapolation to the relevant astrophysical en- ergy}

The extrapolation of the measured cross section to the astrophysical relevant energy $E_{0}=0.3 \mathrm{MeV}$ was done using the R-matrix formalism (see section 1.2.2). To do that I used a code developed by R.E. Azuma ([22] and references therein). The code calculates $\sigma_{E 1}\left(E_{0}\right)$ performing a least squares fit to the experimental data from three different sources:

- the ${ }^{12} \mathrm{C}(\alpha, \gamma){ }^{16} \mathrm{O}$ radiative capture;

- the ${ }^{12} \mathrm{C}(\alpha, \alpha){ }^{12} \mathrm{C}$ elastic scattering;

- the $\alpha$ spectrum from the $\beta$-delayed decay of ${ }^{16} \mathrm{~N}$. 
The $E 1$ part of ${ }^{12} \mathrm{C}(\alpha, \gamma){ }^{16} \mathrm{O}$ is given by:

$$
\sigma_{E 1}(E)=\frac{6 \pi}{k_{\alpha}^{2}} P_{1}\left|\frac{\sum_{\lambda=1}^{q_{1}}\left[\gamma_{1} \Gamma_{\lambda l}^{1} /\left(E_{\lambda 1}-E\right)\right]}{1-\left(S_{1}-B_{1}+i P_{1}\right) R 1}\right|^{2}
$$

while the ${ }^{12} \mathrm{C}(\alpha, \alpha){ }^{12} \mathrm{C}$ phase shift is given by:

$$
\delta_{l}(E)=-\Phi_{l}+\arctan \left[\frac{P_{l}}{\left.R_{l}^{-1}-S_{l}+B_{l}\right)}\right]
$$

and finally the number of $\alpha$ particles per unit energy in the ${ }^{16} \mathrm{~N}$ decay spectrum is given by:

$$
W_{\alpha}(E)=f_{\beta} \sum_{l} P_{l}\left|\frac{\sum_{=1}^{q_{l}}\left[A_{\lambda l} /\left(E_{l}-E\right)\right]}{1-\left[S_{l}-B_{l}+i P_{l}\right] R_{l}}\right|^{2} .
$$

In the previous equations the sums extend over $q_{l}$ levels, characterized by their eigenenergies $E_{\lambda l}$ and reduced $\alpha$-widths $\gamma_{\lambda l}$, where $l$ indicates the angular momentum and $\lambda$ is the level number. As regard the other quantities:

- $k_{\alpha}$ is the $\alpha$ particle wave number;

- $\Gamma_{\lambda \gamma}=2 E_{\gamma}^{3} \gamma_{\lambda \gamma}^{2}$ is the $E 1 \gamma$-width of the level $\lambda$;

- $\Phi_{l}$ is the hard sphere phase shift calculated at $a$, where $a$ is the channel radius;

- $R_{l}=R_{l}(E)$ is defined as $R_{l}(E)=\sum_{=1}^{q_{l}} \frac{\gamma_{\lambda l}}{E_{\lambda l}-E}$;

- $P_{l}=P_{l}(E, a)$ is the penetration factor;

- $S_{l}=S_{l}(E, a)$ is the shift function;

- $f_{\beta}=f_{\beta}(E)$ is the Fermi function for an extended nucleus.

As seen in section 1.2.4, $\sigma_{E 1}\left(E_{0}\right)$ is essentially determined by two $J^{\pi}=1^{-}$states $\left(E_{x}=7117\right.$ and $9580 \mathrm{keV}$ ). Therefore the R-matrix fit is performed considering three levels, two of which account for the mentioned resonances, while the third one represents the effect of all other $1^{-}$levels at higher energy. This means that $\lambda=$ $1, . ., 3$. As regards $l$, one has to consider just $l=1$ for the $\gamma$ channel, while $l=1,3$ for the ${ }^{16} \mathrm{~N}$ and ${ }^{12} \mathrm{C}(\alpha, \alpha){ }^{12} \mathrm{C}$ data. Discussing the validity of this model is beyond the purpose of the present work and the formulas above are reported for the convenience of the reader. The R-matrix code, as regards at least the physics, was used as-is, while a novel approach, based on the Monte Carlo method, was used to estimate the uncertainty on the extrapolated value and to study the interference effects between the three resonances. Coming back to the fit, because on the limitations on $l$ and 
considering some relations between them [22], the total number of parameters to be fitted reduces to 17 . The minimization of the $\chi^{2}$ is performed using the computer routine MINUIT [33].

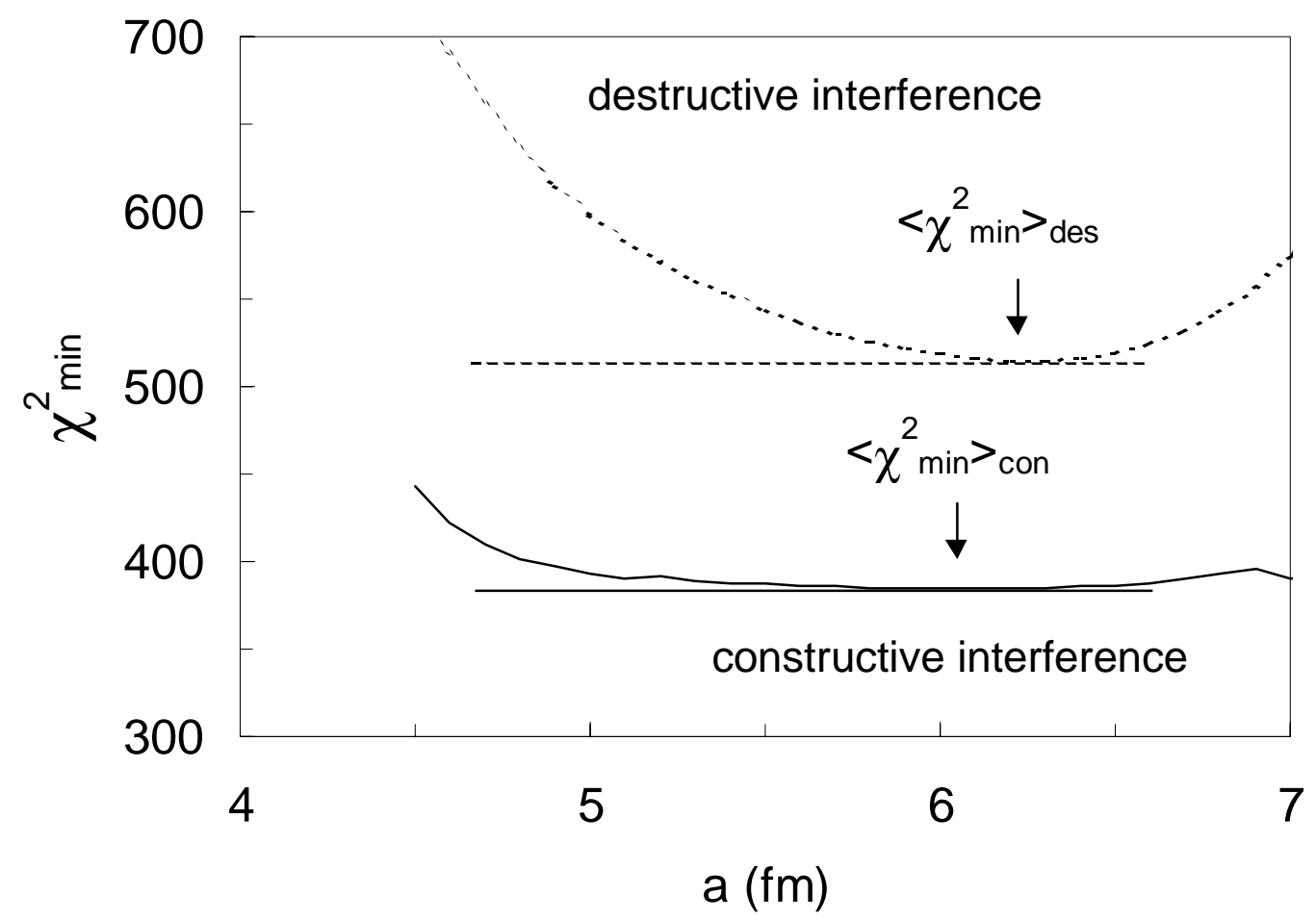

Figure 3.17: Dependence of $\chi_{\min }^{2}$ on the interaction radius for the radiative capture data sets $[14,13,17,16,12]$ and the present one, for both constructive and destructive interference between the two $1^{-}$states.

The interaction radius $a$ is a parameter in the fit and its value has to be optimized by means of a scanning of the minimum value of $\chi^{2}$ as a function of $a$. This procedure was followed first considering all the available radiative capture data sets $[14,13$, $17,16,12$ ] (I will often refer to these works in the following as to all radiative capture data) plus the present one and then considering the present experiment alone. In both cases, as in all fits presented in the following, also the ${ }^{16} \mathrm{~N}$ data of reference [22] and the elastic scattering data of [20] were considered, while the data of reference [19] were excluded in order to have results directly comparable to the previous analysis that excluded them. A reanalysis of the data including the data set of [19] is foreseen. Figure 3.17 shows the results of the combined fit to all available data, while in figure 3.18 just the data presented in this work are included. As seen, a minimum in the $\chi^{2}$ is found for both the constructive and the destructive interference between the two $1^{-}$states $\left(E_{x}=7117\right.$ and $\left.9580 \mathrm{keV}\right)$ : this happens whichever $\gamma$ data set is considered. In the following, the term interference without 
further specification will be referred to the interference between the two $1^{-}$states at $E_{x}=7117$ and $9580 \mathrm{keV}$. The value of $a$ at $\chi_{\min }^{2}$ is in all cases close to $6 \mathrm{fm}$, that was therefore chosen as value for the subsequent fits. The error on $a$ was determined via a $\chi^{2}$ analysis and turned out to be \pm 0.5 .

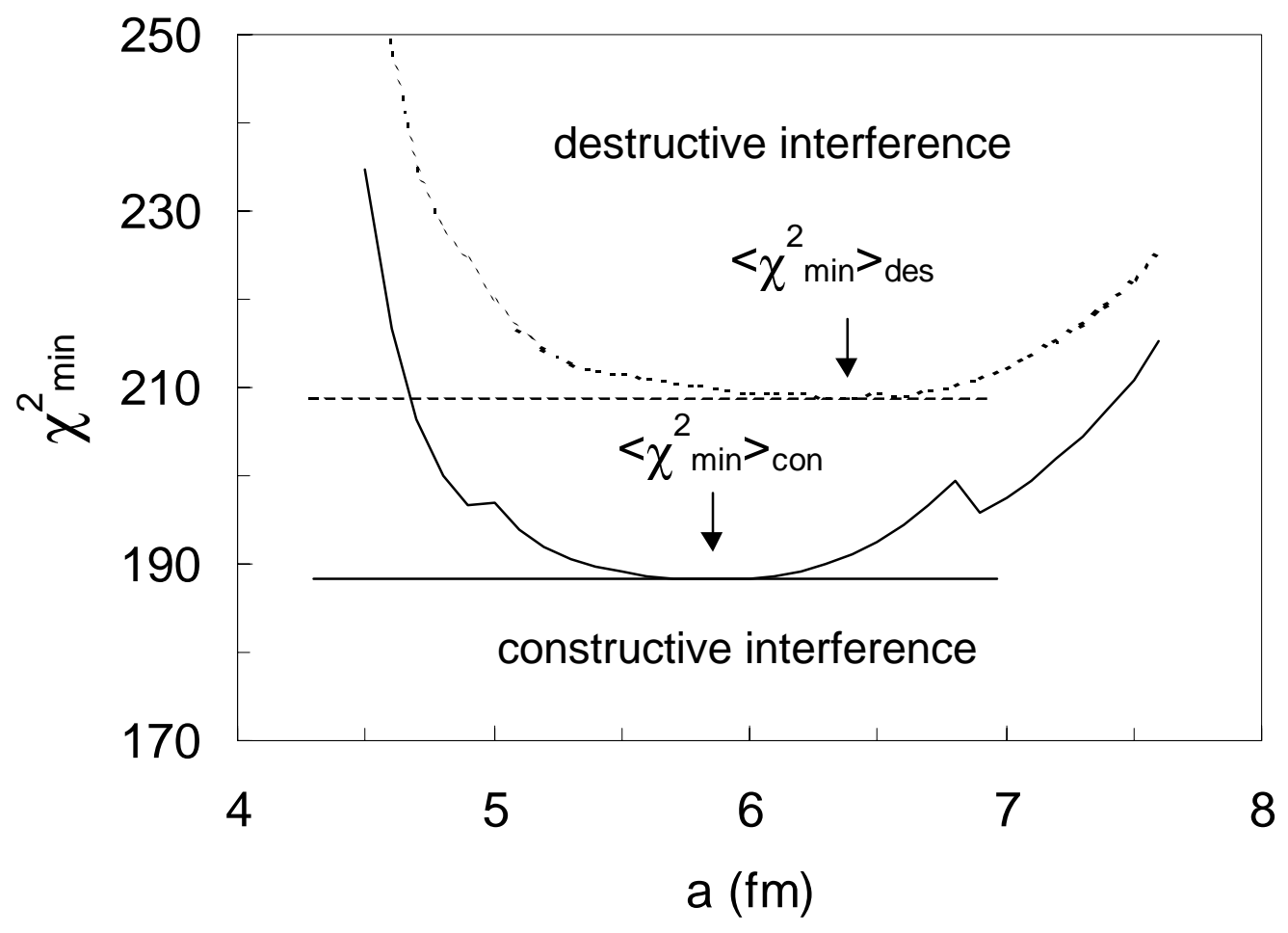

Figure 3.18: Dependence of $\chi_{\min }^{2}$ on the interaction radius for the present data alone, for both constructive and destructive interference between the two $1^{-}$states.

With this value of $a$, a fit to the data of the present work was done. The results are shown in figure 3.19 in form of $S(E)$ factor. The problem is to elaborate a procedure to determine the error of the extrapolated value $S_{E 1}\left(E_{0}\right)$ : indeed a value of $S_{E 1}\left(E_{0}\right)$ without an estimate of the error would not be very useful. One possibility could be to apply the procedure followed for the analysis of the $\gamma$ spectra. This would present two problems. First, $S_{E 1}(300)$ is not a parameter in the fit; this would require a different parameterization from the one adopted here. Second, even having done this change in the model, one would have the problem of performing a $\chi^{2}$ analysis with a large number of parameters and data sets. Therefore a different approach was used here. The basic idea is that the error on $S_{E 1}(300)$ is connected, by means of the fit function, to the errors on the single data points. Now, when one quotes an error for a measurement, it is normally meant that the measured value follows a certain probability distribution, say a gaussian distribution, whose standard deviation $\sigma$ is the error quoted. If one uses a set of data to estimate, 
by means of a fit, the value of a certain quantity, say $S_{E 1}(300)$, this value will follow a probability distribution that one gets by the convolution of the probability distributions of the single data points with the fit function. This multiple integration can be performed with the Monte Carlo method. In practice, the R-matrix code was launched repeatedly and at every execution the data points were smeared using a gaussian deviate, obtained via a routine based on the Box and Mueller method [31], with standard deviation $\sigma_{\text {exp }}$ given by the error on the measurement itself. This means that the gaussian distribution of every measurement was folded with itself and, therefore, the resulting value had a variance $\sigma_{m c}=2 \sigma_{e x p}$ : if one would not take into account that, the resulting $\chi^{2}$ would be artificially increased by a factor of two. Similar fits were performed for each $\gamma$ set: figure 3.21 show the case of the data of the present work for constructive and destructive interference, respectively. The results for each $\gamma$ set are reported in table 3.1. Figure 3.20 shows the results of this procedure considering all $\gamma$-capture, the ${ }^{16} \mathrm{~N}$ and elastic data sets: the extrapolated value is $S_{E 1}(300)=82 \pm 4 \mathrm{keV}$ b at $1 \sigma$ level. To this error one has to add $\pm 6 \mathrm{keV}$ $\mathrm{b}$ given by the uncertainty in the branching ratio of the two $1^{-}$levels populated by the ${ }^{16} N$ decay [22].

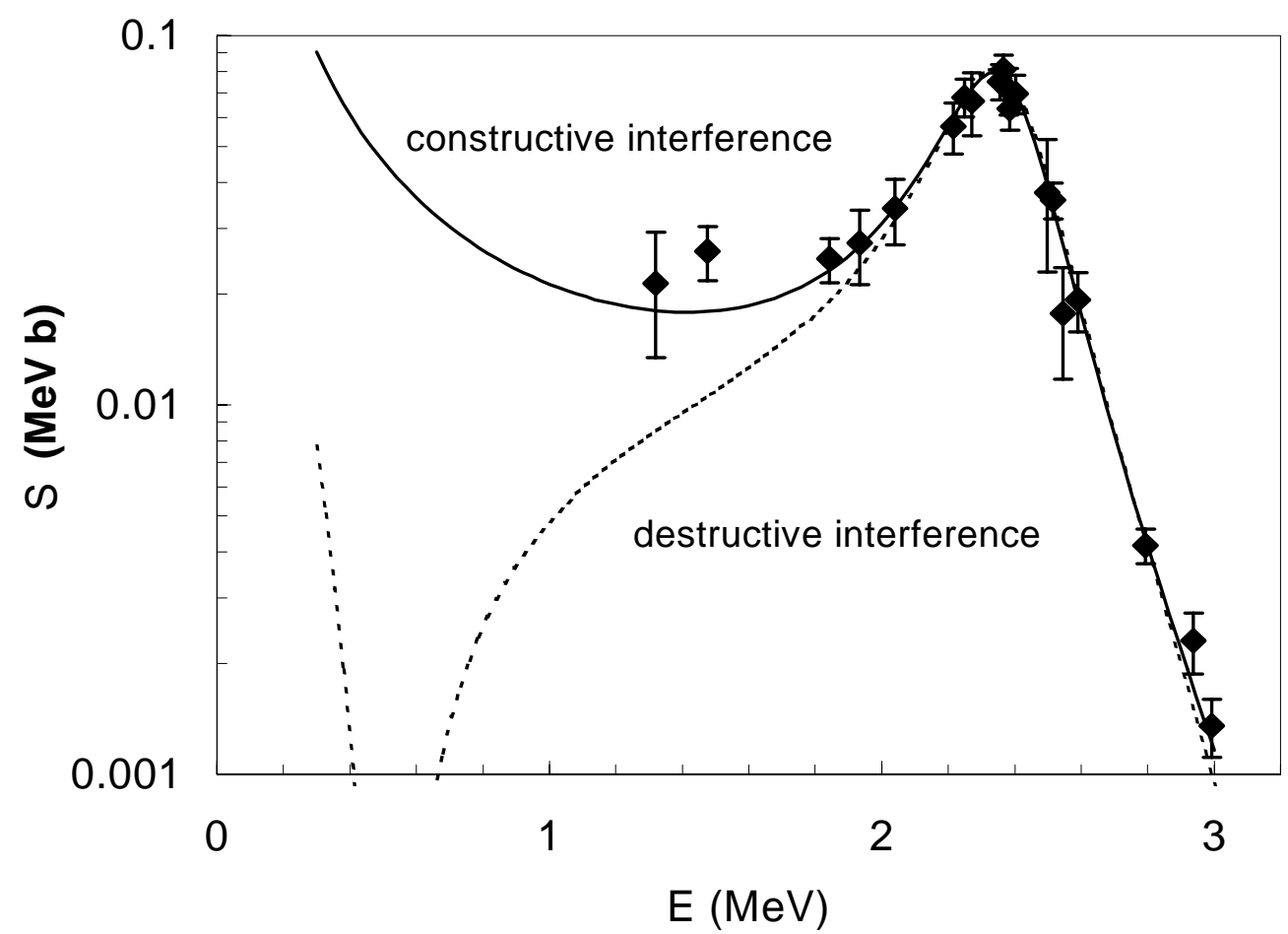

Figure 3.19: Excitation function in form of $S(E)$-factor for the ${ }^{4} \mathrm{He}\left({ }^{12} \mathrm{C}, \gamma\right){ }^{16} \mathrm{O}$ measured in this work. R-matrix fits to the data for both constructive and destructive interference are shown. 


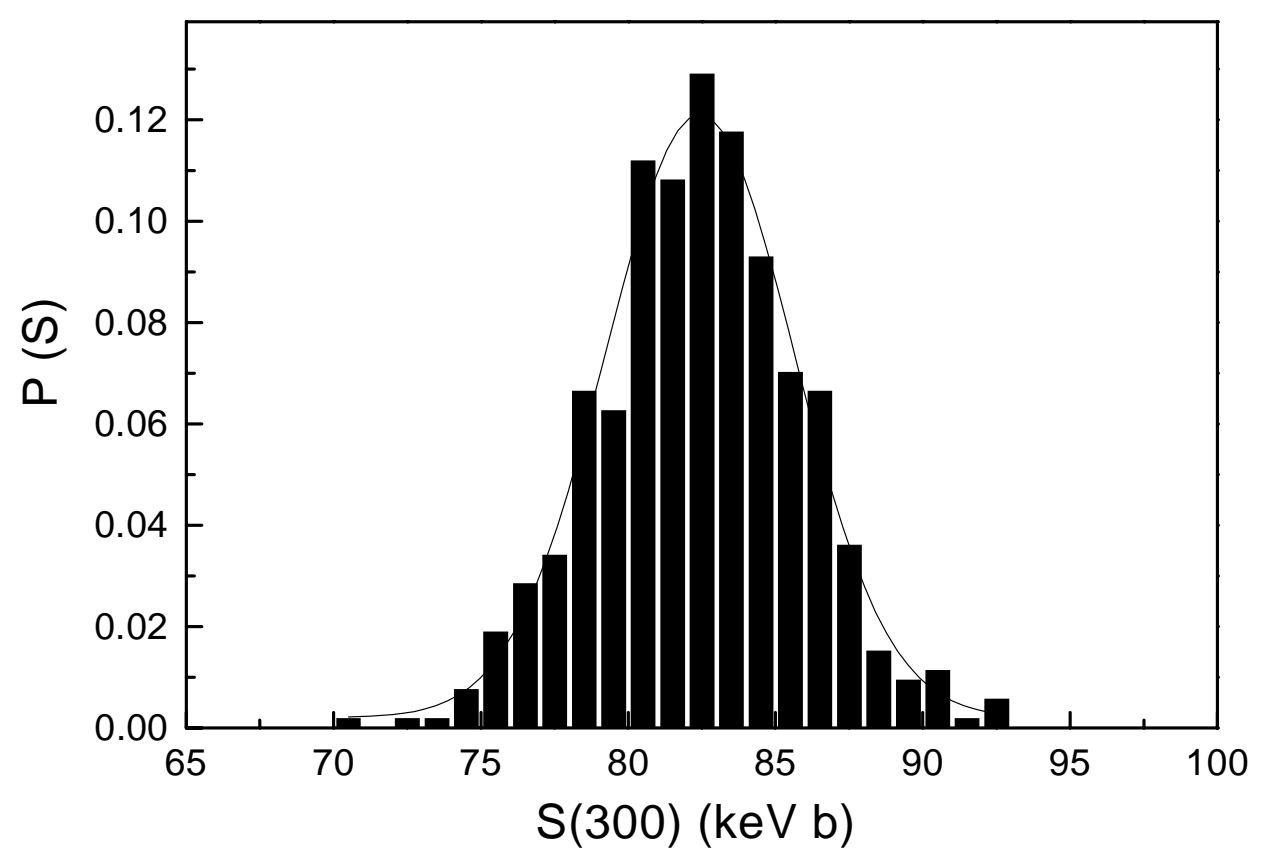

Figure 3.20: Probability distribution of $S_{E 1}(300)$ for constructive interference using the data of references $[14,13,17,16,12]$, those of the present work, and those of references $[22,20]$.

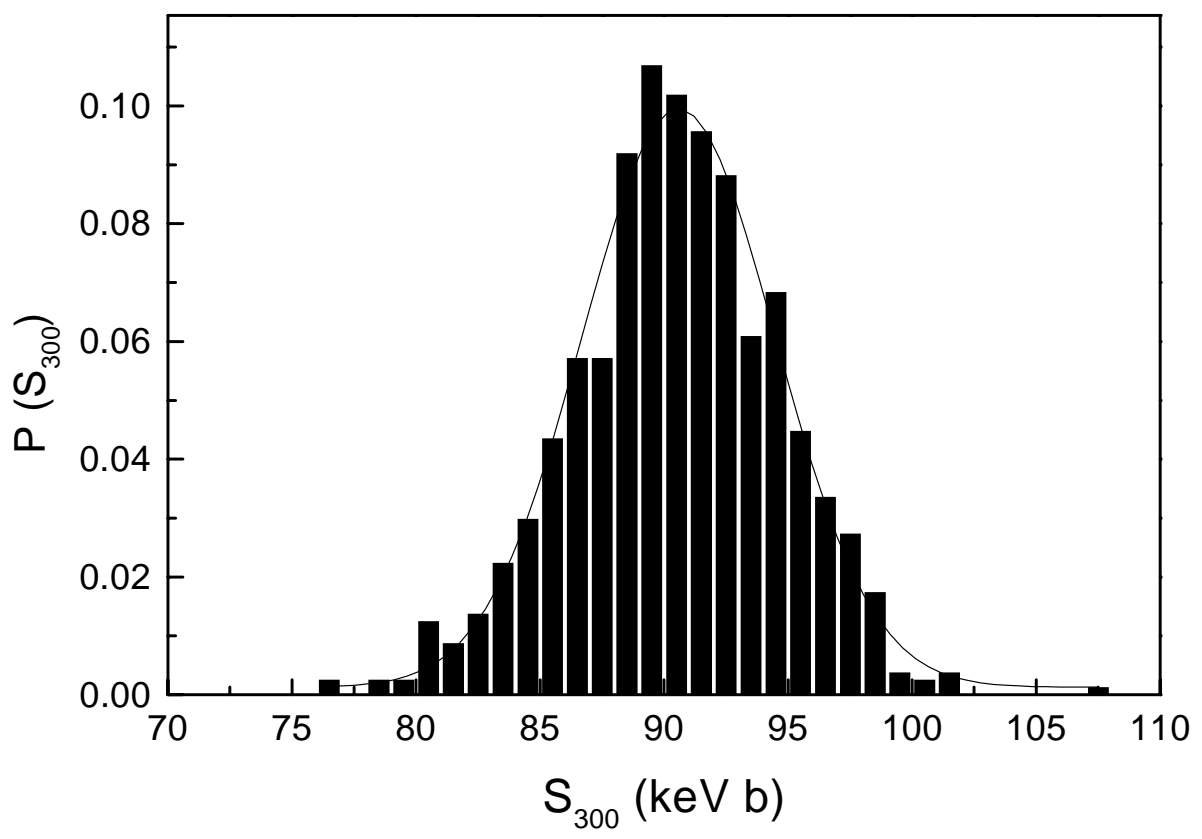

Figure 3.21: Probability distribution of $S_{E 1}(300)$ for the case of constructive interference using data of the present work and those of references [22, 20]. 


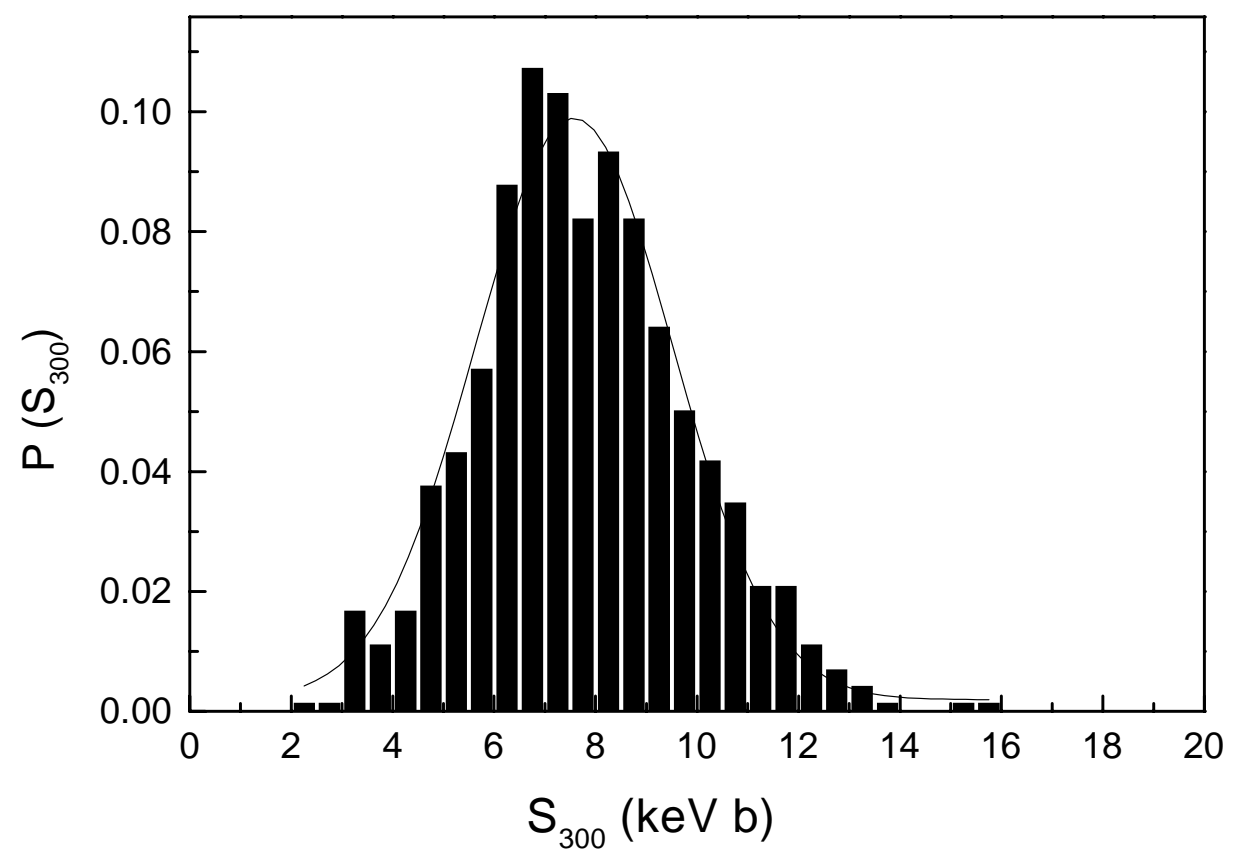

Figure 3.22: Probability distribution of $S_{E 1}(300)$ for the case of destructive interference using data of the present work and those of references $[22,20]$.

\begin{tabular}{|cccccccc|}
\hline Ref. & $\begin{array}{c}S_{C}(300) \\
(\mathrm{keV} \mathrm{b})\end{array}$ & $\begin{array}{c}\delta S_{C}(300) \\
(\mathrm{keV} \mathrm{b})\end{array}$ & $\chi_{C, \min }^{2}$ & $\begin{array}{c}S_{D}(300) \\
(\mathrm{keV} \mathrm{b})\end{array}$ & $\begin{array}{c}\delta S_{D}(300) \\
(\mathrm{keV} \mathrm{b})\end{array}$ & $\chi_{D, \text { min }}^{2}$ & $\nu$ \\
\hline$[14]$ & 81 & 4 & 196 & 6.2 & 1.7 & 219 & 183 \\
{$[17]$} & 80 & 4 & 174 & 9 & 2 & 174 & 171 \\
{$[16]$} & 87 & 4 & 170 & 5.8 & 1.7 & 189 & 168 \\
{$[12]$} & 86 & 5 & 172 & 9 & 2 & 179 & 173 \\
{$[13]$} & 87 & 4 & 196 & 4.9 & 1.7 & 222 & 185 \\
present & 90 & 4 & 175 & 8 & 2 & 187 & 179 \\
all & 82 & 4 & 317 & 2.5 & 0.5 & 383 & 264 \\
\hline
\end{tabular}

Table 3.1: Extrapolation to $E_{0}$ for different $\gamma$ data sets and the data of $[22,20]$ for both possible interference signs ( $C=$ constructive interference, $D=$ destructive interference).

The scattering of the data suggests to add $\pm 4 \mathrm{keV}$ b as an external error to the estimate of the error on $S_{E 1}(300)$. Finally propagating the uncertainty on the interaction radius, evaluated by means of a $\chi^{2}$ analysis to be equal to $\pm 0.5 \mathrm{fm}$, one gets an estimate $S_{E 1}(300)=82 \pm 16 \mathrm{keV}$ b. 


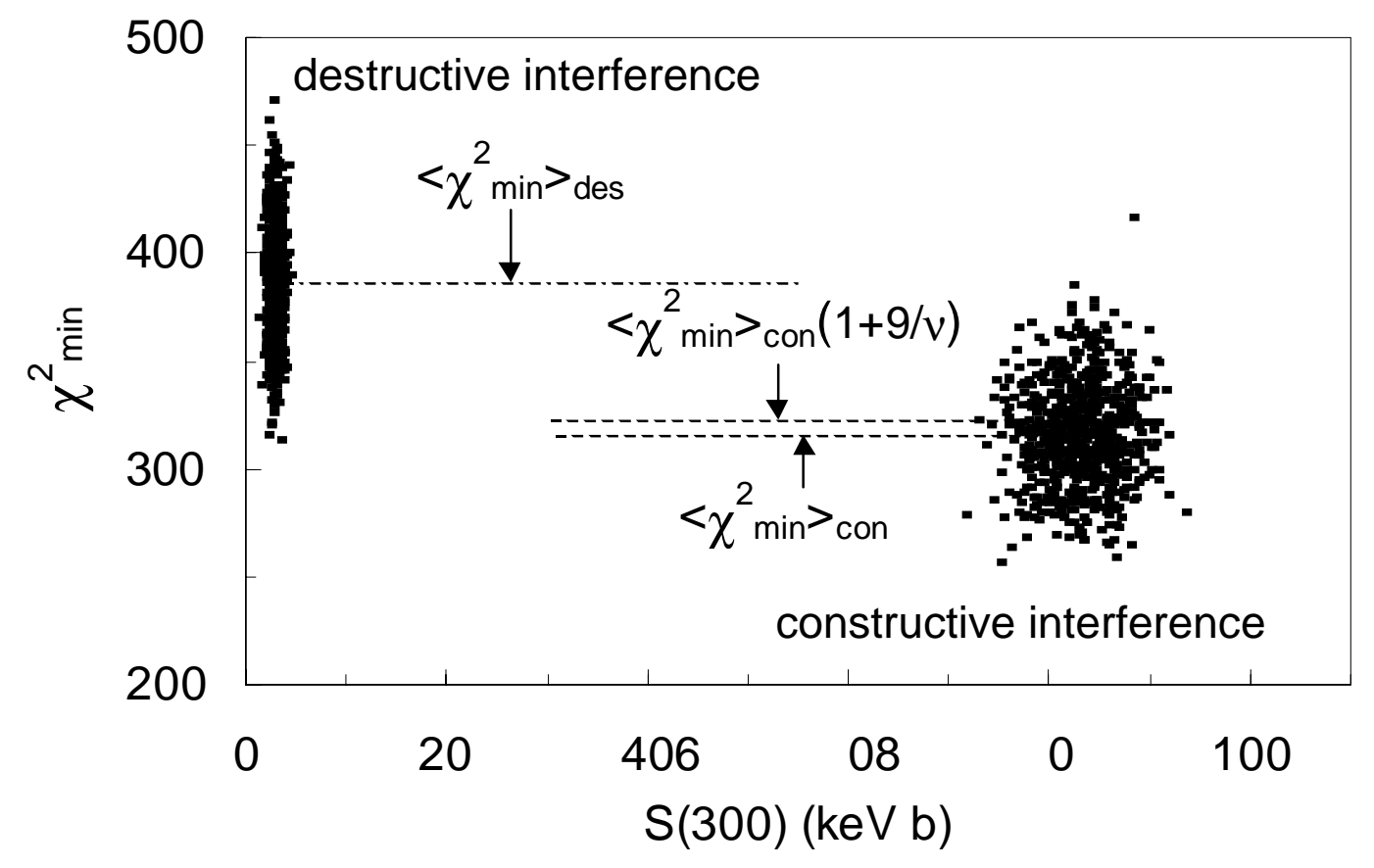

Figure 3.23: Distribution of the possible fits to the data in the $\chi_{m i n}^{2}-S_{E 1}(300)$ plane depending on the interference sign. The horizontal lines indicates the centroids of the two $\chi_{\min }^{2}$ distributions. In the case of constructive interference, a second line indicates the commonly accepted range of variation for $\chi^{2}$, i.e. from $\chi_{\min }^{2}$ to $\chi_{\text {min }}^{2}(1+9 / \nu)$, where $\nu$ is the number of degrees of freedom. The data from the present work and references $[14,13,17,16,12,22,20]$ were included in the fit

This value is in substantial agreement with the one of $79 \pm 21 \mathrm{keV}$ b quoted in [22] and seems to confirm that the $E 1$ component of the ${ }^{12} \mathrm{C}(\alpha, \gamma){ }^{16} \mathrm{O}$ reaction is rather well constrained by the available data. But a closer look at the different $\gamma$ data sets gives a different picture. To show this, I applied the Monte Carlo technique in order to study the effect of the two possible attributions of the interference sign between the two $1^{-}$resonances. Figure 3.23 shows the distributions of the fits obtained for both constructive and destructive interference signs in the $\chi_{\min }^{2}-S_{E 1}(300)$ plane. Using the prescription suggested in [22] to consider acceptable all fits with $\chi^{2}<\chi_{\min }^{2}(1+9 / \nu)$, where $\nu$ is the number of degrees of freedom, the constructive character of the interference term seems confirmed, although one should notice that the mentioned prescription is, according to the authors of reference [22] themselves, rather subjective and the $\chi^{2}$ distributions obtained with the present method suggest that this prescription might be too restrictive. On the other hand the situation looks different if one considers the individual data sets. For example, the same analysis performed on the data presented in this thesis produces the results shown 
in figure 3.24: here the difference between the two solutions is less significant and similar results were obtained for the data of references [16, 12]. Finally, in case of the data of reference [17], the two solutions give two equally good fits, as shown in figure 3.25. A glance at table 3.1 reveals that just the two remaining capture data sets, i.e. references $[14,13]$, give a strong preference to the constructive solution. In summary, the evident presence of systematic differences between the different data sets suggests that a combined fit to all of them can produce a biased estimate of $S_{E 1}(300)$. One might think of performing a fit to the individual data sets and then apply an external error to the estimate of $S_{E 1}(300)$ resulting from the analysis of all extrapolated values. This procedure would be also problematic, because, due to the discrete character of the interference sign, the resulting range for $S_{E 1}(300)$ would be splitted in two parts separated by about one order of magnitude, that is on average the ratio between the values of $S_{E 1}(300)$ obtained for constructive and destructive interference, respectively. Eventually one might re-analyze the available data sets, having access to the primary data, and look for the origin of the systematic differences and, if possible, correct for them. But most likely one has to perform new experiments.

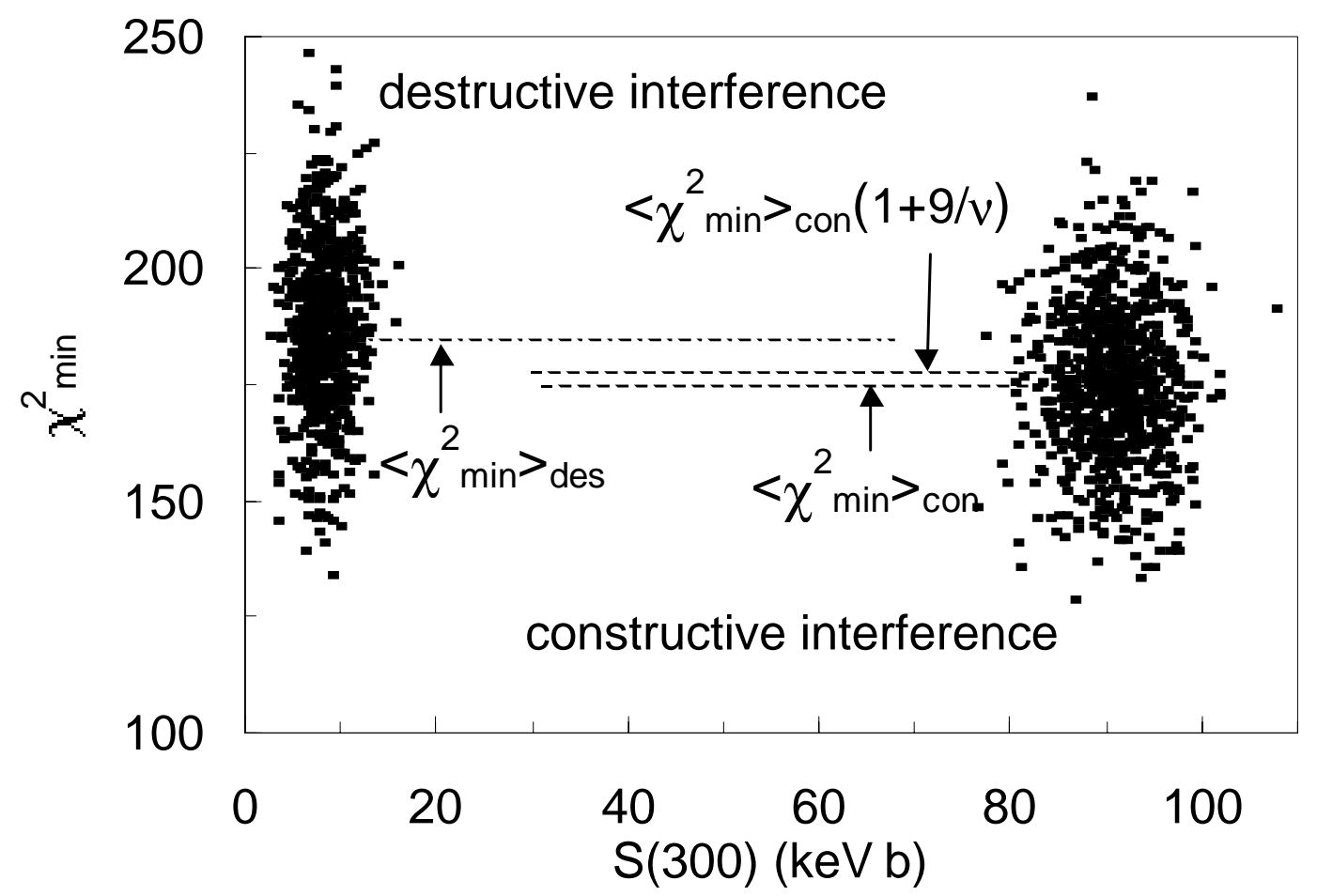

Figure 3.24: Results of the same analysis shown in figure 3.23. The data from the present work and references $[22,20]$ were included in the fit 
For example, the use of a recoil separator in order to detect the ${ }^{16} \mathrm{O}$ recoils in combination with a $\gamma$ detector array would allow to measure concurrently the total cross section $\sigma_{t o t}$ and its components $\sigma_{E 1}$ and $\sigma_{E 2}$ in a nearly background free condition over a broad energy range, extending from below $1 \mathrm{MeV}$ to about $5 \mathrm{MeV}$, centerof-mass energy: the comparison of these three quantities would additionally provide informations about possible non radiative transitions (see section 1.2.4). Finally, one should note that high energy data, say above $E=3 \mathrm{MeV}$ are strongly needed, because they would put some constraints on the background level.

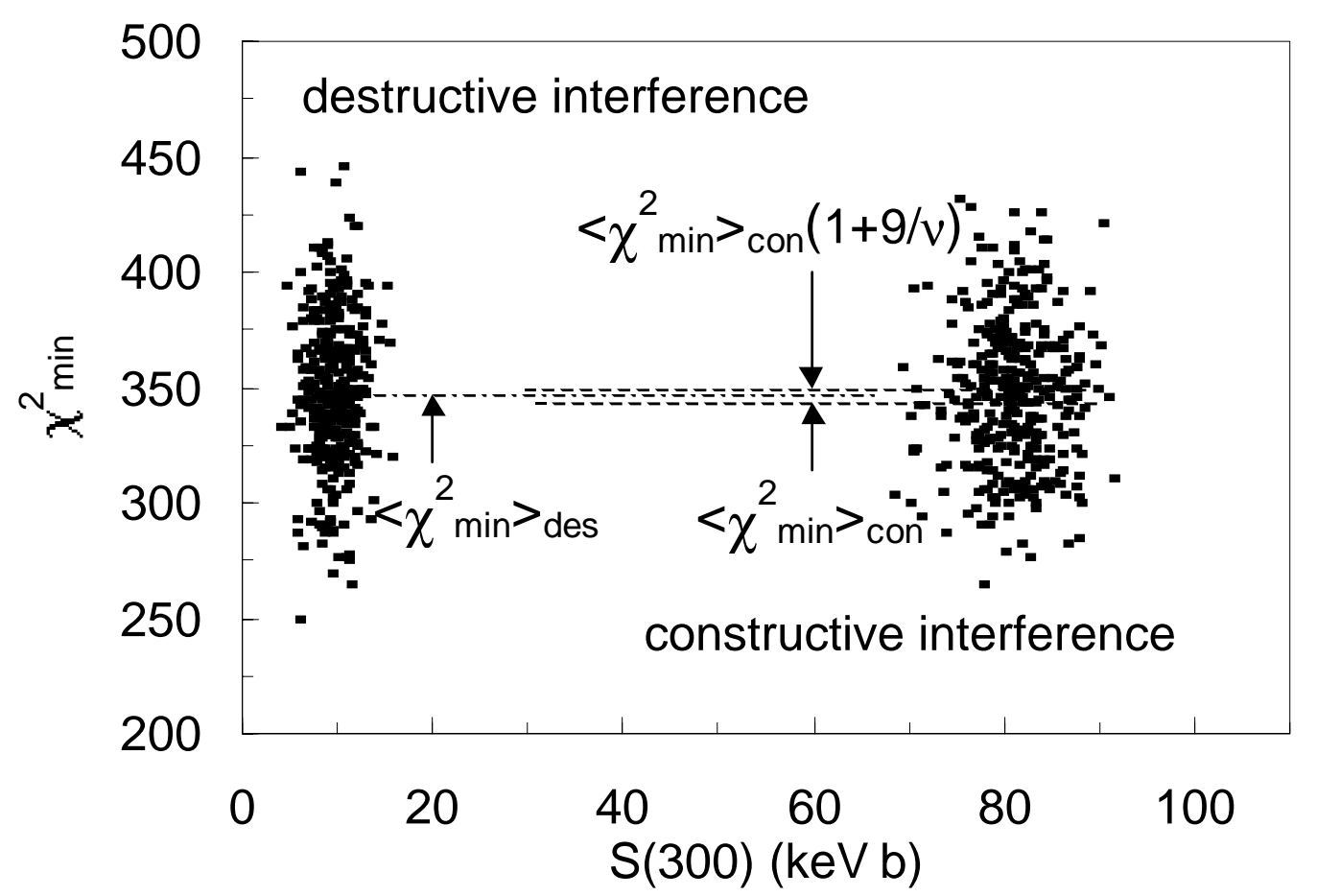

Figure 3.25: Results of the same analysis shown in figure 3.23. The data from the reference [17] for the radiative capture and from $[22,20]$ were included in the fit (see the text) 


\section{Epilogue}

The experimental program planned for the present thesis has been fulfilled: the $E 1$ component of the ground state transition in ${ }^{12} \mathrm{C}(\alpha, \gamma){ }^{16} \mathrm{O}$ has been measured over a wide energy range $(E=1.3$ to $3.0 \mathrm{MeV})$ using a $\gamma$ detection setup essentially insensitive to the $E 2$ component. The use of HPGe detectors in combination with a gas target and an efficient active and passive shielding allowed to obtain spectra of very good quality all over the investigated energy range. Therefore, possible systematic errors arising from an incorrect analysis of the spectra, and particularly of the background, should have been avoided. On the other hand, the price for this setup was a significant reduction of the detection efficiency, that limited the achievable precision, essentially because of the worsening of the signal-to-background ratio. The measured excitation function was extrapolated using a 3 level R-matrix fit. The uncertainty on the extrapolated value was obtained by means of an original Monte Carlo technique. If one considers this data set as the only radiative capture one in a combined fit with the ${ }^{16} \mathrm{~N} \beta$-delayed $\alpha$ decay and ${ }^{12} C(\alpha, \alpha){ }^{12} C$ data, one gets a value $S_{E 1}(300)=90 \pm 16 \mathrm{keV}$ b. This value is comparable with the today's commonly accepted value $S_{E 1}(300)=79 \pm 21 \mathrm{keV}$ b, obtained from a combined fit considering all available $(\alpha, \gamma)$ capture data. On the other hand, the sign of the interference term between the two $1^{-}$levels at $E_{x}=7.12$ and $9.58 \mathrm{MeV}$ is not well constrained as commonly thought. The analysis of each available $(\alpha, \gamma)$ capture data set alone shows that the attribution of the interference sign is not univocal and it seems not correct, from the statistics point of view, to perform global fits on data sets that are in disagreement with each other. The question on the interference sign between the two levels could be solved if one could obtain data below $E=1 \mathrm{MeV}$, where the difference between the two solutions increases steeply. Even having the necessary resources, one could increase the detection efficiency by something like a factor 4 , at least keeping a far geometry, that would be not enough for the low-energy neither or high energy $(E>3 \mathrm{MeV})$ data; the latter data are also highly desirable, because they would constrain the parameters of the background $E 1$ amplitude. Therefore by means of $\gamma$ spectroscopy alone, one will hardly get useful information, unless one does not find a way to efficiently suppress the background. A possibility is given by the use of a $\gamma$ detector array in combination with a recoil 
separator: the coincidence condition between the $\gamma$-rays and the ${ }^{16} \mathrm{O}$ recoils in the separator would substantially eliminate the background. Moreover, the recoil yield would provide a concurrent measurement of the total cross section. Such a system is presently under construction at the Dynamitron Tandem Laboratorium in Bochum and it is expected to be ready by summer of 2001 . 


\section{Acknowledgments}

This work would not have been possible without the contribution of many persons. In spite of their number, here I wish to thank them all and I hope not to forget anyone.

My special thanks go to:

Prof. Dr. Claus Rolfs, chairholder of the Institut für Experimentalphysik III at the Ruhr-Universität Bochum, for having given me the possibility of studying and working in an exciting and comfortable atmosphere and for proposing me the theme of the present work. He constantly supported me during the experiment and during the time I needed to complete the analysis,

P.D. Dr Hans Peter Trauttvetter for having introduced me to the procedure of the peak form analysis of the spectra and for the many discussions about ${ }^{12} \mathrm{C}(\alpha, \gamma){ }^{16} \mathrm{O}$, Dr. Frank Strieder, for his help during the experiment, especially for taking care of the design of the mounting for the HPGe detectors and of the target chamber, for his great help during my first period in Bochum, and some help with German language,

Detlef Rogalla, for providing most of the routines I used for my Geant simulations, for having survived more than three years sharing our room at the EPIII, for his help to solve many problems during the experiment and also some help with German,

Dr. Marialuisa Aliotta, Frank Schümann, Sabine Theis for much help during the long beam time,

Dr. Uwe Greife, for some discussions during the planning of the experiment,

Klaus Brand and all operators at the DTL (Arnd Apool, Thomas Brandner, Helmut Schöngraf, Rolf Wylich), for their successful efforts to provide over about eight months a very intense and stable ${ }^{12} \mathrm{C}$ beam,

Gyury "George" Gyurky, and Dr. Endre Somorjai (ATOMKI, Debrecen) for all they did during the long beam time,

Prof. Dr. Filippo Terrasi and Prof. Dr. Antonio D'Onofrio (Seconda Universita di Napoli) for many interesting discussions about statistics and $\gamma$-spectroscopy and some good tips for the analysis of the spectra, besides what they did during the experiment,

Prof. Dr. Mario Romano (Universita di Napoli Federico II), for his many sug- 
gestions, and the whole group from Naples, Dr. Luigi Campajola, Dr. Gianluca Imbriani and, from Avellino, Dr. Vincenzo Roca, for their help during the beam time,

Prof. Dr. Claudio Spitaleri, Dr. Titti Agodi, Dr. Antonio Del Zoppo, Dr. Pierpaolo Figuera, Dr. Piera Sapienza (INFN Catania) for their precious contribution to set the detection system up and for providing the HPGe detectors,

Prof. Dr. Richard E. Azuma (University of Toronto), for his R-matrix code, for the many tips about its use, for many interesting remarks and for his extraordinary nice hospitality in Toronto,

Mr. Kurt Becker and the staff of the mechanical workshop in Bochum, for their very accurate work, for their help in finding good solutions for the gas target and the detector mountings, and for the patience they had in interpreting some not very clear technical drawings,

Bodo Niesler and the staff of the electronic workshop in Bochum for quickly repairing some electronic units and control systems that had a failure during the experiment, Helmut Przygoda and Gisbert Krüger, for taking care of helium gas and liquid nitrogen provision,

Pasquale Parascandolo and Alfonso Boiano (Electronic workshop INFN Napoli) for the pattern unit and some $\mathrm{CF}$ discriminators that were used during some preliminary tests,

Stefan Kubsky (the Camera-Man, figure 10), for the nice photographs of the experimental setup, and all people at EPIII: P. Baving, Dr. H.-W. Becker, Dr. H.H. Bukow, Dr. Matthias Junker, Dr. J. Meijer, H. Röcken, Dr. Georg Roters, Dr. Daniela Schmidt, Dr. Stefan Schmidt, Dr. H.W. Schulte, Dr. A. Stephan, Prof. Dr. E. Träbert, U. Weidenmüller.

My everlasting gratitude goes to Dr. Nunzio Itaco, who helped me very much in editing my thesis: he might be happy to know that I finally learned how to use Latex, so he should not fear about the future.

A special thank goes to my parents for having always supported me.

Finally I would like thank Debora and Manuela: my work would have been very difficult without them. The present thesis is dedicated to them. 


\section{Data tables}

\begin{tabular}{|ccc|}
\hline $\begin{array}{c}E \\
(\mathrm{MeV})\end{array}$ & $\begin{array}{c}\sigma_{\gamma} \\
(\mathrm{nb})\end{array}$ & $\begin{array}{c}\delta \sigma_{\gamma} \\
(\mathrm{nb})\end{array}$ \\
\hline 1.320 & 0.28 & 0.10 \\
1.476 & 0.80 & 0.13 \\
1.842 & 3.6 & 0.5 \\
1.933 & 5.4 & 1.2 \\
2.039 & 9.4 & 1.9 \\
2.216 & 26 & 4 \\
2.250 & 34 & 4 \\
2.270 & 35 & 7 \\
2.355 & 49 & 5 \\
$2.365(a)$ & $54^{(a)}$ & $1.6(b)$ \\
2.381 & 49 & 7 \\
2.386 & 45 & 6 \\
2.403 & 51 & 6 \\
2.498 & 34 & 13 \\
2.516 & 34 & 4 \\
2.545 & 18 & 6 \\
2.590 & 21 & 4 \\
2.793 & 6.9 & 0.7 \\
2.937 & 4.9 & 0.9 \\
2.992 & 3.2 & 0.6 \\
\hline
\end{tabular}

Table 1: ${ }^{12} \mathrm{C}(\alpha, \gamma){ }^{16} \mathrm{O}$ cross section measured in the present work. The quoted errors are the statistical errors on the relative yield curve, i.e. do not include the accidental error arising from the normalization $\left(\right.$ see $\left.^{(b)}\right)$. ${ }^{(a)}$ Absolute value measured relative to ${ }^{1} \mathrm{H}\left({ }^{19} \mathrm{~F}, \alpha \gamma\right){ }^{16} \mathrm{O}$ (see section 3.1.4). ${ }^{(b)}$ The statistical error considering also the error on the normalization constant is $\pm 6 \mathrm{nb}$. This error has to be propagated to the whole data set as an accidental error. 


\begin{tabular}{|ccc|}
\hline $\begin{array}{c}E \\
(\mathrm{MeV})\end{array}$ & $\sigma_{e l} / \sigma_{R}$ & $\delta \sigma_{e l} / \sigma_{R}$ \\
\hline 1.100 & 1.05 & 0.03 \\
1.225 & 1.00 & 0.03 \\
1.287 & 0.920 & 0.017 \\
1.350 & 0.98 & 0.03 \\
1.475 & 1.01 & 0.03 \\
1.600 & 0.99 & 0.03 \\
1.663 & 0.92 & 0.03 \\
1.726 & 1.05 & 0.03 \\
1.788 & 0.98 & 0.03 \\
1.851 & 1.02 & 0.03 \\
1.976 & 1.05 & 0.03 \\
2.039 & 1.04 & 0.03 \\
2.101 & 1.14 & 0.04 \\
2.164 & 1.15 & 0.04 \\
2.227 & 1.25 & 0.03 \\
2.289 & 1.21 & 0.04 \\
2.289 & 1.22 & 0.03 \\
2.352 & 1.30 & 0.04 \\
2.414 & 1.14 & 0.04 \\
2.477 & 1.13 & 0.03 \\
2.602 & 0.90 & 0.03 \\
2.728 & 0.85 & 0.02 \\
2.853 & 0.87 & 0.03 \\
2.978 & 0.773 & 0.017 \\
3.103 & 0.78 & 0.02 \\
\hline & & \\
\end{tabular}

Table 2: Ratio of the ${ }^{12} \mathrm{C}+\alpha$ elastic scattering cross section to the Rutherford elastic scattering cross section measured in the present work. 


\section{Some photographs}

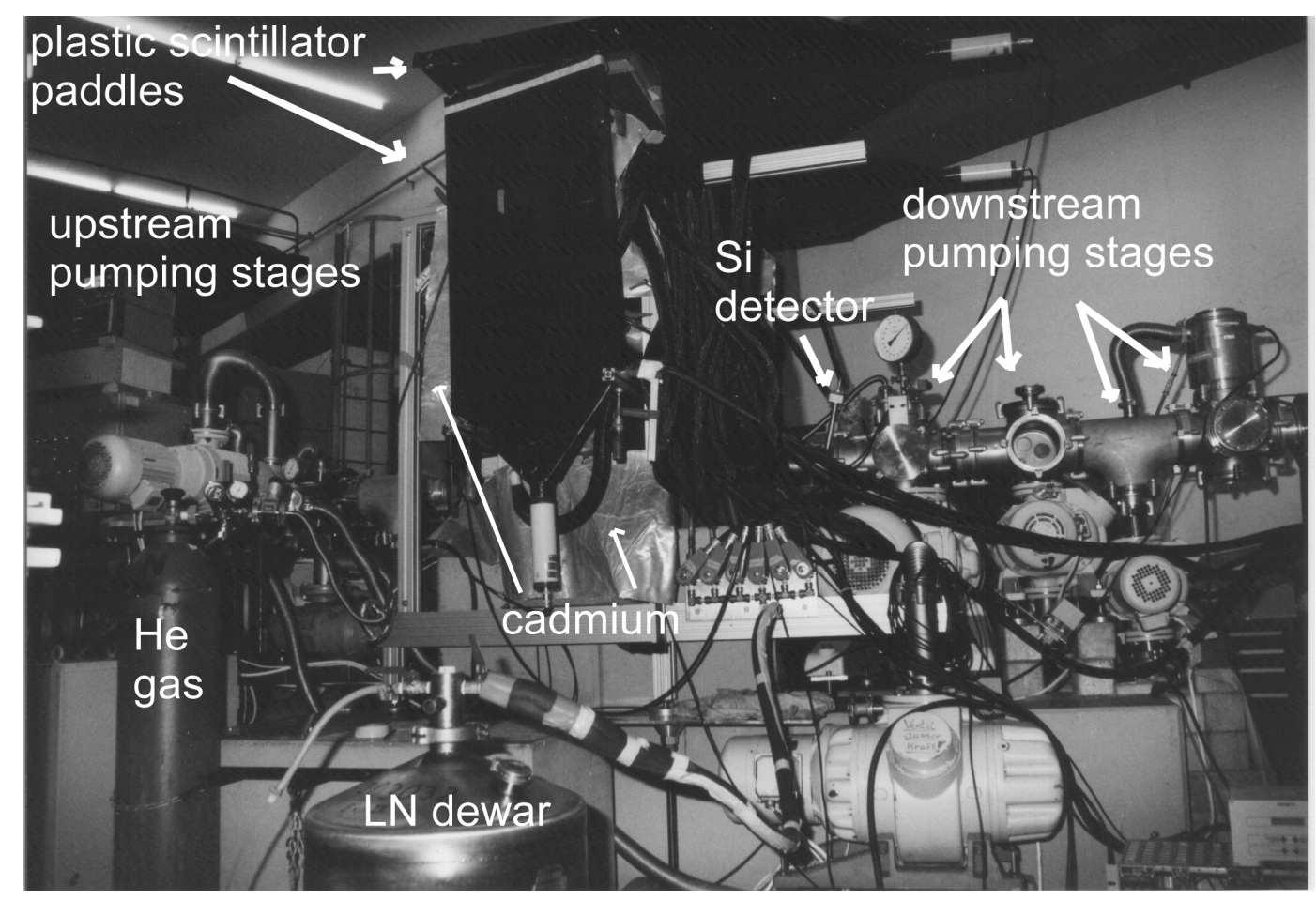

Figure 1: The complete experimental setup seen from the side. 


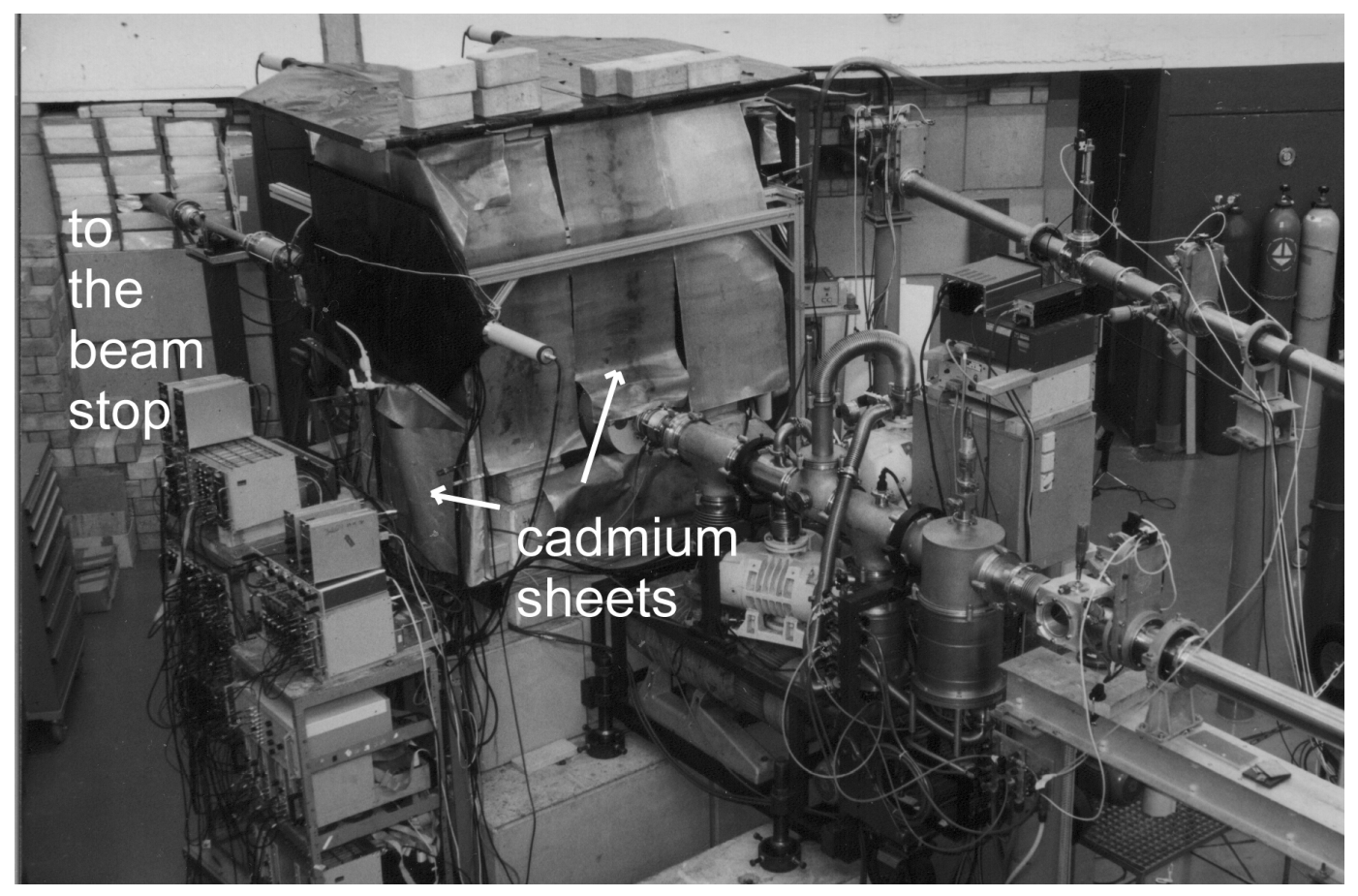

Figure 2: The experimental setup without some plastic scintillator paddles: the cadmium layer surrounding the inner lead detector shielding is partly visible.

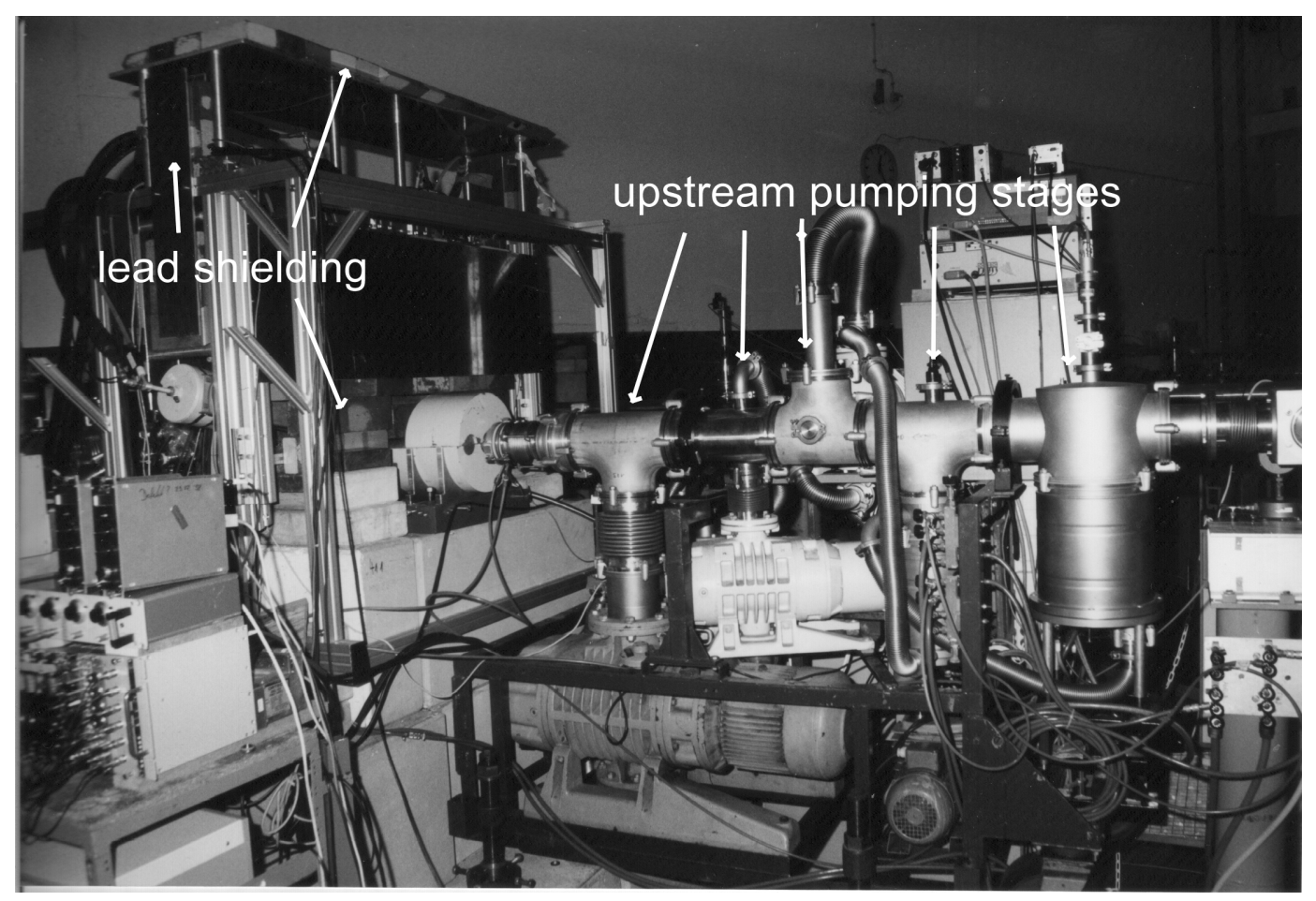

Figure 3: The upstream side of the gas target. The paddles and the cadmium sheets removed and the detector lead shielding is partly visible 


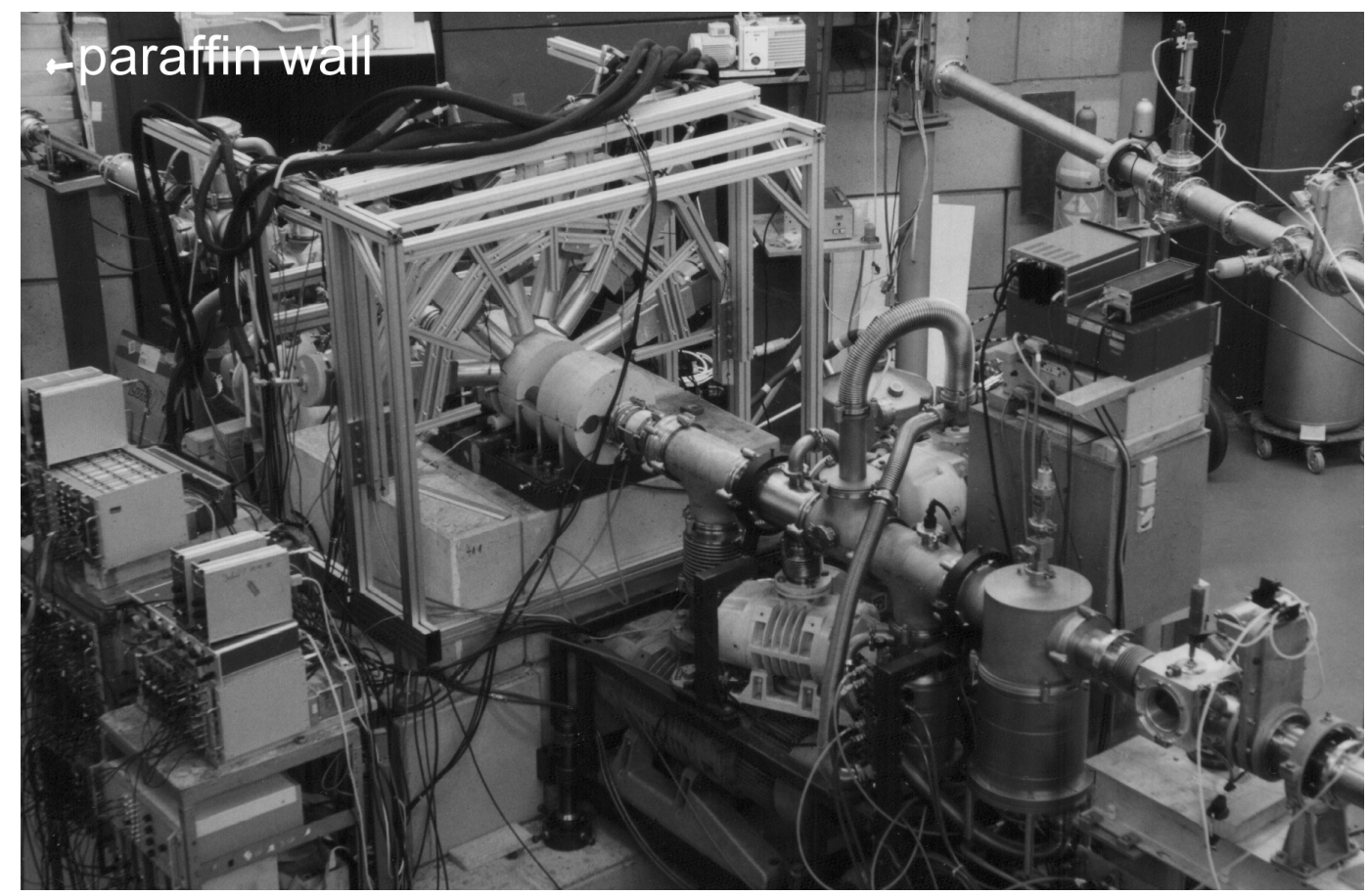

Figure 4: The experimental setup after the removal of all shieldings.

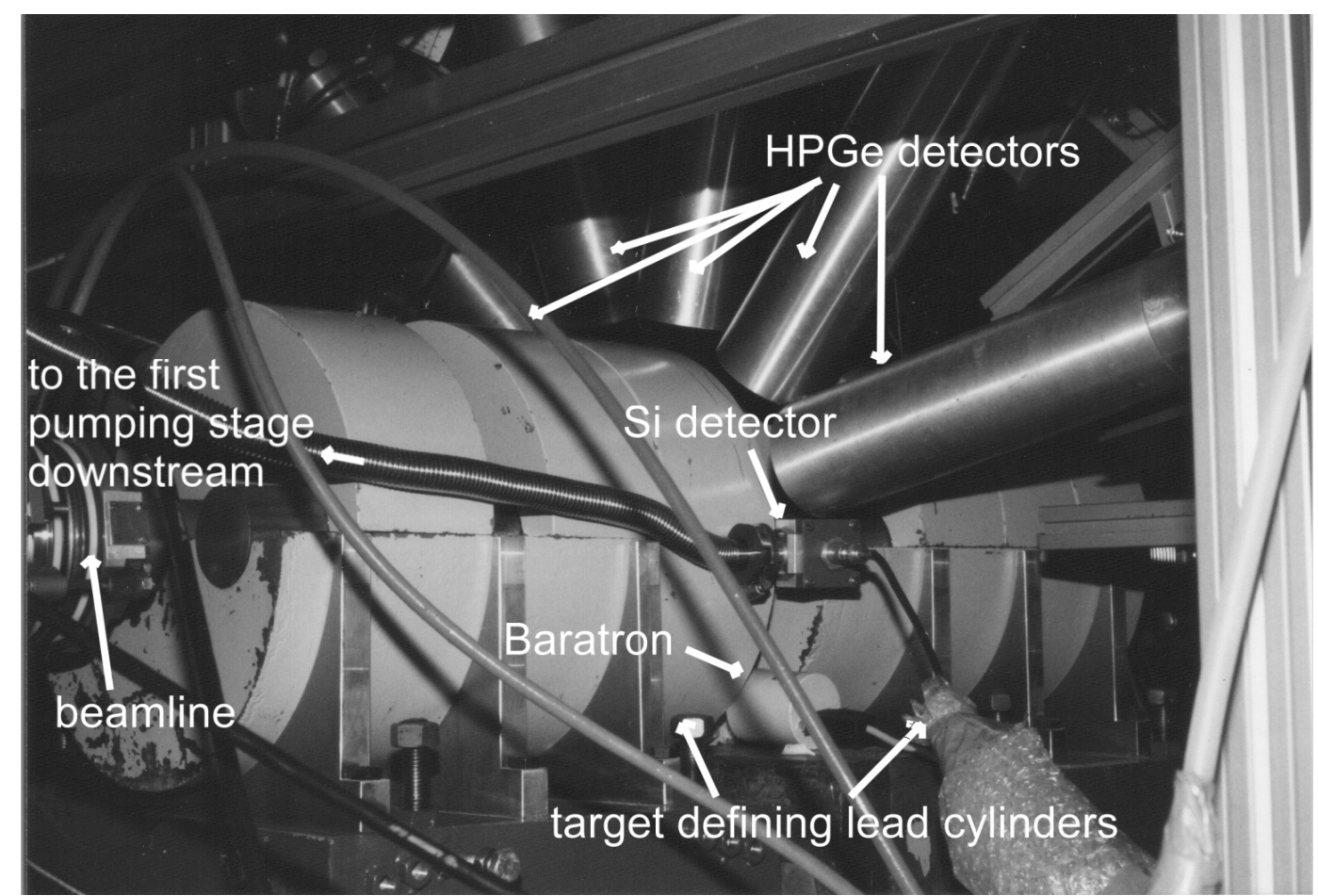

Figure 5: The inner part of the experimental setup: the target defining lead cylinders and the detectors. 


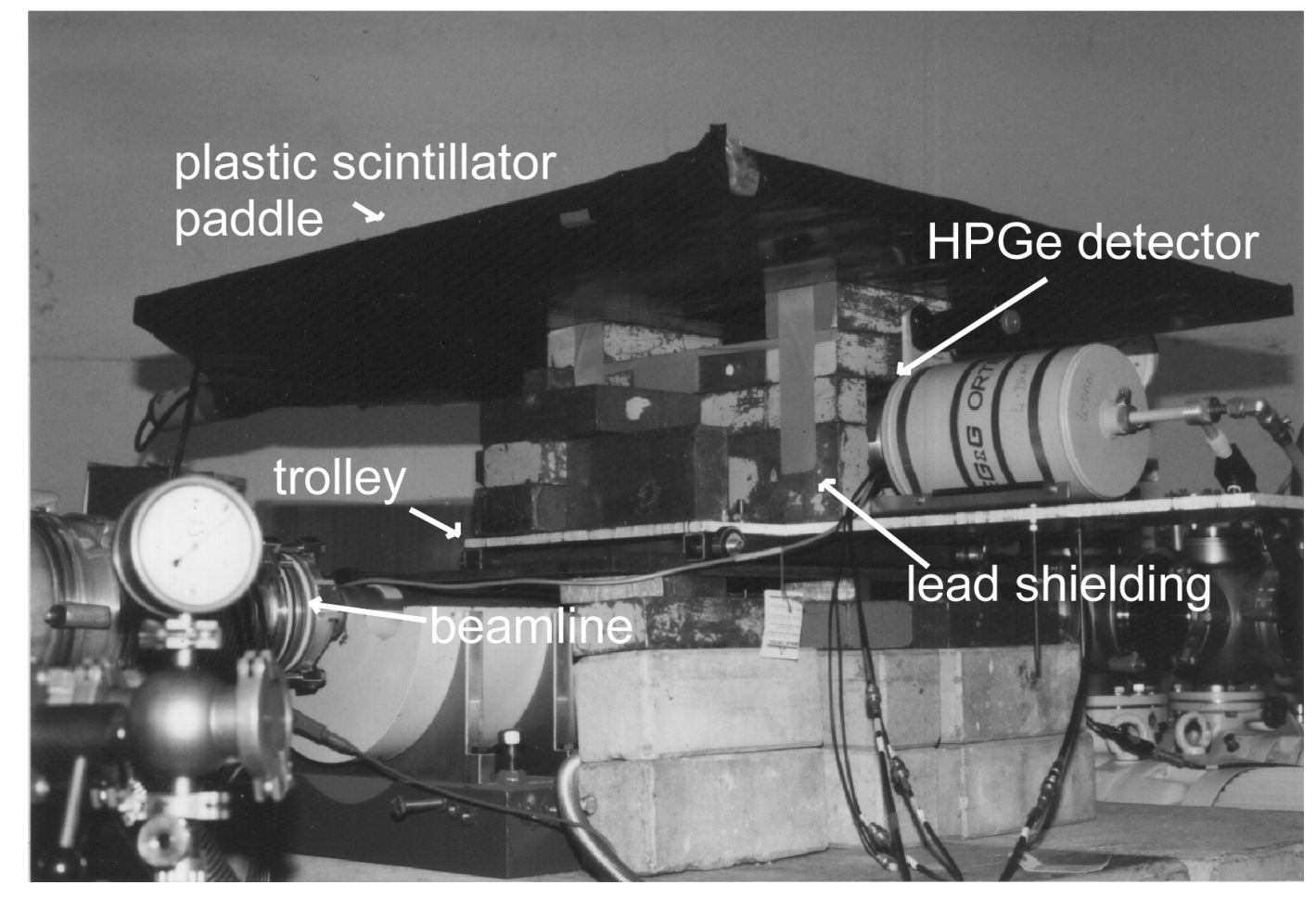

Figure 6: The experimental setup used to measure the gas target pressure profile.

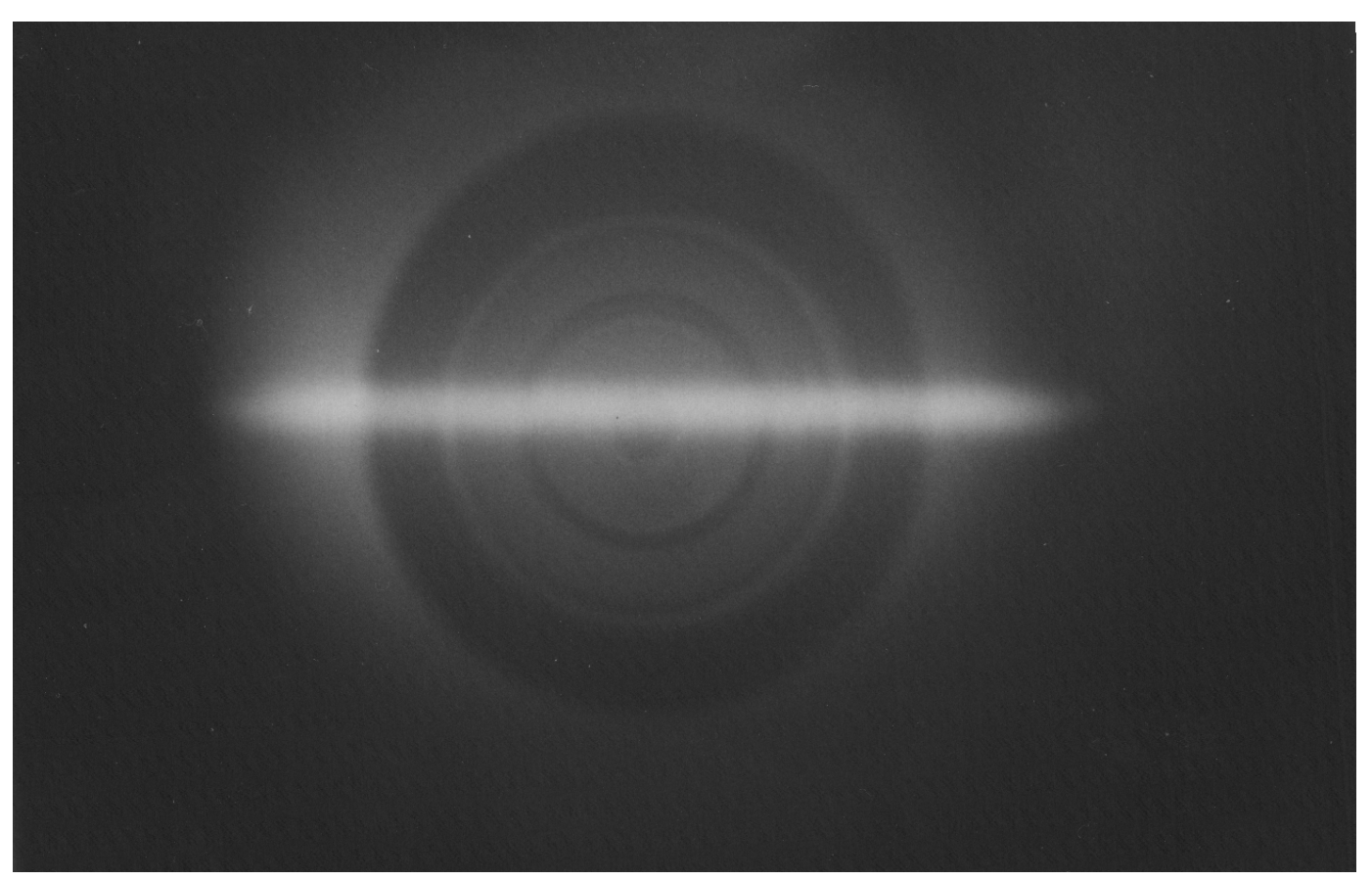

Figure 7: The ${ }^{12} \mathrm{C}$ ion beam in ${ }^{4} \mathrm{He}$ gas photographed through a transparent flange on the second pumping stage down stream 


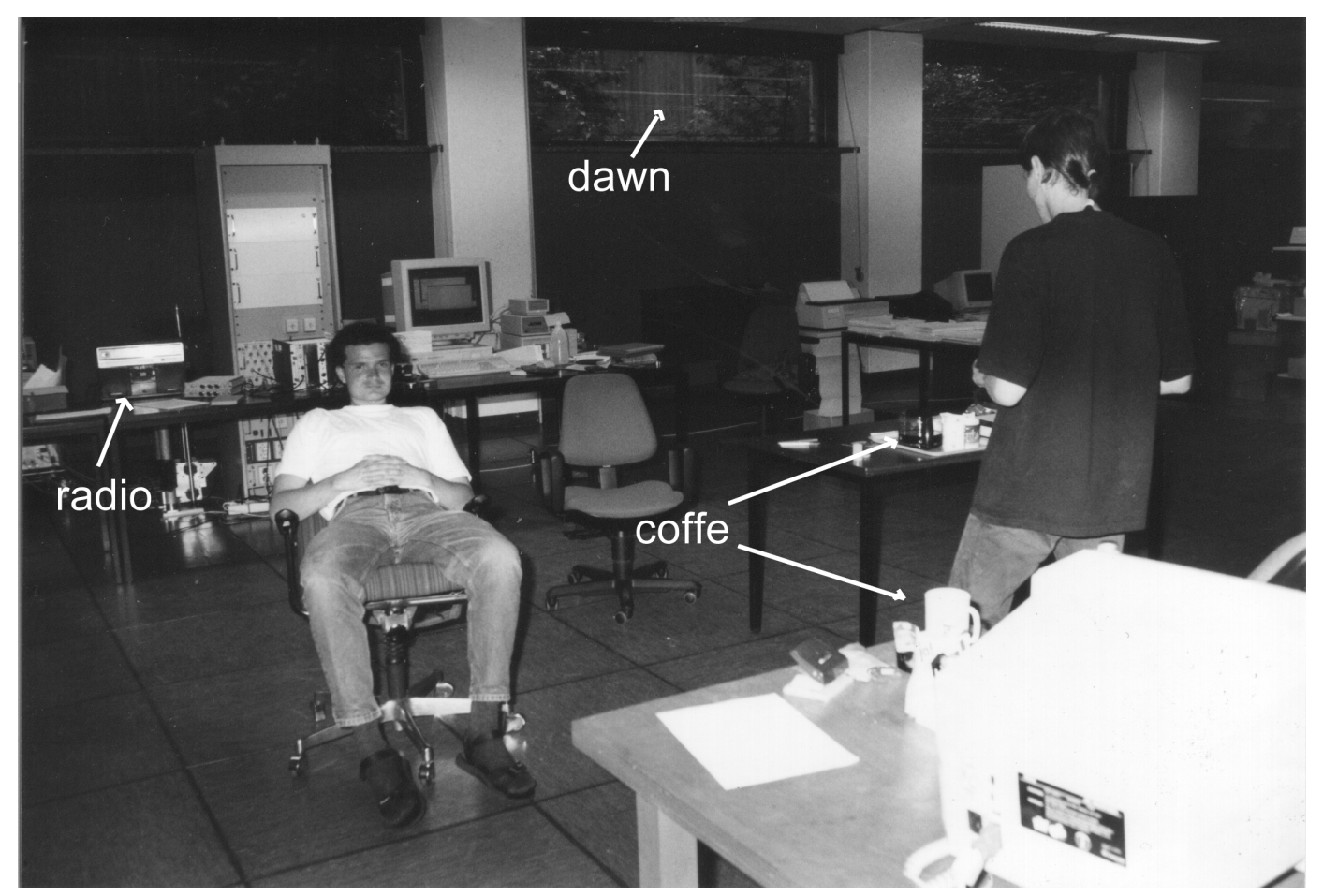

Figure 8: After a night shift.

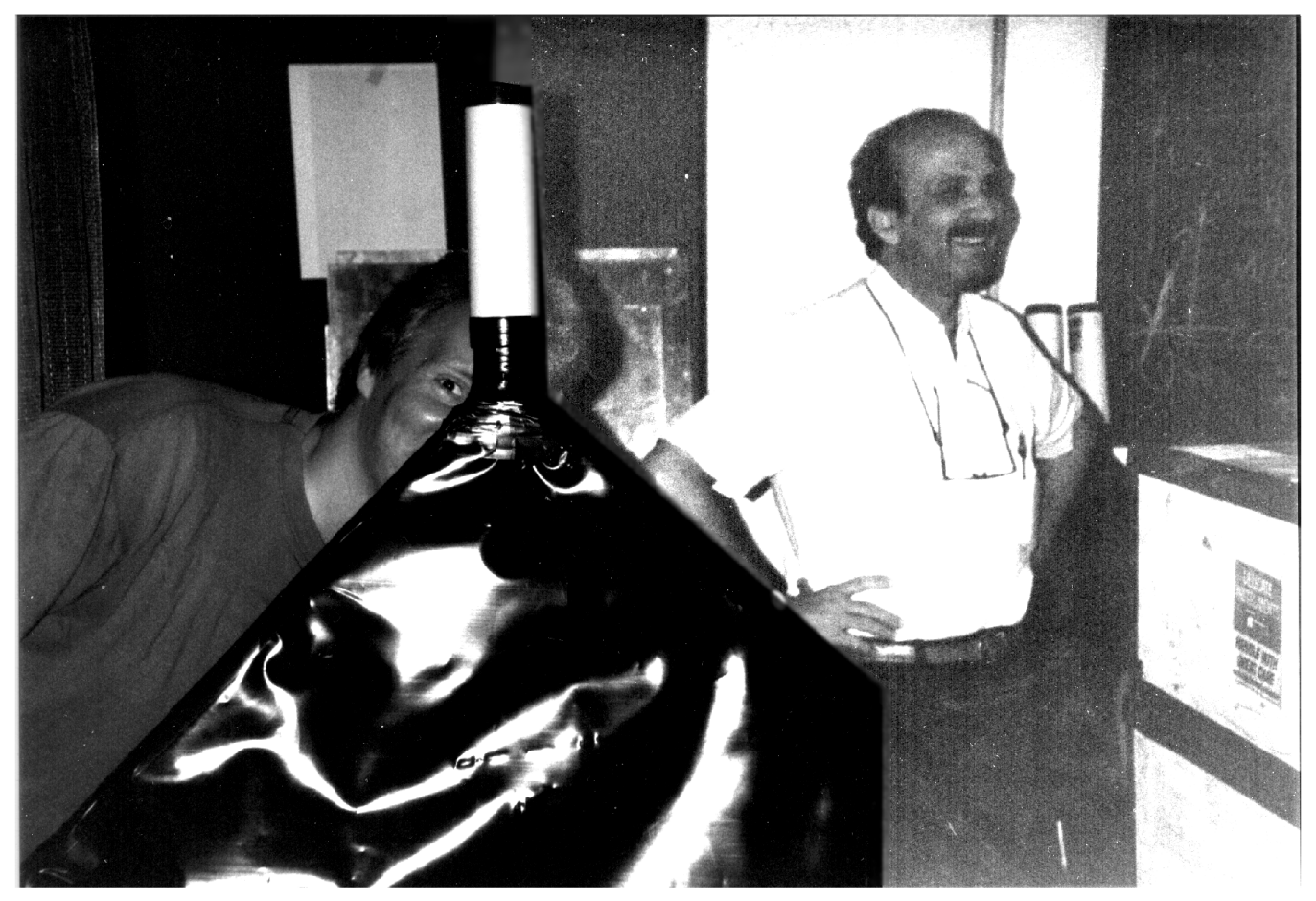

Figure 9: Active shielding misunderstood. 


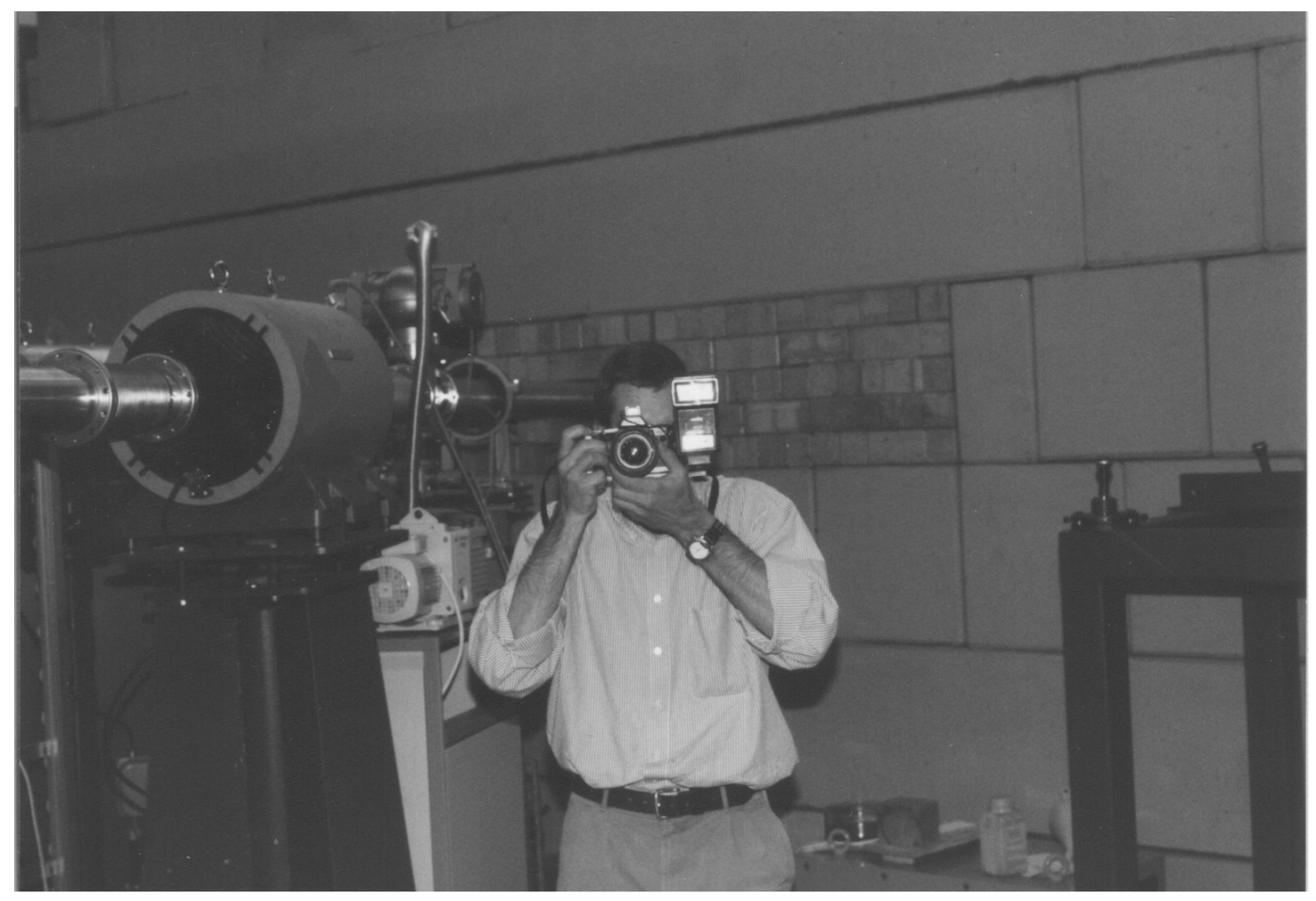

Figure 10: The Camera-Man.

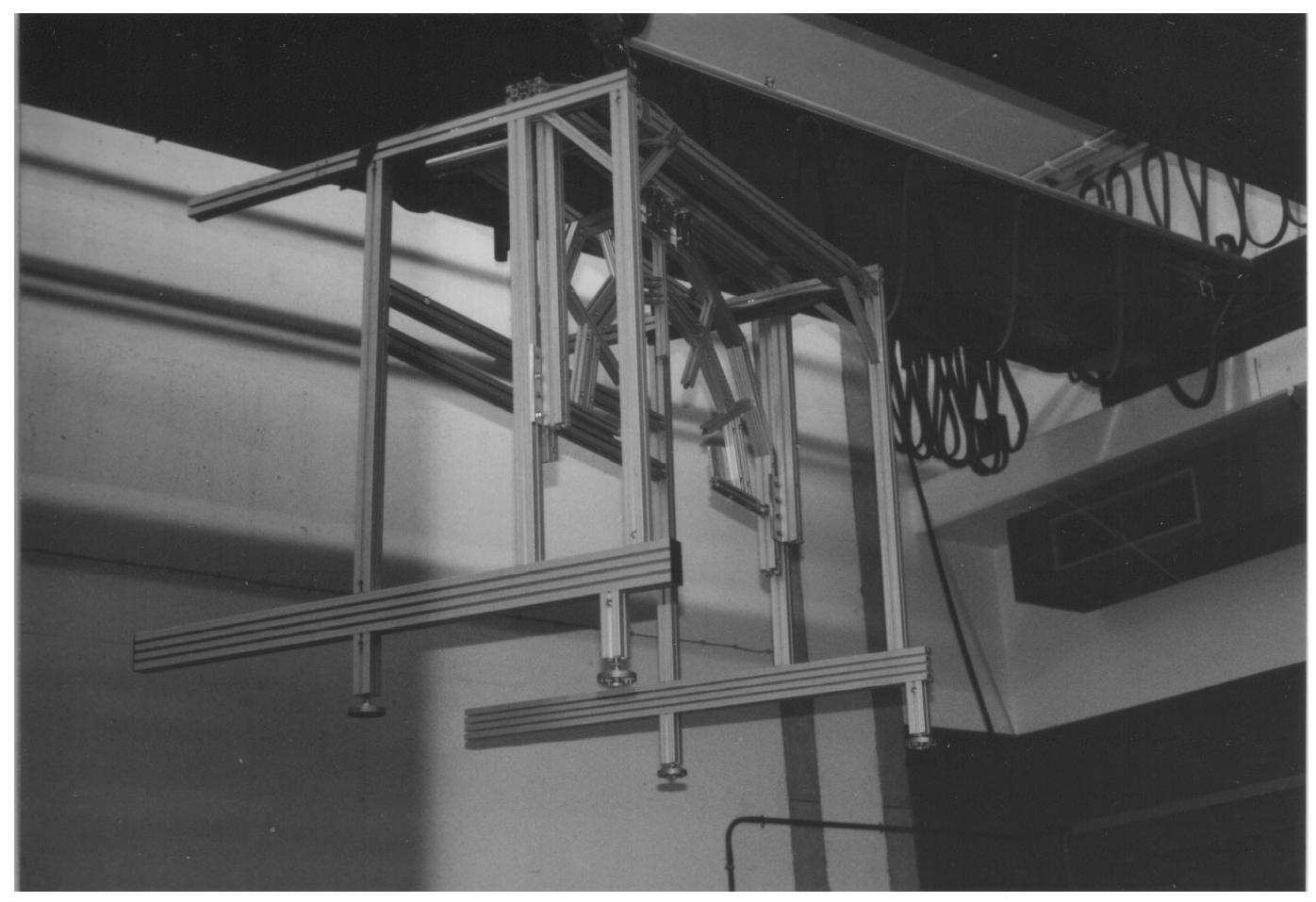

Figure 11: Dismounting the experiment. 


\title{
Deutschsprachige Zusammenfassung
}

\author{
Eine neue Messung der E1 Amplitude in ${ }^{12} \mathrm{C}(\alpha, \gamma){ }^{16} \mathrm{O}$ \\ Kapitel $1 .{ }^{12} \mathrm{C}(\alpha, \gamma){ }^{16} \mathrm{O}$ in den Sternen und im Labor
}

Die elementaren Prozesse der Sternentwicklung und der Elementsynthese sind heute verstanden und allgemein akzeptiert. Dennoch gibt es im Detail viele Fragestellungen und Probleme, die sich auch weiterhin und trotz enormer experimenteller Anstrengungen einem eindeutigen Verständnis entziehen. Im Rahmen der Nuklearen Astrophysik und der Physik der Sternmodelle trifft dies insbesondere auf den Wirkungsquerschnitt der Kernreaktion ${ }^{12} \mathrm{C}(\alpha, \gamma){ }^{16} \mathrm{O}$ zu. Diese Reaktion ist von großer Bedeutung für das Heliumbrennen in Sternen und hat Auswirkungen auf eine ganze Reihe von Entwicklungsszenarien im Leben der Sterne.

Die Energieerzeugung im Inneren der Sterne läuft über eine Kette von verschiedenen Brennphasen ab, die jeweils dafür sorgen, daß sich ein hydrostatisches Gleichgewicht zwischen dem nach außen wirkenden Strahlungsdruck (erzeugt durch $\gamma$-Quanten aus den verschiedenen Kernreaktionen) und der nach innen wirkenden Gravitationskraft ausbildet. Dieser Prozeß beginnt mit dem Wasserstoffbrennen, bei dem vier Protonen zu einem Helium-Kern fusionieren.

Während dieser ersten Brennphase wird somit der Wasserstoff im Kern des Sterns kontinuierlich in Helium umgewandelt. Ist der Wasserstoff soweit verbraucht, daß der Strahlungsdruck durch die Energieproduktion nicht mehr aufrecht erhalten werden kann, beginnt der Stern zu kontrahieren, was zu einer Temperaturerhöhung im Kern führt. Bei Temperaturen in der Größenordnung von $10^{8} \mathrm{~K}$ zündet dann das Heliumbrennen. Dabei werden zunächst drei Helium-Kerne, im sogenannten Tripel- $\alpha$ Proze $\beta$, zu Kohlenstoff verbrannt, der über die Reaktion ${ }^{12} \mathrm{C}(\alpha, \gamma){ }^{16} \mathrm{O}$ in Sauerstoff umgewandelt wird. Eine Erzeugung weiterer Elemente ist in dieser Phase unterdrückt. 
In gleicher Weise kommt es zu weiteren Brennphasen, in denen dann die schwereren Elemente erzeugt werden, so daß am Ende ein Stern mit einem Eisenkern und einer Schalenstruktur aus den übrigen Elementen, die als Asche aus den verschiedenen Brennphasen übrig geblieben sind, entstanden ist. Eisen ist das Endprodukt dieser Kette, da bei noch schwereren Elementen in Fusionsprozessen keine Energie mehr gewonnen werden kann. Die Konsequenz daraus ist, daß keine Quelle für die Aufrechterhaltung des hydrotatischen Gleichgewichtes mehr vorhanden ist. Der Stern kollabiert vollständig und bläst die erzeugten Elemente in einer gewaltigen Explosion in die Umgebung. Dieses Ereignis bezeichnet man als eine Supernova Typ II, wobei natürlich der genaue Ablauf aller genannten Szenarien sehr stark von der Masse des Sterns abhängt und Supernova-Explosionen nur in massiven Sternen vorkommen können, da nur dort ausreichend hohe Temperaturen zum Zünden aller Brennphasen gewährleistet sind. Die Wirkungsquerschnitte der beteiligten Kernreaktionen sind von hoher Bedeutung. Inbesondere der Wirkungsquerschnitt der ${ }^{12} \mathrm{C}(\alpha, \gamma){ }^{16} \mathrm{O}$ Reaktion hat starken Einfluß auf das Verhältnis zwischen ${ }^{12} \mathrm{C}$ und ${ }^{16} \mathrm{O}$ im Sterninneren nach dem Heliumbrennen und somit auf den detaillierten Verlauf der weiteren Entwicklung des Sterns.

Die hohe Empfindlichkeit der Resultate verschiedener Sternmodelle auf die Reaktionsrate von ${ }^{12} \mathrm{C}(\alpha, \gamma){ }^{16} \mathrm{O}$ hat zu der Idee geführt, Informationen über den Wirkungsquerschnitt auch über astrophysikalische Überlegungen zu erhalten, um so die experimentellen Schwierigkeiten bei der Messung zu umgehen. Allerdings haben neuere Rechnungen, die eine komplexere Behandlung der Konvektion in Sternen beinhalten, gezeigt, daß ein höherer oder niedriger Wirkungsquerschnitt von ${ }^{12} \mathrm{C}(\alpha, \gamma){ }^{16} \mathrm{O}$ vorgetäuscht werden kann, je nachdem wie der tatsächliche Konvektionsmechanismus verläuft. Speziell sogenanntes over-shooting bei der Konvektion führt zu einer Kompensation der Auswirkungen des Wirkungsquerschnitts von ${ }^{12} \mathrm{C}(\alpha, \gamma){ }^{16} \mathrm{O}$. Deshalb kann eine Bestimmung des ${ }^{12} \mathrm{C}(\alpha, \gamma){ }^{16} \mathrm{O}$ Wirkungsquerschnitts nicht durch astrophysikalische Argumente erfolgen. Umgekehrt kann eine präzise Kenntnis des Wirkungsquerschnittes von ${ }^{12} \mathrm{C}(\alpha, \gamma){ }^{16} \mathrm{O}$ zu einem Verständnis der Konvektionsvorgänge in Sternen führen.

Die Reaktion ${ }^{12} \mathrm{C}(\alpha, \gamma){ }^{16} \mathrm{O}$ hat einen Q-Wert von $7.162 \mathrm{MeV}$, und das Energiefenster, bei dem das Helium-Brennen in Roten-Riesen-Sternen abläuft, liegt bei ca. $E_{0}=0.3 \mathrm{MeV}$. Der erwartete Wirkungsquerschnitt von $\sigma\left(E_{0}\right) \approx 10^{-17} \mathrm{~b}$ schließt eine direkte Messung mit den heutigen technischen Möglichkeiten aus. Eine Extrapolation der Ergebnisse von höheren Energien zu $E_{0}$ ist notwendig. Der Wirkungsquerschnitt von ${ }^{12} \mathrm{C}(\alpha, \gamma){ }^{16} \mathrm{O}$ kann im wesentlichen entsprechend der Multipolarität der emittierten Strahlung in einen E1 und einen E2 Anteil separiert werden. Diese 2 Komponenten haben ihre unterschiedlichen Winkelverteilungen $\left(W_{E 1} \propto \sin ^{2} \theta_{\gamma}\right.$, $W_{E 2} \propto \sin ^{2} \theta_{\gamma} \cos ^{2} \theta_{\gamma}$ ). Die E1 Komponente wird bei $E_{0}=0.3 \mathrm{MeV}$ durch zwei $1^{-}$Zustände im ${ }^{16} \mathrm{O}$ Kern dominiert: eine unterschwellige Resonanz bei $E_{r}=$ 
$-0.045 \mathrm{MeV}\left(E_{x}=7.117 \mathrm{MeV}\right.$ in $\left.{ }^{16} \mathrm{O}\right)$ und eine Resonanz bei $E_{r}=2.42 \mathrm{MeV}$ $\left(E_{x}=9.58 \mathrm{MeV}\right)$ (siehe Abbildung 1.1). Zusätzlich ist die entsprechende Interferenz zwischen den beiden Zuständen zu berücksichtigen. Die E2 Amplitude sollte ebenfalls von einer unterschwelligen Resonanz $\left(J^{\pi}=2^{+}\right.$Zustand bei $E_{x}=6.92 \mathrm{MeV}$ in ${ }^{16} \mathrm{O}$ ) dominiert werden, allerdings gibt es hier nur wenige detaillierte Informationen. Der totale Wirkungsquerschnitt ist dann die Summe aus dem E1 und dem E2 Anteil.

Die meisten direkten Messungen von ${ }^{12} \mathrm{C}(\alpha, \gamma){ }^{16} \mathrm{O}$ wurden über den Nachweis der entstehenden $\gamma$-Strahlung durchgeführt. Dabei wurde entweder der totale Wirkungsquerschnitt $\sigma_{\text {tot }}$ der Reaktion oder die E1 Komponente gemessen. Allerdings gibt es derzeit nur eine Messung der reinen E1-Strahlung [12], die aber wegen der geringen Nachweiswahrscheinlichkeit einen eingeschränkten Energiebereich überstrichen hat. Insgesamt existieren direkte $\gamma$-Messungen zwischen $E_{c m}=0.9$ und $3.2 \mathrm{MeV}$. Neben direkten Messungen der Reaktion ${ }^{12} \mathrm{C}(\alpha, \gamma){ }^{16} \mathrm{O}$ können auch andere Experimente wichtige Informationen über den Verlauf des Wirkungsquerschnitts liefern, solange die extrahierten Meßwerte dieser Experimente auf den gleichen Parametern des ${ }^{16} \mathrm{O}$ Kerns beruhen. Insbesondere sind die Daten des $\beta$-verzögerten $\alpha$-Zerfalls von ${ }^{16} \mathrm{~N}$ und der elastischen Streuung ${ }^{12} \mathrm{C}+\alpha$ von großer Bedeutung, indem sie einige Parameter einer auf einem R-Matrix Formalismus basierenden Extrapolation bestimmen.

\section{Kapitel 2. Der experimentelle Aufbau}

Die Messung der E1 Komponente des Wirkungsquerschnitts von ${ }^{12} \mathrm{C}(\alpha, \gamma){ }^{16} \mathrm{O}$ erfordert eine starke Unterdrückung der E2 Komponente. Dafür kann man die unterschiedlichen Winkelverteilungen dieser 2 Komponenten (siehe oben) benutzen. Ein Detektoraufbau, der die $\gamma$-Strahlung nur in einem kleinen Winkelbereich um $90^{\circ}$ zur Strahlachse mißt, ist im wesentlichen auf den E1 Anteil sensitiv, welches andererseits zu einer Verringerung der Nachweiswahrscheinlichkeit führt. Daher ist wegen des kleinen Wirkungsquerschnitts dieser Reaktion eine möglichst hohe Unterdrückung des $\gamma$-Untergrundes von großer Bedeutung. Eine Untersuchung der Reaktion ${ }^{12} \mathrm{C}(\alpha, \gamma){ }^{16} \mathrm{O}$ in direkter Kinematik unter Verwendung eines ${ }^{4} \mathrm{He}$ Ionenstrahls wird immer durch Untergrund aus der Reaktion ${ }^{13} \mathrm{C}(\alpha, \mathrm{n}){ }^{16} \mathrm{O}$ behindert, selbst wenn implantierte ${ }^{12} \mathrm{C}$ Targets mit einem geringeren Anteil an ${ }^{13} \mathrm{C}$ verwendet werden. Zusätzlich kommt es zu Problemen durch einen starken Targetabbau durch den Beschuß mit dem intensiven ${ }^{4} \mathrm{He}$ Strahl. Als Alternative kann man die Rolle von Projektil und Target vertauschen, wie es im Rahmen dieser Arbeit gemacht wurde. Diese Methode erfordert ein fensterloses Helium Gastarget. Ein solches System ist aufwendiger als ein Festkörpertarget-Experiment, bietet aber deutliche Vorteile. So ist die Dichte und Zusammensetzung des Gases nahezu unbeeinflußt 
vom Ionenstrahl und durch eine Veränderung des Gasdrucks läßt sich problemlos die Dicke des Targets variieren. Allerdings ist man dafür auf einen relativ komplizierten Aufbau angewiesen (siehe Abbildung 2.1). Der ${ }^{12} \mathrm{C}$ Ionenstrahl von dem Tandem Beschleuniger des Dynamitron Tandem Laboratorium der Ruhr-Universität Bochum wurde zuerst durch fünf Blenden, die die jeweiligen upstream Pumpstufen des Gastarget-Systems voneinander trennen, in die Targetkammer fokussiert. Die Targetkammer bestand aus einer zylindrischen Gaszelle mit einer Länge von $10 \mathrm{~cm}$, begrenzt durch zwei Blenden mit einem Durchmesser von $6 \mathrm{~mm}$. Hinter der Targetkammer verließt der Strahl das Gastarget durch vier Blenden, die die downstream Pumpstufen des Gastarget-Systems voneinander trennen, und wurde nach ca. $5 \mathrm{~m}$ in einem abgeschirmten Faraday-Cup gestoppt. Die im Beam Stop durch den Strahl über Kernreaktionen produzierten Neutronen wurden durch eine $0.5 \mathrm{~m}$ dicke Paraffinwand thermalisiert. Das Pumpensystem des Gastargets bestand aus mehreren leistungsstarken Wälzkolbenpumpen und verschiedenen Turbo-Pumpen, die eine Druckreduzierung von üblicherweise 20 Torr in der Targetkammer auf $1 \times 10^{-7}$ Torr am Übergang zum Strahlrohr des Beschleunigers gewährleistet haben. Die Targetkammer hatte mehrere Anschlüsse für Gaseinlaß, Druckmessung und für einen Teilchendetektor zur Messung der elastischen Streuung der Projektile an den Targetatomen. Letztere ist ein Maß für die Intensität des Ionenstrahls und der Targetdichte. Auf eine Rezirkulation des Gases wurde verzichtet, um mögliche Verunreinigungen des Targetgases durch das Pumpensystem auszuschließen.

Zur Messung der E1 Komponente wurden sechs hochreine Germanium-Detektoren unter $90^{\circ}$ zum Strahlrohr und in einem mittleren Abstand von $170 \mathrm{~mm}$ zur Strahlachse montiert (siehe Abbildung 2.3). Diese Detektoren waren in einer ringförmigen Anordnung um die Gaszelle herum montiert, wobei eine geometrische Targetlänge des $\gamma$-Strahlungsnachweises von $53 \mathrm{~mm}$ durch zwei zylindrische Bleiabschirmungen um das Strahlrohr definiert wurde. Diese $125 \mathrm{~mm}$ dicke Bleiabschirmung hat die Detektoren vor strahlinduziertem Untergrund aus dem Bereich von Ein- und Ausgangsblende der Gaszelle geschützt. Zur Unterdrückung des Raumuntergrundes war der ganze Detektoraufbau von einer $50 \mathrm{~mm}$ starken Bleiwand und einer $0.5 \mathrm{~mm}$ dicken Cadmium-Schicht, zum Einfang thermischer Neutronen, umgeben. Der kosmische Untergrund konnte durch eine aktive Abschirmung aus elf großflächigen, $30 \mathrm{~mm}$ dicken Plastik-Szintillatoren vom Typ NE102A um diesen Aufbau um einen Faktor 10 reduziert werden.

Das Konzept der Datenaufnahme bei diesem Experiment basierte auf der Forderung alle Ereignisse zu sichern. Die notwendigen Bedingungen an die aufgenommenen Ereignisse wurden in einer Offline-Analyse angewendet. Das Trigger-Signal für die Elektronik wurde von einem belibigen Ge- oder Teilchendetektor geliefert, worauf hin alle ADC (Analog-to-Digital Converter) Einheiten eingelesen wurden. Während des Konversionsprozesses wurde ein allgemeines Veto-Signal geliefert, um gleiche 
Todzeit für alle ADC's zu erhalten. Die Offline-Analyse erlaubte nur die Ereignisse zu berücksichtigen, in denen nur einer der $\gamma$-Detektoren ein Signal gesehen hatte. Außerdem wurden auch die Ereignisse aussortiert, bei denen eine Koinzidenz zwischen Ge-Zählern und Plastik-Szintillatoren statt gefunden hatte oder bei denen zwei Trigger aufeinander folgten.

Das Druckprofil des ${ }^{4} \mathrm{He}$ Gases in der Targetkammer wurde mit einem modifizierten Aufbau über eine Messung des $\gamma$-Flusses aus der Reaktion ${ }^{4} \mathrm{He}\left({ }^{16} \mathrm{O}, \gamma\right){ }^{20} \mathrm{Ne}$ bestimmt. Dazu wurde einer der Ge-Detektoren, kollimiert mit einer $10 \mathrm{~cm}$ dicken Bleiabschirmung und einem $2 \mathrm{~cm}$ breiten Schlitz zwischen Detektor und Strahlachse, entlang des Strahlrohres verschoben (siehe Abbildung 2.7). Das Maximum der Thick-TargetYield, gemessen durch Variation der Strahlenergie bei einer festen Position, gibt dann ein Maß, das proportional zur Höhe des Druckprofils an der jeweiligen Position ist. Diese Messung ergab ein Ergebnis von $l_{\text {eff }}=101 \pm 2 \mathrm{~mm}$ (siehe Abbildung 2.9). Das ist in hervorragender Übereinstimmung mit dem geometrischen Abstand der beiden den Targetbereich begrenzenden Blenden $l_{\text {geo }}=100 \mathrm{~mm}$. Auf die gleiche Art und Weise wurde auch die effektive $\gamma$ Targetlänge bestimmt, allerdings mit dem kompletten Detektoraufbau unter Verwendung aller 6 ortsfesten GermaniumDetektoren. Diese Größe wird durch die Bleiabschirmung um das Strahlrohr, welche die Detektoren vor Untergrundstrahlung von den Blenden in der Targetkammer schützt, bestimmt. Die Messung (siehe Abbildung 2.11) ergab eine effektive Targetlänge von $l_{\gamma, e f f}=66 \pm 4 \mathrm{~mm}$. Dieses Ergebnis wurde verglichen mit einer Monte Carlo-Simulation, die mit Hilfe des GEANT-Programmpakets vom CERN durchgeführt worden ist. Auch diese beiden Ergebnisse stimmen hervorragend innerhalb der Fehler überein.

Die Normierung der $\gamma$-Ausbeute benötigt die Kenntniss des Produktes aus Anzahl der ${ }^{12} \mathrm{C}$ Projektile und der ${ }^{4} \mathrm{He}$ Targetkerne. Dieses Größe kann über die Messung der elastischen Streuung ${ }^{4} \mathrm{He}\left({ }^{12} \mathrm{C},{ }^{12} \mathrm{C}\right){ }^{4} \mathrm{He}$ bestimmt werden. Daher ist es notwendig den tatsächlichen Streuquerschnitt im Verhältnis zum Rutherford-Wirkungsquerschnitt zu kennen. Dies wird durch eine Messung mit einem Gasgemisch aus Helium und Argon ermöglicht, wobei sicher gestellt ist, daß die elastische Streuung im System ${ }^{12} \mathrm{C}+{ }^{40} \mathrm{Ar}$ dem Rutherford-Gesetz folgt. Ein Vergleich der simultan gemessenen Reaktionsausbeuten der elastischen Streuung beider Systeme ergibt dann den Korrekturfaktor für das System ${ }^{12} \mathrm{C}+{ }^{4} \mathrm{He}$ (siehe Abbildung 2.15).

Die Energieeichung der $\gamma$-Spektren wurde mit Hilfe der Kernreaktion ${ }^{1} \mathrm{H}\left({ }^{11} \mathrm{~B}, \gamma\right){ }^{12} \mathrm{C}$ auf einer Resonanz bei der Energie $E_{r}=148 \mathrm{keV}$ durchgeführt (siehe Abbildung 2.6.2). Der zugehörige Zustand in ${ }^{12} \mathrm{C}$ zerfällt über $\gamma$-Kaskaden mit Energien von $E_{\gamma}=4.44$ und $11.67 \mathrm{MeV}$, so daß eine zuverlässige Eichung im notwendigen Energiebereich für die Messung von ${ }^{12} \mathrm{C}(\alpha, \gamma){ }^{16} \mathrm{O}$ gewährleistet war. Diese Eichung wurde mehrfach im Zeitraum der Messungen wiederholt. Dabei konnte keine signifikante Veränderung der Koeffizienten der Energieeichung festgestellt werden. 
Einer der wichtigsten Parameter für die Messung der E1 Amplitude ist der Unterdrückungsfaktor der E2 Komponente in diesem Detektoraufbau. Die E2 Verunreinigung in den $\gamma$-Spektren wurde experimentell über die $J^{\pi}=2^{+}$Resonanz von ${ }^{12} \mathrm{C}(\alpha, \gamma){ }^{16} \mathrm{O}$ bei $E_{x}=9.847 \mathrm{MeV}$ abgeschätzt. Dieser Zustand geht mit einer Wahrscheinlichkeit von $61 \%$ mit einer E2 Winkelverteilung in den Grundzustand über und mit $21 \%$ in einen weiteren $J^{\pi}=2^{+}$Zustand bei $E_{x}=6.917 \mathrm{MeV}$, so daß die Winkelverteilung der daraus resultierenden $\gamma$-Kaskade als isotrop angenommen werden kann. Das Verhältnis der gemessenen Ausbeute aus diesen Übergängen, korrigiert auf die unterschiedlichen Übergangswahrscheinlichkeiten, führt, im Fall von gleichen Intensitäten der zwei Komponenten, zu einer oberen Grenze für die E2 Kontamination in den Messungen von $9 \%$ (siehe Abbildung 2.6.4). Eine entsprechende Monte Carlo-Simulation ergibt einen Wert von $6 \%$.

\section{Kapitel 3. Die Datenanalyse}

Die Messungen haben den Energiebereich zwischen $E_{c m}=1.3$ und $3.0 \mathrm{MeV}$ abgedeckt. Die Intensität des ${ }^{12} \mathrm{C}$ Ionenstrahls betrug üblicherweise zwischen 30 und $50 \mathrm{p} \mu \mathrm{A}$. Der Untergrund im $\gamma$-Spektrum im Bereich der relevanten Energien verändert sich signifikant mit der Einschußenergie. Bei niedrigeren Strahlenergien dominiert der kosmische Untergrund, während strahlinduzierter Untergrund bei höheren Energien relevant wird. Um die Strahlaufweitung, und somit den strahlinduzierten Untergrund, der durch verschiedene Kernreaktionen, z.B. an Blenden, erzeugt wird, zu reduzieren, wurde bei Energien oberhalb von $E_{l a b}=10.6 \mathrm{MeV}$ der Standarddruck im Target von $P_{0}=20$ Torr auf $P_{0}=10$ Torr gesenkt.

Der kosmische Untergrund konnte durch eine vierwöchige Untergrundmessung, während der Beschleuniger abgeschaltet war, sehr genau bestimmt werden. Deutlich schwieriger gestaltete sich die Behandlung des strahlinduzierten Untergrundes. Versuche mit anderen Gassorten, um Straggling-Effekte zu simulieren, führten nicht zu einem befriedigenden Ergebnis. Die starke Energieabhängigkeit des Untergrundes erschwerte natürlich zusätzlich die korrekte Auswertung der $\gamma$-Spektren. Deshalb wurde zur Bestimmung der Reaktionsausbeute nur der Photopeak des Grundzustandsübergangs verwendet. Durch das enge Energiefenster dieses Peaks im Spektrum (ca. $100 \mathrm{keV}$ ) erhält man bei dessen Auswertung das beste Signal-zu-Untergrund Verhältnis.

Die Auswertung der Messung wurde durch eine Monte Carlo-Simulation des Experimentes mit Hilfe von GEANT unterstützt. Dabei wurde die Simulation benutzt, um sowohl die Nachweiswahrscheinlichkeit des Detektoraufbaus (siehe Abbildung 3.3), wie auch die theoretische Form des Photopeaks zu bestimmen(siehe 
Abbildung 3.4). Die simulierten relativen Nachweiswahrscheinlichkeiten ergaben im Vergleich zu einer Messung der Reaktion ${ }^{1} \mathrm{H}\left({ }^{11} \mathrm{~B}, \gamma\right){ }^{12} \mathrm{C}$ eine gute Übereinstimmung, wobei die unterschiedlichen Winkelverteilungen im Vergleich zu ${ }^{12} \mathrm{C}(\alpha, \gamma){ }^{16} \mathrm{O}$ berücksichtigt wurden. Die Peakform-Studie erlaubt die Analyse des Peakinhaltes bei einem zumeist unbekannten Untergrundverlauf durchzuführen. Bei niedrigen Strahlenergien ist der strahlinduzierte Untergrund vernachlässigbar, so daß hier das Ergebniss der Simulation mit der experimentellen Peakform verglichen werden kann. Da die Peakform mit der Energie der $\gamma$-Quanten und damit mit der Strahlenergie korreliert ist, muß die Simulation für jeden Meßpunkt einzeln durchgeführt werden. Jedes mal ist die Peakform mit dem Untergrundverlauf anzufitten. Die Trennung in der Fit-Prozedur von Untergrund und Peakform erlaubte den Peakinhalt zu ermitteln, dessen Fehler durch eine komplette $\chi^{2}$-Analyse bestimmt wurde (siehe Abbildung 3.7 und Abbildung 3.8).

Die Analyse der Spektren der elastischen Streuung wurde nach einem ähnlichen Schema durchgeführt. Hier besteht die Spektrumstruktur aus einem einzelnen Peak, der auf einem exponentiellen Untergrund gelegen ist (siehe Abbildung 3.10 und Abbildung 3.11).

Der absolute Wirkungsquerschnitt der Reaktion ${ }^{12} \mathrm{C}(\alpha, \gamma){ }^{16} \mathrm{O}$ im gemessenen Energiebereich wurde relativ zur Reaktion ${ }^{1} \mathrm{H}\left({ }^{19} \mathrm{~F}, \alpha \gamma\right){ }^{16} \mathrm{O}$ bestimmt. Diese Reaktion hat eine sehr gut bekannte Resonanz bei $E_{r, c m}=0.323 \mathrm{MeV}\left(E_{l a b}=6.46 \mathrm{MeV}\right)$ mit einer Breite von $\Gamma_{l a b}=46 \mathrm{keV}$ und einem Wirkungsquerschnitt von $\sigma^{F}=$ $88 \pm 3 \mathrm{mb}$. Diese Resonanz zerfällt über einen angeregten Zustand in ${ }^{16} \mathrm{O}$ und sendet dabei $\gamma$-Quanten der Energie $E_{\gamma}=6.13 \mathrm{MeV}$ aus. Für die Normierungsmessung wurde ein ${ }^{19} \mathrm{~F}$ Strahl verwendet und der $\mathrm{H}_{2}$ Druck im Gastarget auf $P_{0}=0.1$ Torr eingestellt, um ein dünnes Target wie im Fall von ${ }^{12} \mathrm{C}(\alpha, \gamma){ }^{16} \mathrm{O}$ zu gewährleisten. Die Auswertung wurde entsprechend der vorangegangenen Diskussion für die Reaktion ${ }^{12} \mathrm{C}(\alpha, \gamma){ }^{16} \mathrm{O}$ durchgeführt (siehe Abbildung 3.12). Dadurch ergab sich für die Messung der Reaktion ${ }^{12} \mathrm{C}(\alpha, \gamma){ }^{16} \mathrm{O}$ auf der $J^{\pi}=1^{-}$Resonanz bei $E_{c m}=2.42 \mathrm{MeV}$ ein absoluter Wirkungsquerschnitt von $\sigma_{a b s}^{C}=54 \pm 6 \mathrm{nb}$.

Zur Extrapolation des gemessenen Wirkungsquerschnittes zu der astrophysikalisch relevanten Energie von $E_{0}=0.3 \mathrm{MeV}$ wurde ein auf dem R-Matrix Formalismus basierendes Computer-Programm von R.E. Azuma verwendet. Dieser ComputerCode fittet den Wirkungsquerschnitt $\sigma_{E 1}(E)$ der E1 Komponente unter Verwendung der ${ }^{12} \mathrm{C}(\alpha, \gamma){ }^{16} \mathrm{O}$ direkten Messungen, der Messungen der ${ }^{12} \mathrm{C}(\alpha, \alpha){ }^{12} \mathrm{C}$ elastischen Streuung und der Ergebnisse aus einer Messung des $\alpha$ Spektrums des verzögerten $\beta$ Zerfalls von ${ }^{16} \mathrm{~N}$ an. Dieser R-Matrix Fit berücksichtigt drei verschiedene Zustände im ${ }^{16} \mathrm{O}$ Kern: die beiden $1^{-}$Zustände bei $E_{x}=7.117$ und $9.580 \mathrm{MeV}$ sowie einen dritten, der alle Einflüsse höherenergetischer Resonanzen beinhaltet. Es sei angemerkt, daß aus den Fits aller verfügbaren experimentellen Daten immer ein Wechselwirkungsradius von $a \approx 6 \mathrm{~mm}$ mit einem Fehler von \pm 0.5 ( $\chi^{2}$ Analyse $)$ folgt 
(siehe Abbildung 3.17 und Abbildung 3.18). Mit diesem Wert für a wurde auch der Fit an die Daten dieser Arbeit durchgeführt und in Form des astrophysikalischen S-Faktors $S(E)$ dargestellt (siehe Abbildung 3.19). Das Problem war nun ein Schema zur Bestimmung des Fehlers des extrapolierten Wertes $S_{E 1}\left(E_{0}\right)$ zu entwickeln. Der hier verwendete Ansatz ist, daß der Fehler von $S_{E 1}\left(E_{0}\right)$ über die Fit-Funktion mit den experimentellen Fehlern der einzelnen Datenpunkte korreliert ist. Die Wahrscheinlichkeitsverteilung eines Meßwertes folgt üblicherweise einer Gauß-Verteilung, deren Standardabweichung $\sigma$ als Fehler angegeben wird. Die Wahrscheinlichkeitsverteilung eines gegebenen Wertes, z.B. von $S_{E 1}\left(E_{0}\right)$, der über einen Fit an experimentelle Datenpunkte ermittelt wird, ist dann direkt mit der Wahrscheinlichkeitsverteilung dieser einzelnen Datenpunkte verbunden. Dies kann durch Verwendung von Monte Carlo-Methoden zur Fehlerbestimmung verwendet werden. Dazu wurde der R-Matrix Fit mehrfach wiederholt und bei jeder neuen Ausführung die Werte der einzelnen Datenpunkte im Fehlerintervall entsprechend einer Gauß-Verteilung variiert. Dies führt zu einem Satz von Werten für $S_{E 1}\left(E_{0}\right)$, so daß daraus der experimentelle Fehler von $S_{E 1}\left(E_{0}\right)$ abgeleitet werden kann. Diese Auswertung wurde nicht nur für die Daten aus dieser Arbeit durchgeführt (siehe Abbildung 3.21), sondern auch für alle anderen verfügbaren direkten $\gamma$-Messungen (siehe Abbildung 3.20). Außerdem wurde das Vorzeichen der Interferenz zwischen den beiden $1^{-}$Zuständen von ${ }^{16} \mathrm{O}$ bei $E_{x}=7.117$ und $9.580 \mathrm{MeV}$ berücksichtigt und sowohl eine Analyse mit konstruktiver (wie in den meisten bisherigen Auswertungen in der Literatur) wie auch mit destruktiver Interferenz gemacht. Dabei stellte sich heraus (siehe Tabelle 3.1), daß nur zwei der sechs direkten $\gamma$-Messungen (Referenzen $[14,17,13,16,12]$ und die hier dargestellte Arbeit), nämlich die Messungen von Referenzen [13, 14], eindeutig eine konstruktive Interferenz bevorzugen. Bei allen anderen Messungen kann eine derartig eindeutige Aussage nicht getroffen werden, wobei jedoch das $\chi_{\min }^{2}$ für die konstruktive Lösung jeweils etwas niedriger liegt.

Mit dem Ansatz einer konstruktiven Interferenz erhält man ein Resultat von $S_{E 1}\left(E_{0}\right)=$ $90 \pm 4 \mathrm{keV} \cdot \mathrm{b}$ für die vorliegende Messung und $S_{E 1}\left(E_{0}\right)=82 \pm 4 \mathrm{keV} \cdot \mathrm{b}$ für einen gemeinsamen Fit aller verfügbaren Datensätze. Zu den angegebenen Unsicherheiten hat man zusätzlich einen Fehler von $\pm 6 \mathrm{keV} \cdot \mathrm{b}$ aus der Analyse der ${ }^{16} \mathrm{~N}$ Daten, sowie einen externen Fehler von $\pm 4 \mathrm{keV} \cdot \mathrm{b}$ aufgrund der Streuung der Ergebnisse zu addieren. Dieses Resultat der Auswertung stimmt hervorragend mit dem Ergebnis einer ausführlichen Analyse von Referenz [22] von $S_{E 1}\left(E_{0}\right)=79 \pm 21 \mathrm{keV} \cdot \mathrm{b}$ überein. Dennoch sei angemerkt, daß für den Fall der destruktiven Interferenz der astrophysikalische S-Faktor mehr als eine Größenordnung kleiner ist als der hier angegebene Wert.

Abschließend sei gesagt, daß eine endgültige sichere Entscheidung über das Interferenzmuster nur über eine neue Messung geschehen kann. Hierzu bietet sich ein Rückstoß-Massen-Separator an, wie er derzeit am Dynamitron-Tandem Laborato- 
rium der Ruhr-Universität Bochum aufgebaut wird. Ein derartiger Aufbau erlaubt eine gleichzeitige Beobachtung der Ejektile und der $\gamma$-Emission in Koinzidenz, so daß eine nahezu untergrundfreie Messung der $\gamma$-Strahlung möglich sein sollte und somit eine systematische Fehlerquelle deutlich reduziert ist. Außerdem kann in diesem Experiment ein deutlich größerer Energiebereich als in der vorliegenden Messung abgedeckt werden. 


\section{References}

[1] C. E. Rolfs and W. S. Rodney. Cauldrons in the cosmos. The University of Chicago Press, 1988.

[2] D.D. Clayton. Principles of stellar evolution and nucleosynthesis. McGraw Hill, New York, 1968.

[3] S. E. Woosley and T. A. Weaver. Astr. Jour. Supplement Series, 101:181, 1995.

[4] W.D. Arnett and F.-K. Thielemann. Astr. Jour., 295:589, 1983.

[5] T. A. Weaver and S.E. Woosley. Phys. Rep., 227:65, 1993.

[6] G.A. Caughlan and W.A. Fowler. Atomic data and nuclear data tables. 40:238, 1988.

[7] G. Imbriani. Dependence of stellar evolution on the ${ }^{12} C(\alpha, \gamma){ }^{16} O$ reaction rate. Nuclei in the Cosmos 2000, Aarhus, Denmark, 2000.

[8] J.M. Blatt and V.F. Weisskopf. Theoretical nuclear physics. John Wiley \& sons, New York, 2 edition, 1952.

[9] A. J. Ferguson. Angular correlation methods in gamma-ray spectroscopy. NorthHolland, Amsterdam, 1965.

[10] E. Vogt. Nuclear reactions, volume I. North-Holland, Amsterdam, 1959. edited by P. M. Endt and M. Demeur.

[11] C. Rolfs. Nucl. Phys. A, 217:29, 1973.

[12] G. Roters, C. Rolfs, F. Strieder, and H.P. Trautvetter. Eur. Phys. J. A, 6:451, 1999.

[13] A. Redder, H.W. Becker, C. Rolfs, H.P. Trautvetter, T.R. Donoghue, T.C. Rinkel, J.W. Hammer, and K. Langanke. Nucl. Phys., A462:385, 1987.

[14] P. Dyer and C.A. Barnes. Nucl. Phys., A233:495, 1974. 
[15] K. U. Kettner, H.W. Becker, L. Buchmann, J. Goerres, H. Krawinkel, C. Rolfs, P. Schmalbrock, H.P. Trautvetter, and A. Vlieks. Z. Phys., A308:73, 1982.

[16] J.M.L. Ouellet, M.N. Butler, H.C. Evans, H.W. Lee, J.R. Leslie, J.D. MacArthur, W. McLatchie, H.B. Mak, P. Skensved, J.L. Whitton, X. Zhahao, and T.K. Alexander. Phys. Rev. C, 54(4):1982, 1996.

[17] R.M. Kremer, C.A. Barnes, K.H. Chang, H.C. Evans, B.W. Filippone, K.H. Hahn, and L.W. Mitchell. Phys. Rev. Lett., 60:1475, 1988.

[18] K. Bethge. Kernphysik. Springer Verlag, 1996.

[19] M. D'Agostino Bruno, I. Massa, A. Uguzzoni, G. Vannini, E. Verondini, and A. Vitale. Nuovo Cim., 27 A:1, 1975.

[20] R. Plaga, H.W. Becker, A. Redder, C. Rolfs, and H.P. Trautvetter. Nucl. Phys., A465:291, 1987.

[21] L. Buchmann, P. Tischhauser, R.E. Azuma, J. Goerres, R. Detwiler, U. Giesen, M. Heil, J. Hinnefeld, F. Kaeppeler, J.J. Kolata, H. Schatz, A. Shotter, E. Stech, S. Vouzoukas, and M. Wiescher. Restrictions on the stellar ${ }^{12} C(\alpha, \gamma){ }^{16} O$ reaction rate from elastic ${ }^{12} C+\alpha$ scattering. Nuclei in the Cosmos 2000, Aarhus, Denmark, 2000.

[22] Azuma R.E., L. Buchmann, F.C. Barker, C.A. Barnes, J.M. D'Auria, M. Dombsky, U. Giesen, K.P. Jackson, J.D. King, R.G. Korteling, McNeely, J. Powell, G. Roy, J. Vincent, T.R. Wang, S.S.M. Wong, and P.R. Wrean. Phys. Rev., 50(2):1194, 1994.

[23] C.R. Brune, W.H. Geist, R.W. Kavanagh, and K.D. Veal. Phys. Rev. Lett., 83(20):4025, 1999.

[24] C. Spitaleri, M. Aliotta, P. Figuera, M. Lattuada, R.G. Pizzone, S. Romano, A. Tumino, C. Rolfs, L. Gialanella, F. Strieder, S. Cherubini, A. Musumarra, D. Miljanic, S. Typel, and H.H. Wolter. Eur. Phys. J., A7:181, 2000.

[25] H.W. Becker, M. Bahr, M. Berheide, L. Borucki, M. Buschmann, C. Rolfs, G. Roters, S. Schmidt, W.H. Schulte, G.E. Mitchell, and J.S. Schweitzer. Z. Phys., A351:453, 1995.

[26] R. Weber. EG\&G ORTEC, Private comunication, 1999.

[27] J.P. Biersack and J.F. Ziegler. Transport of ions in matter, SRIM program, version 2000.39. IBM Research, New York and Hahn Meitner Institute, Berlin, 2000 . 
[28] R.B. Firestone. Table of Isotopes. Editor: V.S. Shirley, 1996.

[29] D. Rogalla. Untersuchung der ${ }^{12} \mathrm{C}(\alpha, \gamma){ }^{16} \mathrm{O}$ Reaktion mit dem Summenkristall. Diplom Thesis Ruhr-Universitaet Bochum, 1997.

[30] CERN Computing and Networks Division (Application Software Group). Geant 3.21 - detector description and simulation tool. Technical report, CERN, CH1211 Geneva 23 Switzerland, 1994.

[31] B.R. Bevington and D.K. Robinson. Data reduction and error analysis for the physical sciences. WCB/McGraw-Hill, 1992.

[32] H.W. Becker, W.E. Kieser, C. Rolfs, H.P. Trautvetter, and M. Wiescher. $Z$. Phys., A305:319, 1982.

[33] CERN Computing and Networks Division (Application Software Group). Minuit, function minimization and error analysis. Technical report, CERN, CH1211 Geneva 23 Switzerland. 